\title{
ESPECTROSCOPIA VIBRACIONAL DE FILMES AUTOMONTADOS DE POLIELETRÓLITOS ATRAVÉS DA GERAÇÃO DE SOMA DE FREQUÊNCIAS
}

Heurison de Sousa e Silva

\begin{abstract}
Dissertação apresentada ao Instituto de Física de São Carlos, da Universidade de São Paulo, para a obtenção do título de Mestre em Ciências: Física Aplicada.
\end{abstract}

Orientador: Prof. Dr. Paulo Barbeitas Miranda 
Aos meus pais, Zacarias e Francisca, pelo apoio incondicional e sempre presente, pela fé e empenho que sempre me dedicaram.

À minha esposa, pelo amor e compreensão. 


\section{AGRADECIMENTOS}

- A Deus: Pai e Senhor de todas as coisas.

- Ao Prof. Dr. Paulo Barbeitas Miranda, meu orientador neste trabalho, pela paciência e dedicação que sempre dispôs, pela amizade e confiança em mim depositadas na realização deste trabalho, e ainda pelos valiosos ensinamentos que promoveram o meu crescimento acadêmico e profissional.

- Aos professores da Universidade Federal do Piauí-UFPI, Prof. Dr. João Mariz Guimarães Neto e Prof. Dr. Helder Nunes da Cunha, pelo primeiro incentivo rumo à jornada que culmina com este trabalho de Dissertação.

- Ao Prof. Dr. Roberto Mendonça Faria, pelo auxilio e apoio dados durante a minha chegada e adaptação à São Carlos.

- Aos professores do Grupo de Polímeros "Prof. Bernhard Gross". Em especial, aos professores Débora Terezia Balogh, Valtencir Zucolotto, Osvaldo Novais de Oliveira Jr., pela amizade e pelas valiosas discussões.

- Aos amigos Vicente Galber Freitas Viana e sua esposa Deuzuíta Viana, pela preciosa amizade, apoio e acolhida durante os primeiros meses da minha chegada a São Carlos.

- Aos colegas do Grupo de Polímeros; em particular, aos amigos Marcelo Meira Faleiros, Edvaldo Leal Queiroz e sua esposa Rosiele, Bruna Fostachini e Thiago Cazati, Adriana Pavinatto e Felippe Pavinatto, Maurício Foschini, Luciano Caseli e demais, pela amizade.

- Ao Prof. Dr. José Ribamar e sua esposa Márcia Lozano, pela valiosa amizade, torcida e apoio. 
- À secretária do Grupo e Polímeros, Rosângela Maria Marcondes de Oliveira, pela valiosa amizade e ajuda.

- Ao Elderson Cássio Domenicucci, técnico de laboratório do Grupo Crescimento de Cristais e Materiais Cerâmicos, pela imensa ajuda no polimento e limpeza de substratos de fluoreto de cálcio.

- Aos técnicos do Grupo de Polímeros, pelo apoio técnico.

- Ao Instituto de Física de São Carlos, pela oportunidade de crescimento profissional e acadêmico.

- À Capes, pela bolsa de estudos de que dispus durante este Curso de Mestrado. 


\section{SUMÁRIO}

LISTA DE FIGURAS vii

LISTA DE TABELAS $\quad \mathrm{x}$

RESUMO $\quad$ xi

ABSTRACT $\quad$ xii

1. FILMES POLIMÉRICOS AUTOMONTADOS .............................................. 13

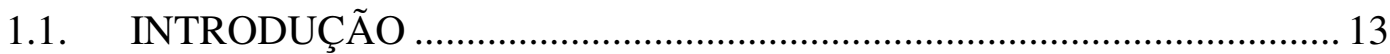

1.2. A TÉCNICA DE AUTOMONTAGEM ELETROSTÁTICA ..................... 15

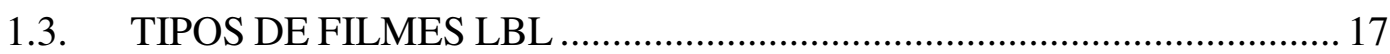

1.4. MECANISMO DE ADSORÇÃO POLIÔNICA …..................................... 18

1.5. MOTIVAÇÃO PARA ESTE TRABALHO ............................................ 20

2. ÓPTICA NÃO-LINEAR E A GERAÇÃO DE SOMA DE

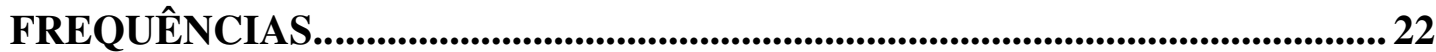

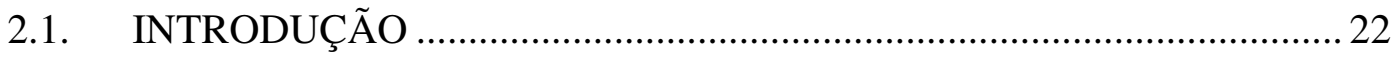

2.2. SUSCEPTIBILIDADE NÃO-LINEAR DE SEGUNDA ORDEM $\chi^{(2)} \ldots . .24$

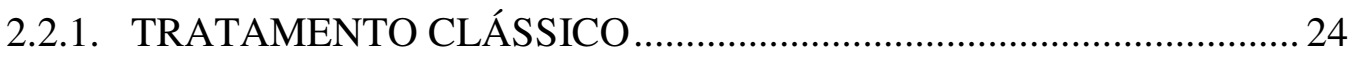

2.2.2. TRATAMENTO MECÂNICO-QUÂNTICO ..................................... 28

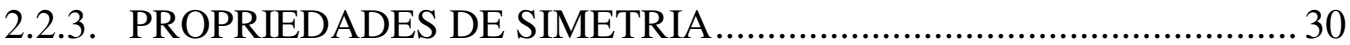

2.3. GERAÇÃO DE SOMA DE FREQUÊNCIAS NO VOLUME ................... 31

2.4. GERAÇÃO DE SOMA DE FREQÜÊNCIAS EM INTERFACES............. 37

2.5. IMPLICAÇÕES DO SFG EM INTERFACES...................................... 40

2.6. HIPERPOLARIZABILIDADE DE SEGUNDA ORDEM $\beta$.................... 44

2.7. INTERPRETAÇÃO DO ESPECTRO DE SOMA DE FREQUÊNCIAS... 46

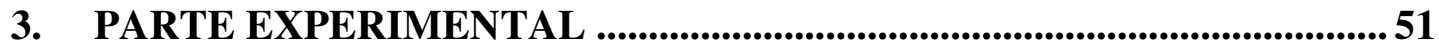

3.1. PREPARAÇÃO DAS AMOSTRAS …................................................... 51

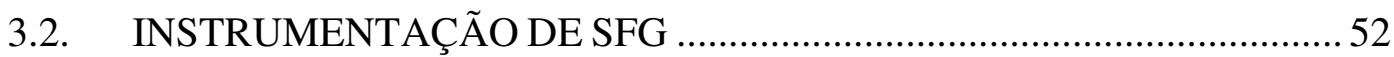

3.3. ARRANJO EXPERIMENTAL PARA ESTUDO IN SITU E EX SITU .... 54

4. FILMES AUTOMONTADOS SOBRE O QUARTZO .................................5 57

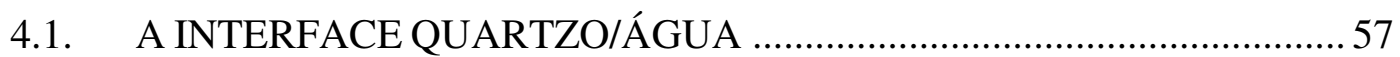

4.2. FILMES PREPARADOS A PARTIR DE SOLUÇÕES COM PH 4 ...........60

4.3. FILMES PREPARADOS A PARTIR DE SOLUÇÕES COM PH $12 \ldots . . . . .68$ 
5. FILMES AUTOMONTADOS SOBRE FLUORETO DE CÁLCIO............75

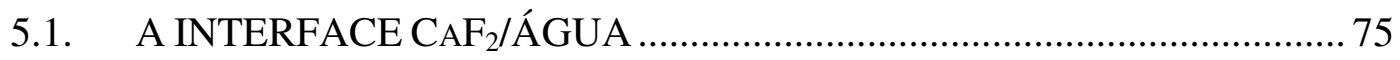

5.2. FILMES PREPARADOS A PARTIR DE SOLUÇÕES COM PH 4 .......... 77

5.3. FILMES PREPARADOS A PARTIR DE SOLUÇÕES COM PH 12 ........86

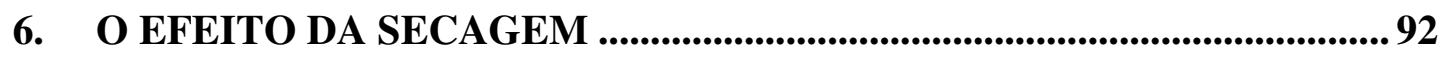

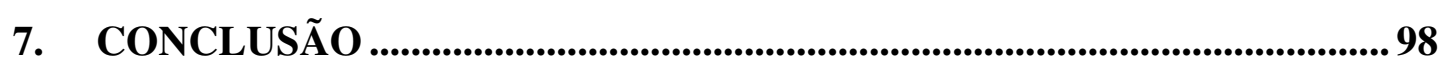

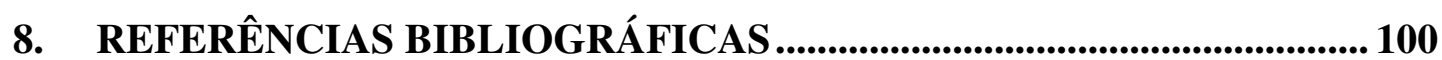




\section{LISTA DE FIGURAS}

FIGURA 1: FóRMULA ESTRUTURAL DE ALGUNS POLIELETRÓLITOS ........................... 15

FigURA 2: PROCESSO de AUTOMONTAGEM .................................................................... 16

Figura 3: REPRESEnTAÇão ESQUemática da Geração de SOMA DE

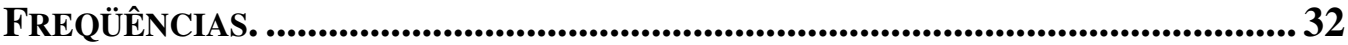

FiguRA 4: EFEITO DA DIFERENÇA DE VETOR DE ONDA $\triangle$ K NA EFICIÊNCIA DA GERAÇÃ̃ DE SOMA DE FREQÜÊNCIAS. .......................................................................... 36

Figura 5: Geometria da GeraÇão de Soma de FreqüÊnCia a PARTIR dA INTERFACE ENTRE DOIS MEIOS

FIGURA 6: UMA SUPERFÍCIE PLANA SIMÉTRICA EM TORNO DA DIREÇÃO NORMAL À SUPERFÍCIE. 42

FigURA 7: MODOS VIBRACIONAIS DO METIL E DO METILENO 46

FiguRA 8: POSSÍvEIS FORMAS ESPECTRAIS DE UMA RESSONÂNCIA . 48

Figura 9: GRÁficos $\quad$ DE $\quad \chi_{N R}^{(2)}+\operatorname{Re}\left\lfloor\chi_{R}^{(2)}\right\rfloor, \quad$ DE $\quad \operatorname{Im}\left\lfloor\chi_{R}^{(2)}\right\rfloor, \quad \mathbf{E} \quad$ DE

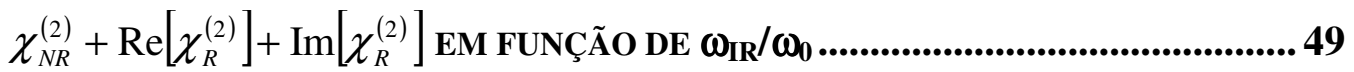

FIGURA 10: LAYOUT DO SISTEMA DE SFG ..................................................................5 52

FIGURA 11: FOTOS DO LENI .......................................................................5

FIGURA 12: ARRANJO EXPERIMENTAL PARA MEDIDAS.......................................54

FIGURA 13: CÉLULA DE TEFLON UTILIZADA NAS MEDIDAS IN SITU ........................... 55

FiguRA 14: ESPECTROS SFG dA INTERFACE QUARTZO/ÁGUA COM DIFERENTES VALORES DE PH NO VOLUME .....................................................................58

FIGURA 15: ESPECTRO SFG DA INTERFACE QUARTZO/ÁGUA A PH 4 ........................ 60

FiguRA 16: ESPECTROS SFG DE FILMES IN SITU DE PAH/PSS SOBRE O QUARTZO A PARTIR DE SOLUÇÕES COM PH 4 61

Figura 17: MODElo da CAMAda ADSORVIDA A PARTIR DAS MEDIDAS IN SITU DE PAH E PSS SOBE O QUARTZO A PH 4 .63

Figura 18: ESPECTRO SFG DE FILMES EX SITU DE PAH/PSS (PH 4) SOBRE O QUARTZO COM SECAGEM ESPONTÂNEA 64

Figura 19: Espectros SFG De filmes EX SITU DE PAH/PSS A PH 4 COM SECAGEM ESPONTÂNEA SOBRE O QUARTZO......................................................65

FigURA 20: ESPECTRO SFG DE FILMES AUTOMONTADO DE PAH/PVS................... 67 
Figura 21: Modelo Proposto Para as Medidas ex SITU de PAH e PSS SObE O QUARTZO A PH 4 68

FigURA 22: ESPECTRO SFG DA INTERFACE QUARTZO/ÁGUA A PH 12 69

Figura 23: ESPECTROS SFG DE FILMES IN SITU DE PAH/PSS SOBRE O QUARTZO A PARTIR DE SOLUÇÕES COM PH 12 .70

Figura 24: Modelo proposto para as medidas in SITU de PAH e PSS SObe o QUARTZO A PH 12 71

Figura 25: EsPectro SFG DE FILMES EX SITU DE PAH/PSS (PH 12) SOBRE O QUARTZO COM SECAGEM ESPONTÂNEA .72

Figura 26: Espectros SFG de filmes eX SITU De PAH/PSS A PH 12 COM SECAGEM ESPONTÂNEA SOBRE O QUARTO .73

Figura 27: EsPeCtros SFG da INTERFACE CAF 2 /ÁGUA COM DIFERENTES VALORES DE PH NO VOLUME 76

FigURA 28: ESPECTRO SFG DA INTERFACE CAF 2 /ÁGUA A PH 4 78

Figura 29: Espectros SFG de filmes in Situ de PAH/PSS SObRe O CAF a PARTIR DE SOLUÇÕES COM PH 4 79

Figura 30: Modelo proposto para as medidas in Situ de PAH e PSS SObe O FLUORETO DE CÁLCIO A PH 4

Figura 31: ESPECTRO SFG DE FILMES EX SITU DE PAH/PSS (PH 4) SOBRE O CAF COM SECAGEM ESPONTÂNEA 81

FIGURA 32: ASPECTO DOS FILMES SOBRE O QUARTZO E SOBRE O CAF 82

Figura 33: EsPectros SFG de FILMES EX SITU DE PAH/PSS COM SECAGEM ESPONTÂNEA .83

Figura 34: Modelo proposto para as medidas ex Situ de PAH/PSS SObE O $\mathrm{CAF}_{2}$, A PH 4 .85

FIGURA 35: ESPECTRO SFG DA INTERFACE CAF 2 /ÁGUA A PH 12 86

Figura 36: Espectros SFG de filmes in Situ de PAH/PSS SObRe O CAF $\mathrm{C}_{2}$ A PARTIR DE SOLUÇÕES COM PH 12 87

Figura 37: Modelo Proposto Para as Medidas in Situ de PAH e PSS SOBE O FLUORETO DE CÁLCIO A PH 12. .88

Figura 38: Espectro SFG de fILMES EX SITU DE PAH/PSS (PH 12) SOBRE O CAF $_{2}$ COM SECAGEM ESPONTÂNEA 89 
Figura 39: Espectros SFG de FILMES EX SITU DE PAH/PSS COM SECAGEM

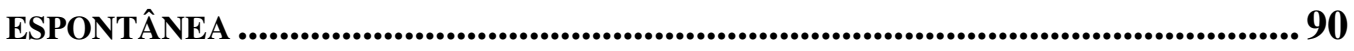

Figura 40: EsPectros SFG de FILMES PAH/PSS SECANDo COM NITROGÊNIO, A

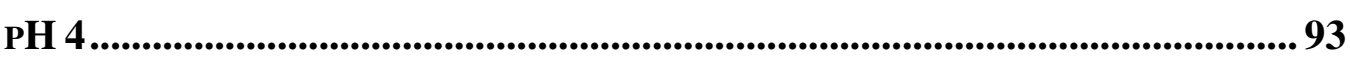

Figura 41: EsPeCTROS SFG DE FILMES PAH/PSS SECANDO COM NITROGÊNIO, A PH 4. 94

Figura 42: EsPectros SFG de FILMES PAH/PSS SECADOS COM NITROGÊNIO, A

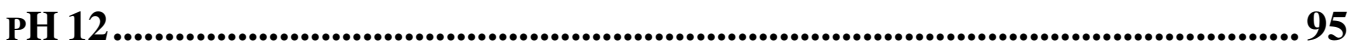

Figura 43: EsPeCtros SFG de FILMES PAH/PSS SECANDO COM NITROGÊNIO, A

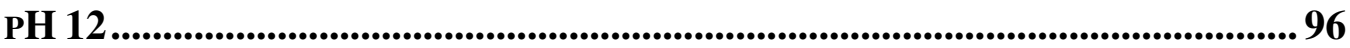




\section{LISTA DE TABELAS}

TABEla I: ElEMENTOS NÃO-NUlOS DE $\chi_{i j k}^{(2)}$ PARA O CASO DE UMA SUPERFícIE

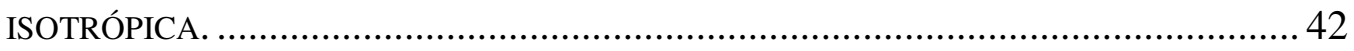

TABELA II: As POSSÍVEIS COMBINAÇÕES DE POLARIZAÇÕES E ELEMENTOS DE $\chi_{i j k}^{(2)}$ QUE PODEM CONTRIBUIR PARA O ESPECTRO SFG .43

TABELA III: ATRIBUIÇÕES RESSONANTES E NÚMEROS DE ONDA DOS MODOS ESTIRAMENTOS DOS GRUPOS C-H OBSERVADOS POR SFG................................. 47

TABELA IV: RESULTADOS DO AJUSTE DOS ESPECTROS DA FIGURA 33 ........................ 84 


\section{RESUMO}

Neste trabalho foi utilizada Espectroscopia Vibracional por Geração de Soma de Freqüências, uma técnica óptica não-linear que é sensível à conformação molecular em interfaces e superfícies, para caracterizar o ordenamento molecular de filmes poliméricos automontados de polieletrólitos durante todos os passos do processo de fabricação, tendo como modelo o par de polieletrólitos PAH (poli(cloreto de alilamina)) / PSS (poli(estireno sulfonato de sódio)). Os espectros SFG permitiram verificar que durante o mergulho (in situ) do substrato na solução de polieletrólitos, estes adsorvem, mas se encontram numa configuração desordenada. Observou-se também que a secagem dos filmes pela ação de jato de nitrogênio produz filmes menos homogêneos do que por secagem espontânea, e às vezes até destruindo completamente o ordenamento molecular. Além disso, verificou-se também que camadas de polieletrólitos adsorvidas influenciam o ordenamento das camadas previamente adsorvidas. Com base nos resultados, modelos para a representação das estruturas desses filmes de polieletrólitos in situ e ex situ foram propostos. 


\begin{abstract}
In this work, Sum-Frequency Vibrational Spectroscopy, a nonlinear optical technique that is sensitive to molecular conformation at interfaces and surfaces, was used to characterize the molecular ordering of self-assembled films during all steps of self-assembly, having as model poly(allylamine hydrochloride) (PAH) / poly(styrene sulfonate) (PSS) polyelectrolyte assemble. SFG spectra showed that during immersion (in situ) of substrate in polyelectrolytes solutions, adsorption occurs but the molecules are in a disordered configuration. It was observed that the films drying by nitrogen flow are more inhomogeneous than those dried by spontaneous water evaporation. In some cases, dried films by nitrogen flow are quite disordered. Furthermore, it was observed that polyelectrolytes layers affect the ordering of the previously adsorbed layers. Based on our results, models were proposed to represent the structure of polyelectrolytes films in both: in situ and ex situ.
\end{abstract}




\section{FILMES POLIMÉRICOS AUTOMONTADOS}

\subsection{INTRODUÇÃO}

Os filmes poliméricos automontados têm inúmeras aplicações em nanotecnologia, dentre elas a construção de dispositivos optoeletrônicos como diodos orgânicos ${ }^{[1,2]}$ e biossensores ${ }^{[3]}$. Além disso, podem servir para estudos básicos como modelos de membranas biológicas ${ }^{[4,5]}$ e de sistemas com transições de fase em duas dimensões ${ }^{[6]}$, e outras.

Como característica marcante dos filmes finos, os filmes automontados poliméricos podem possuir espessuras de alguns nanômetros a até centenas de micrômetros, dada a técnica de fabricação, que é um processo baseado na atração de cargas opostas ${ }^{[7,8,9,10,11]}$. Este processo de fabricação foi inicialmente proposto por Iler et al. ${ }^{[12]}$ que descreviam a adsorção alternada de partículas coloidais de cargas opostas. Vale lembrar também o trabalho pioneiro de Sagiv et al. ${ }^{[13,14]}$, onde eles relatam a formação de sistemas de multicamadas. Estas, entretanto, se baseavam em interações químicas (ligações covalentes) entre camadas adjacentes. Tinha-se como limitação o requisito de que as moléculas envolvidas deveriam apresentar funcionalidades específicas a fim de realizar as ligações necessárias.

Dessa forma, Decher et al. ${ }^{[7,15]}$ sugeriram um novo método de fabricação de filmes finos baseado em interações físicas de moléculas com cargas opostas. Assim, eliminava-se o inconveniente da realização de ligações moleculares entre as 
camadas adsorvidas. Basicamente, o método sugerido consiste na imersão alternada de um substrato sólido em soluções catiônicas e aniônicas. Esse processo de automontagem eletrostática camada-a-camada é denominado $E L B L$ (do inglês electrostatic layer-by-layer) ou SA (self-assembled). Os filmes assim produzidos são designados simplesmente filmes LBL (layer-by-layer); neste trabalho, utilizaremos simplesmente o termo "automontado" ou LBL para designar esses filmes. A técnica será descrita em maiores detalhes na Seção 1.2.

Particularmente, esse processo tem ainda outras vantagens sobre outros tipos de fabricação de filmes finos como, por exemplo, os Langmuir-Blodgett (LB). Com relação a estes, que está limitado ao uso de moléculas insolúveis em água, o método LBL permite a formação de filmes a partir de moléculas hidrossolúveis, o que aumenta consideravelmente a variedade de materiais que podem ser utilizados. Além disso, para o método LBL, tem-se o fato de que a atração iônica entre cargas opostas ser a força motriz na construção das multicamadas (o que facilita o controle do processo), de ser independente do tamanho do substrato e de sua topologia ${ }^{[7,9,10]}$, de permitir a formação de um conjunto de multicamadas ordenadas, e ainda de, a princípio, todos os polieletrólitos (cadeias poliméricas carregadas eletricamente) poderem ser utilizados na adsorção ${ }^{[8,9,10]}$. Quanto ao substrato, qualquer sólido hidrofílico ou hidrofóbico pode ser usado como vidro, quartzo, mica ou ouro ${ }^{[11]}$.

Para uma grande maioria de filmes fabricados pelo processo de automontagem ocorre aumento linear da espessura, ou da quantidade adsorvida por unidade de área, com relação ao número de bicamadas, exceto nas primeiras bicamadas, que sofrem uma maior influência do substrato ${ }^{[9,10,11]}$. Essa influência tem origem nos diferentes tipos de interações eletrostáticas, que podem ser do tipo fracas ou fortes. Após as primeiras bicamadas, a quantidade adsorvida ou espessura por 
bicamada torna-se independente do substrato, quando então ocorre o crescimento linear.

\subsection{A TÉCNICA DE AUTOMONTAGEM ELETROSTÁTICA}

Um polieletrólito é um polímero no qual alguns monômeros são sais de grupos iônicos e não-metálicos. Em solução, esses grupos são parcialmente ionizados, e dessa forma podemos ter diversas densidades de carga na cadeia, conforme a porcentagem de monômeros ionizados numa cadeia polimérica inteira de polieletrólito. Uma vez que não existem restrições na escolha dos polieletrólitos, muitos são os materiais que podem ser empregados na fabricação de filmes LBL. Assim, alguns dos mais utilizados são o PEI (poli(etileno imina)), o PAH (poli(cloreto de alilamina)), e o PDAC (poli(cloreto de dimetildialilamônia)), como policátions; e o PVS (poli(ácido vinilsulfônico)), PSS (poli(estireno sulfonato de sódio)), e o PAA (poli(ácido acrílico)), como poliânions. Abaixo, na Figura 1, temos as fórmulas estruturais de alguns desses polieletrólitos.

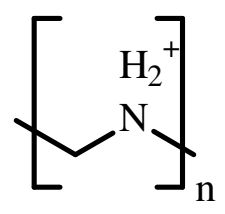

PEI

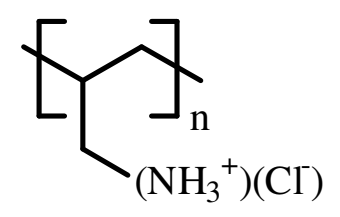

PAH

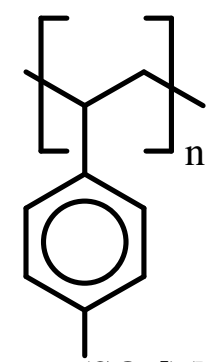

$\left(\mathrm{SO}_{3}{ }^{-}\right)\left(\mathrm{Na}^{+}\right)$<smiles>CCC(C)CC1CC1(C)CC</smiles>

PAA

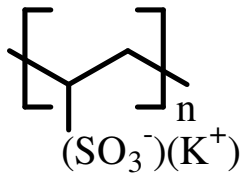

PVS

PSS

Figura 1: Fórmula estrutural de alguns polieletrólitos. 
No processo de automontagem (self-assembly), um substrato sólido com uma superfície carregada negativamente é mergulhado numa solução contendo polieletrólitos catiônicos. Uma monocamada de policátion é adsorvida, sobrecompensando a carga negativa do substrato e alterando assim o sinal da carga na superfície.

A
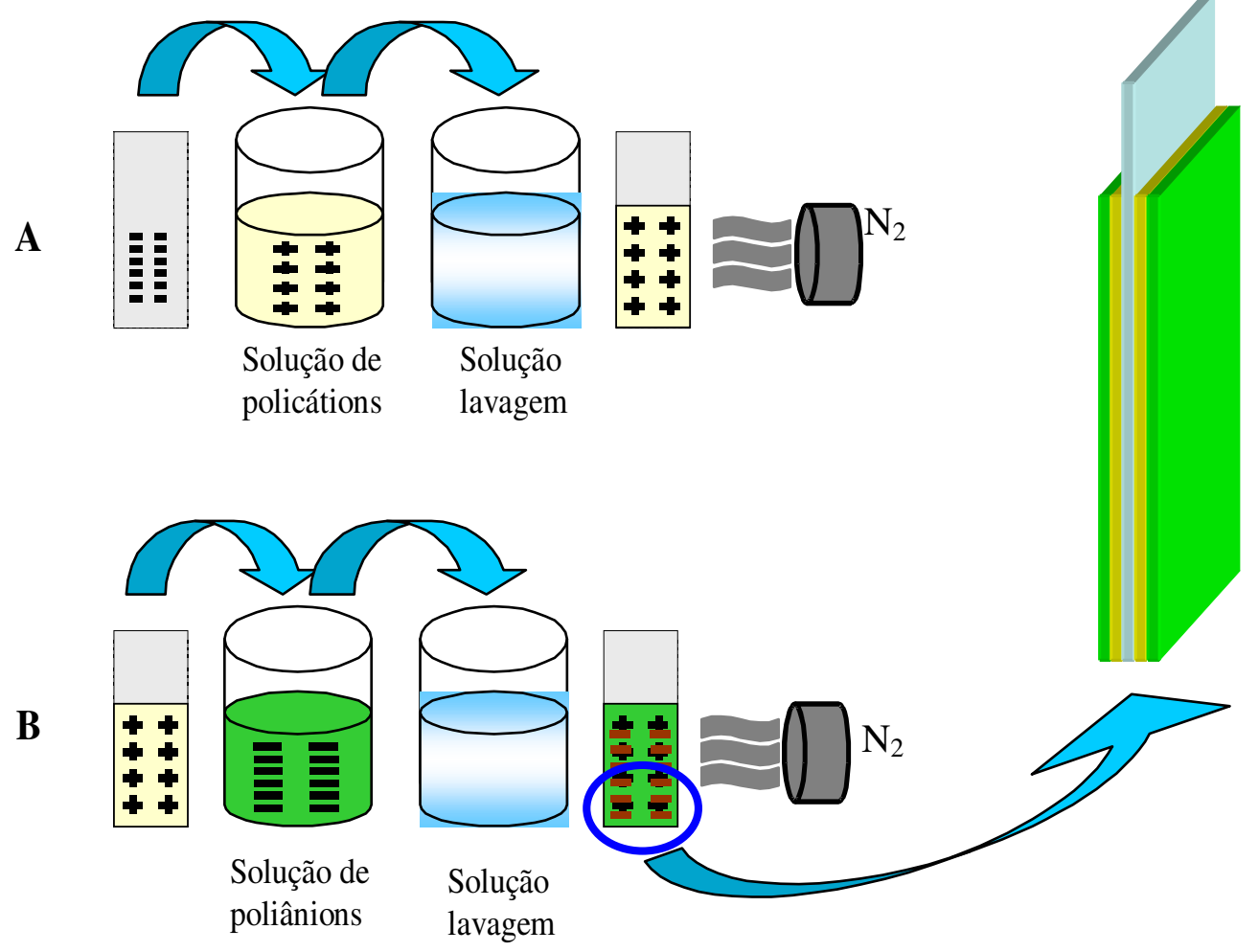

Figura 2: Processo de automontagem. Parte A: o substrato hidrofilizado e carregado negativamente (-) é mergulhado na solução de policátions (+) e enxaguado na solução lavagem de mesmo $\mathrm{pH}$ que a primeira solução. Pode-se em seguida secar o filme com jato de $\mathrm{N}_{2}$. Parte B: o substrato com uma primeira monocamada positiva é mergulhado na solução de poliânions (-), recuperando assim o sinal da carga do substrato e após novo enxágüe, tem-se uma bicamada. A repetição do processo determina o número de bicamadas desejadas.

Após lavar-se o substrato com solução aquosa de mesmo pH que a solução de policátions, seca-se o substrato com jato de $\mathrm{N}_{2}$, mergulhando-o em seguida na solução de poliânions. Novamente uma monocamada é adsorvida, mas o sinal original da carga no substrato é restaurado. Tem-se então uma bicamada. Repetindo-se os passos, obtém-se o número de bicamadas desejadas e um filme 
automontado de espessura controlada. O processo está representado Figura 2. Obviamente, o processo descrito acima também é válido se o substrato estiver carregado positivamente, devendo-se então iniciar a automontagem com poliânions.

\subsection{TIPOS DE FILMES LBL}

Os filmes automontados LBL são convenientemente classificados

mediante o mecanismo responsável pela adsorção ${ }^{[7,11,16]}$, recebendo a denominação como segue.

Primeiramente, temos os filmes $L B L$ de polieletrólitos altamente carregados, onde a atração iônica (eletrostática) é a força motriz para a adsorção, levando a camadas molecularmente finas $(\sim 1 \mathrm{~nm})$ e muito estáveis. O mecanismo é autolimitado, pois a adsorção cessa após o equilíbrio das cargas, resultado das interações entre as moléculas e o substrato (atração) e entre as moléculas já adsorvidas e as moléculas da solução (repulsão) ${ }^{[17]}$. Os filmes formados são homogêneos, podendo haver algum grau de interpenetração. Ocorre também a sobrecompensação das cargas, que é um fator essencial para promover o crescimento do filme e tem sido confirmada por medidas de potencial Zeta ${ }^{[18]}$, onde após cada deposição de polieletrólito, o potencial se torna altamente positivo ou altamente negativo. Em geral, a rugosidade do filme aumenta com o número de camadas, levando à formação de sítios para a adsorção, e assim ao aumento da espessura de cada camada com o número de camadas depositadas.

Em seguida temos os filmes LBL de polieletrólitos parcialmente carregados, onde a força motriz para a adsorção ainda é a atração iônica, mas a quantidade de material adsorvido é variável por uma ordem de grandeza (adsorção 
anômala), dependendo das condições experimentais. Um exemplo é a mudança na quantidade de material por camada ou a espessura desta quando se altera o $\mathrm{pH}$ da solução de polímero. Para os polieletrólitos fracos, sob pH onde ocorra ionização incompleta, a adsorção pode dar origem a camadas espessas, uma vez que as moléculas tendem a enovelar-se, devido à menor repulsão eletrostática entre os monômeros. Para esse tipo de filme, a espessura das monocamadas pode ser controlada variando-se os diversos parâmetros que influenciam a adsorção. Por exemplo, variando-se o pH, pode-se aumentar a ionização dos polieletrólitos, aumentando a força iônica da solução e resultando num aumento da repulsão entre as cargas eletrostáticas da molécula de polieletrólito, gerando alterações na espessura e rugosidade do filme à medida que este cresce.

O terceiro tipo de filmes LBL se refere aos filmes adsorvidos via interações secundárias, como ligações de hidrogênio, interações de Van der Waals ou interações hidrofóbicas, ou ainda em conjunto com interações iônicas.

Por fim temos os filmes LBL produzidos mediante interações específicas, tais como atração biotina-avidina e certos sistemas protéicos ${ }^{[19,20]}$. Neste caso, o filme pode ser formado por polieletrólitos de mesma carga. Esses filmes são menos comuns, pois eles seguem um mecanismo de adsorção completamente diferente. Em casos particulares de filmes LBL de proteínas têm-se mencionado ser a complexação protéica o agente responsável pela formação das multicamadas ${ }^{[11]}$.

\subsection{MECANISMO DE ADSORÇÃO POLIÔNICA}

O mecanismo primário para a adsorção poliônica em filmes LBL é a atração iônica de monocamadas com cargas opostas. No entanto, outras interações 
podem ser relevantes, como contribuições entrópicas ou a existência de ligações de H, como mencionado na Seção anterior.

A adsorção poliônica depende intensamente de certos fatores tais como o peso molecular do polímero, sua densidade linear de carga, a distribuição de carga ao longo da cadeia, a força iônica da solução, a carga do substrato, e ainda da afinidade não-eletrostática entre o substrato e o polieletrólito ${ }^{[11]}$.

A dependência com relação ao peso molecular ocorre porque moléculas menores (baixo peso molecular) são as primeiras a serem adsorvidas. Quando o equilíbrio é alcançado, as moléculas grandes (alto peso molecular) tomam no filme.

Quanto à densidade de carga, três situações podem ser consideradas ${ }^{[18]}$ :

1. Quando a densidade de carga no polímero é baixa, isto é, menor que $5 \%$, temos muito pouca complexação e assim as multicamadas não são formadas.

2. Quando a densidade de carga é alta, entre $5 \%$ e $20 \%$, podemos não ter a formação de multicamadas ou, se ocorrer, a formação de multicamadas instáveis.

3. Se a densidade de carga é maior que $20 \%$, temos finalmente a formação de multicamadas estáveis.

Ou seja, a densidade de carga está diretamente ligada à sobrecompensação das cargas e assim à complexação das multicamadas.

A densidade de carga na cadeia polimérica também tem relevante influência na morfologia do filme. Como já mencionado, camadas de moléculas de polieletrólitos pouco carregados podem enovelar-se, originando monocamadas mais espessas, enquanto que moléculas mais carregadas tendem a ser mais distendidas devido à repulsão entre os monômeros, formando camadas mais finas ${ }^{[17]}$.

Para polieletrólitos fracos, a densidade de carga é afetada pelo $\mathrm{pH}$ e pela força iônica, o que não ocorre tão criticamente para os polieletrólitos fortes. Para 
baixa carga no polieletrólito, a atração com o substrato, e conseqüentemente a quantidade de polímero adsorvido, aumenta com o aumento da carga. No entanto, em determinados valores de $\mathrm{pH}$ haverá muitas cargas na cadeia do polieletrólito levando a uma repulsão entre as cadeias, e assim diminuindo a quantidade de polímero $\operatorname{adsorvido}^{[17]}$.

A formação das multicamadas é também um processo entropicamente favorável, pois embora a adsorção das cadeias sobre o substrato ou filme reduza a sua contribuição para a entropia do sistema, a liberação para a solução dos contraíons que estavam complexados às cadeias que se adsorveram causa um aumento da entropia total do sistema.

\subsection{MOTIVAÇÃO PARA ESTE TRABALHO}

Como pôde ser notado pelo que foi dito acima, muito já se conhece a respeito da natureza dos filmes automontados e seus mecanismos de formação e de suas propriedades. No entanto, para a otimização de suas aplicações faz-se necessário um estudo mais detalhado, a nível molecular, mas que é difícil de ser obtido por técnicas tradicionais.

A motivação deste trabalho foi a necessidade de um melhor entendimento da estrutura molecular e dos mecanismos de adsorção e formação de filmes poliméricos através da técnica de automontagem. Para isso, utilizamos a Espectroscopia Vibracional por Geração de Soma de Frequiências (ou SumFrequency Vibrational Spectroscopy - SFVS), uma técnica óptica não-linear que é sensível à conformação molecular e específica a superfícies. Ela permite inclusive o monitoramento in situ (em contato com a solução) de interfaces e superfícies. Assim, 
objetivamos estudar o processo de adsorção de filmes automontados de polieletrólitos, bem como caracterizar o ordenamento molecular desses filmes, investigando todos os passos do processo de automontagem: adsorção dos polieletrólitos em solução (in situ), o efeito da lavagem (in situ), e o efeito da secagem.

Para um melhor entendimento a respeito do desenvolvimento deste trabalho, passamos a uma breve introdução dos fenômenos ópticos não-lineares, com considerável destaque aos de segunda ordem. Isto será executado no Capítulo 2 a seguir, onde também será detalhada a técnica de SFVS.

No Capítulo 3, descreveremos os detalhes do procedimento experimental e suas particularidades, como os sistemas para a detecção em medidas in situ e ex situ. Descreveremos ainda os equipamentos utilizados na aquisição dos espectros SFG e os parâmetros considerados.

Após isso, no Capítulo 4, apresentaremos nossos resultados com filmes de polieletrólitos PAH e PSS, tanto em amostras in situ quanto em amostras ex situ sobre substrato de quartzo, e no Capítulo 5, os filmes sobre o fluoreto de cálcio $\left(\mathrm{CaF}_{2}\right)$. Discutiremos qualitativamente os espectros $\mathrm{SFG}$ obtidos, propondo modelos para ilustrar a estrutura das moléculas durante a adsorção poliônica.

No Capítulo 6, apresentaremos os espectros SFG de filmes automontados de PAH/PSS sobre o quartzo secados por jato de nitrogênio, e discutiremos o efeito da secagem sobre o ordenamento molecular desses filmes. Por fim, no Capítulo 7, exporemos nossas conclusões e nossas perspectivas futuras a respeito deste trabalho. 


\section{2. ÓPTICA NÃO-LINEAR E A GERAÇÃO DE SOMA DE FREQUÊNCIAS}

\subsection{INTRODUÇÃO}

A matéria e a radiação se interrelacionam de maneira que a presença de um altera as características do outro. Por exemplo, ondas eletromagnéticas (EM) atuam em átomos e moléculas, seja orientando seu momento de dipolo elétrico (se já existir), seja criando uma polarização momentânea. De forma recíproca, a presença da matéria altera a configuração das linhas de força de um campo elétrico (e/ou magnético) modificando assim as suas características no espaço.

Conforme a intensidade do campo elétrico $\mathrm{E}(\mathrm{r}, \mathrm{t})$ de uma radiação eletromagnética, podemos ter fenômenos de interação diferentes. A ação de um campo elétrico na matéria se apresenta de modo principalmente a orientar (ou criar) os momentos de dipolo elétrico das moléculas ou átomos. Isto leva então a uma polarização $\mathrm{P}(\mathrm{r}, \mathrm{t})$ que está relacionada ao campo elétrico por

$$
\begin{aligned}
\vec{P}(t) & =\chi^{(1)} \vec{E}(t)+\chi^{(2)} \vec{E}^{2}(t)+\chi^{(3)} \vec{E}^{3}(t)+\ldots \\
& \equiv \vec{P}^{(1)}(t)+\vec{P}^{(2)}(t)+\vec{P}^{(3)}(t)+\ldots
\end{aligned}
$$

Equação 1

Os termos $\chi^{(\mathrm{n})}$ e $\mathrm{P}^{(\mathrm{n})}$ são as susceptibilidades e as polarizações de ordem $n$, respectivamente. 
Se o campo elétrico for pequeno em comparação ao campo eletrostático de interação entre os elétrons e seus núcleos, então as contribuições das susceptibilidades para n > 1 são irrelevantes, tornando-se desprezíveis, ou seja,

$$
\chi^{(2)} \vec{E}^{2}, \chi^{(3)} \vec{E}^{3}, \chi^{(4)} \vec{E}^{(4)} \rightarrow 0
$$

Equação 2

Dessa forma, a polarização total do meio se torna:

$$
\vec{P}(t)=\chi^{(1)} \vec{E}(t)
$$

Equação 3

que é a polarização de primeira ordem, ou polarização linear, considerando assim o regime da Óptica Linear.

Entretanto, à medida que o campo $\mathrm{E}(\mathrm{r}, \mathrm{t})$ cresce, as contribuições de ordem superior se tornam significativas e então teremos a expressão mais geral da Equação 1. Esses são os fenômenos não-lineares, razão pela qual se denominam as grandezas $\chi^{(\mathrm{n})}$ de susceptibilidades não-lineares de ordem $\mathrm{n}(\mathrm{n}>1)$, e o regime então é o da Óptica Não-Linear.

A susceptibilidade é, portanto, uma grandeza que relaciona o campo elétrico que se propaga num meio com a polarização que ele provoca nesse meio. Sendo $E(t)$ e $P(t)$ ambas grandezas vetoriais, temos então a susceptibilidade nãolinear de ordem $\mathrm{n}$ como um tensor de ordem $\mathrm{n}+1$. Por exemplo, num espaço tridimensional $(\mathrm{N}=3)$, para $\mathrm{n}=2$ (susceptibilidade de segunda ordem), temos um tensor de $\mathrm{N}^{\mathrm{n}+1}=27$ elementos. 


\subsection{SUSCEPTIBILIDADE NÃO-LINEAR DE SEGUNDA ORDEM $\chi^{(2)}$}

Neste trabalho, centramos nossa atenção nos processos de geração óptica de segunda ordem, mais especificamente a Geração de Soma de Freqüências. Por esse motivo, é imprescindível uma revisão sobre as características mais relevantes da susceptibilidade não-linear de segunda ordem. O tratamento clássico é bem conhecido $^{[21,22,23]}$, fornecendo resultados satisfatórios com uma teoria fenomenológica. No entanto, a interpretação quântica ${ }^{[21]}$ é mais abrangente e geral, permitindo calcular as susceptibilidades não-lineares e sua dispersão.

\subsubsection{TRATAMENTO CLÁSSICO}

Consideremos uma onda real da forma

$$
\vec{E}(t)=\overrightarrow{E_{1}} e^{-i \omega_{1} t}+\overrightarrow{E_{2}} e^{-i \omega_{2} t}+\text { c.c. }
$$

Equação 4

se propagando num meio dielétrico e isotrópico, e consideremos ainda o domínio da Óptica Não-Linear. A Equação 4 representa duas ondas de freqüências $\omega_{1}$ e $\omega_{2}$ se propagando nesse meio, e assim teremos uma polarização não-linear de segunda ordem do tipo:

$$
\begin{aligned}
\vec{P}^{(2)}(t) & =\chi^{(2)}\left[\vec{E}_{1}^{2} e^{-i 2 \omega_{1} t}+\vec{E}_{2}^{2} e^{-i 2 \omega_{2} t}+2 \vec{E}_{1} \vec{E}_{2} e^{-\left(\omega_{1}+\omega_{2}\right) t}\right. \\
& \left.+2 \vec{E}_{1} \vec{E}_{2}^{*} e^{-i\left(\omega_{1}-\omega_{2}\right) t}+\text { c.c. }\right]+2 \chi^{(2)}\left[\vec{E}_{1} \vec{E}_{1}^{*}+\vec{E}_{2} \vec{E}_{2}^{*}\right]
\end{aligned}
$$

Equação 5

As amplitudes complexas das várias componentes da freqüência representam processos físicos particulares, ou seja, 


$$
\begin{array}{lc}
P\left(2 \omega_{1}\right)=\chi^{(2)} \vec{E}_{1}^{2} & \left(\text { SHG de } \omega_{1}\right) \\
P\left(2 \omega_{2}\right)=\chi^{(2)}{\overrightarrow{E_{2}}}^{2} & \left(\text { SHG de } \omega_{2}\right) \\
P\left(\omega_{1}+\omega_{2}\right)=2 \chi^{(2)} \overrightarrow{E_{1}} \vec{E}_{2} & (S F G) \\
P\left(\omega_{1}-\omega_{2}\right)=2 \chi^{(2)} \vec{E}_{1} \vec{E}_{2}^{*} & (D F G) \\
P(0)=2 \chi^{(2)}\left(\vec{E}_{1} \vec{E}_{1}^{*}+\vec{E}_{2} \vec{E}_{2}^{*}\right) & (O R)
\end{array}
$$

Equação 6

Aqui, destacamos os processos ópticos de Geração de Segundo Harmônico (SHG), Geração de Soma de Freqüências $(S F G)$, Geração de Diferença de Freqüências $(D F G)$, e o processo de Retificação Óptica $(O R)$.

Definimos agora as componentes do tensor $\chi^{(2)}$ como constantes de proporcionalidade entre as componentes do campo elétrico e a polarização, ou seja,

$$
P_{i}\left(\omega_{s}=\omega_{1}+\omega_{2}\right)=\Phi^{(2)} \sum_{j k} \chi_{i j k}^{(2)}\left(\omega_{s}=\omega_{1}+\omega_{2} ; \omega_{1}, \omega_{2}\right) E_{j}\left(\omega_{1}\right) E_{k}\left(\omega_{2}\right)
$$

Equação 7

Os índices $i j k$ se referem às coordenadas cartesianas $x, y, z$ do campo elétrico. $\mathrm{O}$ fator de degenerescência $\Phi^{(2)}$ pode tomar os valores 1 ou 2 conforme os campos sejam indistinguíveis ou distinguíveis entre si, respectivamente. A Equação 7 expressa então a susceptibilidade não-linear de segunda ordem em termos do campo $E(t)$ e da polarização $\mathrm{P}(\mathrm{t})$.

Na Óptica Linear, tratam-se os átomos como osciladores harmônicos ${ }^{[24]}$. Entretanto, para efeitos ópticos não-lineares, utiliza-se um potencial não-harmônico refletindo uma força não-linear atuando no elétron. Esse tratamento difere quando o meio apresenta ou não simetria de inversão. Pode-se mostrar ${ }^{[21]}$ que para meios nãocentrossimétricos, é possível associar-se uma não-linearidade óptica de segunda ordem, enquanto que para meios centrossimétricos, a menor susceptibilidade possível 
é a de terceira ordem. Como é o interesse deste texto tratar fenômenos ópticos de segunda ordem, consideremos então somente meios onde não ocorre simetria de inversão.

Para esses meios, e admitindo-se um potencial não-harmônico, consideremos a equação de movimento do elétron na coordenada $x$ como sendo

$$
\ddot{x}+2 \not \dot{x}+\omega_{0}^{2} x+a x^{2}=-\frac{e E(t)}{m},
$$

Equação 8

onde o campo aplicado é $\mathrm{E}(\mathrm{t}),-e$ é a carga do elétron, e a grandeza $-2 m \gamma \dot{x}$ é uma força amortecedora. A não-harmornicidade está na força restauradora

$$
F_{\text {restauradora }}=-m \omega_{0}^{2} x-m a x^{2}
$$

Equação 9

que pode ser mais bem vista através da energia potencial a que ela corresponde, ou seja,

$$
U=-\int F_{\text {restauradra }} d x=\frac{1}{2}\left(m \omega_{0}^{2}\right) x^{2}+\frac{1}{3}(m a) x^{3}
$$

Equação 10

Para campos elétricos da forma da Equação 4, a Equação 8 não possui solução conhecida. No entanto, se esse campo não é muito intenso de forma que possamos aplicar a Teoria da Perturbação, pode-se expressar a Equação 8 como:

$$
\ddot{x}+2 \not \dot{x}+\omega_{0}^{2} x+a x^{2}=-\lambda \frac{e E(t)}{m} .
$$

Equação 11

e o deslocamento $x$ como uma série de potências, tal como

$$
x=\lambda x^{(1)}+\lambda^{2} x^{(2)}+\lambda^{3} x^{(3)}+\ldots,
$$


Equação 12

onde $\lambda$ é a intensidade da perturbação. Inserindo a Equação 12 na Equação 11, obtemos as equações para o deslocamento em primeira, segunda e demais ordens da Equação 12. A solução para a primeira ordem do deslocamento é

$$
x^{(1)}(t)=x^{(1)}\left(\omega_{1}\right) e^{-i \omega_{1} t}+x^{(1)}\left(\omega_{2}\right) e^{-i \omega_{2} t}+\text { c.c. },
$$

Equação 13

onde as amplitudes $x^{(1)}\left(\omega_{j}\right)$ são dadas pela expressão

$$
x^{(1)}\left(\omega_{j}\right)=-\frac{e}{m} \frac{E_{j}}{D\left(\omega_{j}\right)},
$$

Equação 14

e com $D\left(\omega_{j}\right)=\omega_{0}^{2}-\omega_{j}^{2}-2 i \omega_{0} \lambda$. E para a segunda ordem do deslocamento, temos $x^{(2)}\left(\omega_{n} \pm \omega_{m}\right)$, com $\mathrm{n}, \mathrm{m}=1,2$. Como exemplo, podemos ter

$$
x^{(2)}\left(\omega_{1}+\omega_{2}\right)=-\frac{2 a(e / m)^{2} E_{1} E_{2}}{D\left(\omega_{1}+\omega_{2}\right) D\left(\omega_{1}\right) D\left(\omega_{2}\right)} .
$$

Equação 15

A susceptibilidade não-linear de segunda ordem é definida pela Equação

7:

$$
P^{(2)}\left(\omega_{3}=\omega_{1}+\omega_{2}\right)=\chi^{(2)}\left(\omega_{3}=\omega_{1}+\omega_{2} ; \omega_{1}, \omega_{2}\right) E\left(\omega_{1}\right) E\left(\omega_{2}\right)
$$

Equação 16

onde $\mathrm{P}^{(2)}\left(\omega_{3}\right)$ é a polarização não-linear que oscila com freqüiência $\omega_{3}$, e é dada por

$$
P^{(2)}\left(\omega_{3}\right)=-N e x^{(2)}\left(\omega_{1}+\omega_{2}\right),
$$

Equação 17

sendo $N$ a densidade volumétrica de átomos. Igualando a Equação 16 à Equação 17, obtemos a expressão para $\chi^{(2)}$ como 


$$
\chi^{(2)}=2 N \frac{\left(e^{3} / m^{2}\right) a}{D\left(\omega_{1}+\omega_{2}\right) D\left(\omega_{1}\right) D\left(\omega_{2}\right)} .
$$

Equação 18

Esta última equação é a expressão clássica da susceptibilidade não-linear de segunda ordem. Quando $\omega_{1}$ ou $\omega_{2}$ ou $\omega_{1}+\omega_{2}$ se aproximam da ressonância $\omega_{0}$, a freqüência natural de vibração, então a Equação 18 atinge seu valor máximo.

\subsubsection{TRATAMENTO MECÂNICO-QUÂNTICO}

Um tratamento mecânico-quântico considera uma função de onda atômica $\psi(\mathrm{r}, \mathrm{t})$ que é solução da equação de Schrödinger dependente do tempo

$$
i \hbar \frac{\partial \psi(\vec{r}, t)}{\partial t}=\hat{H} \psi(\vec{r}, t)
$$

Equação 19

onde $\hat{H}$ é o operador Hamiltoniano, e é dado por

$$
\hat{H}=\hat{H}_{0}+\hat{V}(t),
$$

Equação 20

descrito como a soma do Hamiltoniano do átomo livre $\left(\hat{H}_{0}\right)$ e um Hamiltoniano de

interação do átomo com o campo EM $\left(\hat{V}_{0}(t)\right)$. Tomemos o Hamiltoniano de interação na forma

$$
\hat{V}(t)=-\hat{\mu} \cdot \vec{E}(t)
$$


onde $\hat{\mu}(t)=-e \hat{r}(t)$ é o operador momento de dipolo. Admitamos ainda que o campo elétrico seja uma soma discreta de termos com freqüências positivas e negativas como

$$
E(t)=\sum_{p} E\left(\omega_{p}\right) e^{-i \omega_{p} t}
$$

Equação 22

Para os auto-estados de energia na ausência do campo externo, o Hamiltoniano $\hat{H}$ se torna apenas $\hat{H}_{0}$ de modo que a equação de Schrödinger possui soluções na forma de estados estacionários. Essas soluções têm a forma

$$
\psi_{n}(r, t)=u_{n}(r) e^{-i \omega_{n} t}
$$

Equação 23

Assumimos aqui que essa função de onda é autofunção de $\hat{H}_{0}$ com autovalor $E_{n}=$ $\hbar \omega_{n}$. O conjunto da Equação 23 deve constituir um conjunto completo de funções ortonormais, satisfazendo a condição de ortonormalização:

$$
\int u_{m}^{*} u_{n} d^{3} r=\delta_{m n}
$$

Equação 24

Através da Teoria da Perturbação (processo que omitiremos aqui), podemos encontrar a expressão para a susceptibilidade de segunda ordem como

$$
\begin{aligned}
\chi_{i j k}^{(2)}\left(\omega_{3}=\omega_{p}\right. & \left.+\omega_{q}, \omega_{q}, \omega_{p}\right)=\frac{N}{\hbar^{2}} \wp_{I} \sum_{m n} \frac{\mu_{g n}^{i} \mu_{n m}^{j} \mu_{m g}^{k}}{\left(\omega_{n g}-\omega_{p}-\omega_{q}\right)\left(\omega_{m g}-\omega_{p}\right)} \\
& +\frac{\mu_{g n}^{j} \mu_{n m}^{i} \mu_{m g}^{k}}{\left(\omega_{n g}^{*}+\omega_{q}\right)\left(\omega_{m g}-\omega_{p}\right)}+\frac{\mu_{g n}^{i} \mu_{n m}^{j} \mu_{m g}^{k}}{\left(\omega_{n g}^{*}+\omega_{q}\right)\left(\omega_{m g}^{*}+\omega_{p}+\omega_{q}\right)}
\end{aligned}
$$

Equação 25 
A Equação 25 é a expressão mecânico-quântica da susceptibilidade não-linear de segunda ordem. Nela, $\mu$ é o momento de transição de dipolo elétrico, $N$ é o número de átomos por unidade de volume do meio dielétrico, e $\mho_{I}$ é o operador permutação intrínseca, que garante as permutações entre as freqüências $\omega_{\mathrm{p}}$ e $\omega_{\mathrm{q}}$ dos campos aplicados.

\subsubsection{PROPRIEDADES DE SIMETRIA}

Retomando a Equação 7, podemos tentar observar que diferença pode existir na polarização de segunda ordem se trocarmos a ordem do produto dos campos aplicados, ou seja, se permutarmos $E_{j}\left(\omega_{1}\right) E_{k}\left(\omega_{2}\right) \Leftrightarrow E_{k}\left(\omega_{2}\right) E_{j}\left(\omega_{1}\right)$. Pode-se notar que nenhuma mudança foi feita na Equação 7, isto é, não foi alterado o seu sinal nem seu valor absoluto. Isso já era de se esperar, uma vez que na permutação acima os índices $\mathrm{j}, \mathrm{k}$ (cartesianos) e 1,2 (que distinguem a freqüência dos campos aplicados) foram permutados simultaneamente. A importância disso está no fato de que, por exemplo, se os campos forem polarizados em planos perpendiculares, então a permutação $\mathrm{E}_{\mathrm{x}}\left(\omega_{1}\right) \mathrm{E}_{\mathrm{y}}\left(\omega_{2}\right) \Leftrightarrow \mathrm{E}_{\mathrm{x}}\left(\omega_{2}\right) \mathrm{E}_{\mathrm{y}}\left(\omega_{1}\right)$ poderá alterar o valor da polarização. Essa é uma primeira simetria aparente da susceptibilidade não-linear. Pode-se então expressar as propriedades de simetria como

$$
\chi_{i j k}^{(2)}\left(\omega_{3}=\omega_{1}+\omega_{2} ; \omega_{1}, \omega_{2}\right)=\chi_{i k j}^{(2)}\left(\omega_{3}=\omega_{1}+\omega_{2} ; \omega_{2}, \omega_{1}\right) .
$$

Equação 26

A Equação 26 é conhecida como simetria de permutação intrínseca.

Além disso, levando em conta a chamada condição de simetria de Kleinman, segundo a qual em interações ópticas não-lineares cujas freqüências $\omega_{\mathrm{i}}$ são 
muito menores que a menor freqüência de ressonância do sistema material, o valor de $\chi^{(2)}$ não depende da freqüência, e valem as permutações:

$$
\begin{aligned}
\chi_{\mathrm{ijk}}{ }^{(2)}\left(\omega_{3}=\omega_{1}+\omega_{2}\right) & =\chi_{\mathrm{jki}}{ }^{(2)}\left(\omega_{3}=\omega_{1}+\omega_{2}\right)=\chi_{\mathrm{kij}}^{(2)}\left(\omega_{3}=\omega_{1}+\omega_{2}\right) \\
& =\chi_{\mathrm{ikj}}{ }^{(2)}\left(\omega_{3}=\omega_{1}+\omega_{2}\right)=\chi_{\mathrm{jik}}{ }^{(2)}\left(\omega_{3}=\omega_{1}+\omega_{2}\right) \\
& =\chi_{\mathrm{kji}}{ }^{(2)}\left(\omega_{3}=\omega_{1}+\omega_{2}\right) .
\end{aligned}
$$

Equação 27

\subsection{GERAÇÃO DE SOMA DE FREQUÊNCIAS NO VOLUME}

A Geração de Soma de Frequiências é um fenômeno óptico não-linear de segunda ordem que envolve a existência de duas ondas EM de frequiências $\omega_{1}$ e $\omega_{2}$ para gerar uma outra onda de freqüência $\omega_{3}=\omega_{1}+\omega_{2}$. Isso ocorre naturalmente da Equação 5:

$$
\begin{aligned}
\vec{P}^{(2)}(t) & =\chi^{(2)}\left[\vec{E}_{1}^{2} e^{-i 2 \omega_{1} t}+\vec{E}_{2}^{2} e^{-i 2 \omega_{2} t}+2 \vec{E}_{1} \vec{E}_{2} e^{-\left(\omega_{1}+\omega_{2}\right) t}\right. \\
& \left.+2 \vec{E}_{1} \vec{E}_{2}^{*} e^{-i\left(\omega_{1}-\omega_{2}\right) t}+\text { c.c. }\right]+2 \chi^{(2)}\left[\vec{E}_{1} \vec{E}_{1}^{*}+\vec{E}_{2} \vec{E}_{2}^{*}\right]
\end{aligned}
$$

Equação 28

Consideremos então o efeito óptico da Geração de Soma de Freqüências num meio óptico não-linear, opticamente isotrópico ${ }^{\dagger}$ e não-dispersivo, de comprimento $L$, tal como ilustra a Figura 3. A equação de onda para o caso considerado é da forma ${ }^{\ddagger}$ :

$$
-\nabla^{2} \vec{E}+\frac{\varepsilon^{(1)}}{c^{2}} \frac{\partial^{2} \vec{E}}{\partial t^{2}}=-\frac{4 \pi}{c^{2}} \frac{\partial^{2} \vec{P}^{N L}}{\partial t^{2}} .
$$

\footnotetext{
${ }^{\dagger}$ O sentido é de que o índice de refração do meio não varia com a posição dentro do meio.

* Mais detalhes a respeito do comportamento de ondas de luz na fronteira entre meios ópticos não-lineares e da dedução da equação de onda para esses meios podem ser encontrados nas Referências 21, 22, e 29.
} 
Equação 29

Nesta equação, E é o campo elétrico da onda, $\mathrm{P}^{\mathrm{NL}}$ é a polarização não-linear que surge no meio, e $\varepsilon^{(1)}$ é um tensor dielétrico real e independente da freqüência, que relaciona $\mathrm{E}$ e $\mathrm{D}$ por

$$
D^{(1)}=\varepsilon^{(1)} \cdot E,
$$

Equação 30

onde D é o vetor deslocamento elétrico.

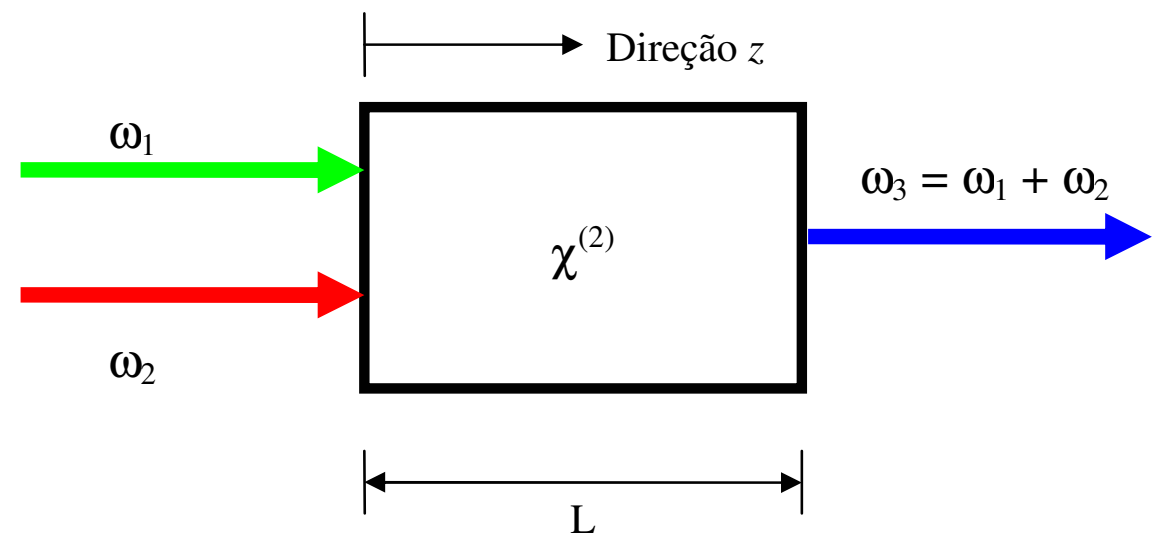

Figura 3: Representação esquemática da Geração de Soma de Freqüências.

A Equação 29 indica que a resposta não-linear do meio ao campo elétrico atua como um termo fonte que aparece no lado direito da equação. Representemos os campos elétrico, deslocamento elétrico e polarização pela soma de suas várias componentes da freqüência:

$$
\vec{E}(\vec{r}, t)=\sum_{n} \overrightarrow{E_{n}}(\vec{r}, t)
$$

Equação 31

$$
\vec{D}^{(1)}(\vec{r}, t)=\sum_{n} \overrightarrow{D_{n}}(\vec{r}, t)
$$

Equação 32 


$$
\vec{P}^{N L}(\vec{r}, t)=\sum_{n} \vec{P}_{n}^{N L}(\vec{r}, t)
$$

Equação 33

onde o somatório é efetuado somente sobre todos os campos de freqüências positivas. Assim, a equação de onda que é válida para cada componente da freqüência é:

$$
-\nabla^{2} \overrightarrow{E_{n}}+\frac{\varepsilon^{(1)}\left(\omega_{n}\right)}{c^{2}} \frac{\partial^{2} \overrightarrow{E_{n}}}{\partial t^{2}}=-\frac{4 \pi}{c^{2}} \frac{\partial^{2} \vec{P}_{n}^{N L}}{\partial t^{2}}
$$

Equação 34

Vejamos agora como a equação de onda da Óptica Não-Linear pode ser usada para descrever interações ópticas específicas, em particular, a Geração de Soma de Freqüências. Consideremos um meio óptico não-linear no qual não haja perda de energia e os feixes de entrada são colimados, monocromáticos e contínuos. A configuração está representada na Figura 3, onde os feixes aplicados apresentam incidência normal.

A Equação 34 deve ser aplicada para cada componente da frequiência do campo e em particular, à componente da soma de freqüências, $\omega_{3}$. Na ausência do termo fonte, a solução dessa equação para uma onda plana de frequiência $\omega_{3}$ se propagando na direção $+z$ é:

$$
E_{3}(z, t)=A_{3} e^{i\left(k_{3} z-\omega_{3} t\right)}+c . c .
$$

Equação 35

onde

$$
k_{3}=\frac{n_{3} \omega_{3}}{c}, \quad n_{3}=\left[\varepsilon^{(1)}\left(\omega_{3}\right)\right]^{1 / 2},
$$


e onde a amplitude da onda $A_{3}$ é uma constante. Para um termo fonte não-linear não muito grande, a solução da equação de onda também é a Equação 35, mas com $A_{3}$ variando lentamente como uma função de $z$.

O termo fonte não-linear pode ser expresso como

$$
P_{3}(z, t)=P_{3} e^{-i \omega_{3} t}+c . c .,
$$

Equação 37

onde $P_{3}=2 \chi^{(2)} E_{1} E_{2}$. Representando os campos aplicados por $E_{i}(z, t)=E_{i} e^{-i \omega_{i} t}+c . c ., i=1,2$, com $E_{i}=A_{i} e^{-i k_{i} z}, i=1,2$, a amplitude da polarização não-linear pode ser escrita como

$$
P_{3}=2 \chi^{(2)} A_{1} A_{2} e^{i\left(k_{1}+k_{2}\right) z} .
$$

Equação 38

Inserindo as Equações Equação 35, Equação 37 e Equação 38 na Equação 34, temos

$$
\frac{d^{2} A_{3}}{d z^{2}}+2 i k_{3} \frac{d A_{3}}{d z}=\frac{-8 \pi \chi^{(2)} \omega_{3}^{2}}{c^{2}} A_{1} A_{2} e^{i\left(k_{1}+k_{2}-k_{3}\right) z}
$$

Equação 39

Na aproximação da amplitude variando lentamente, podemos negligenciar o primeiro termo do lado esquerdo da Equação 39, uma vez que ele é muito menor que o segundo. Isto requer que a variação fracional de $A_{3}$ numa distância de um comprimento de onda é muito menor que a unidade, e assim a Equação 39 pode ser escrita como

$$
\frac{d A_{3}}{d z}=\frac{4 \pi i \chi^{(2)} \omega_{3}^{2}}{k_{3} c^{2}} A_{1} A_{2} e^{i \Delta k z}
$$

Equação 40

onde a quantidade 


$$
\Delta k=k_{1}+k_{2}-k_{3}
$$

Equação 41

é chamada descasamento de vetor de onda ${ }^{\S}$, e expressa a diferença entre o vetor de onda total gerado no final do processo óptico $\left(\mathrm{k}_{3}\right)$ e o vetor de onda total $\left(\mathrm{k}_{1}+\mathrm{k}_{2}\right)$ que dá origem ao processo. A Equação 40 é conhecida como equação de amplitudes acopladas, pois mostra como a amplitude de onda $\omega_{3}$ varia como conseqüência do seu acoplamento com as ondas $\omega_{1}$ e $\omega_{2}$. Em geral, a variação espacial das ondas $\omega_{1}$ e $\omega_{2}$ também deve ser lavada em consideração, e de forma análoga, encontramos duas outras equações de amplitude acopladas:

$$
\frac{d A_{1}}{d z}=\frac{4 \pi i \chi^{(2)} \omega_{1}^{2}}{k_{1} c^{2}} A_{3} A_{2}^{*} e^{-i \Delta k z},
$$

Equação 42

e

$$
\frac{d A_{2}}{d z}=\frac{4 \pi i \chi^{(2)} \omega_{1}^{2}}{k_{2} c^{2}} A_{3} A_{1}^{*} e^{-i \Delta k z} .
$$

Equação 43

Por simplicidade, assumamos que as amplitudes $A_{1}$ e $A_{2}$ na Equação 40 sejam constantes. Para o caso especial

$$
\Delta \mathrm{k}=0
$$

Equação 44

a amplitude $A_{3}$ da onda de soma de freqüências aumenta linearmente com $z$. A Equação 44 é conhecida como a condição de perfeito casamento de fase ${ }^{* *}$. Quando esta condição é satisfeita, as ondas geradas estão aptas a extrair energia mais

\footnotetext{
${ }^{\S}$ Essa denominação é uma tentativa de tradução para termo inglês wavevector mismatch.

*** Tentativa de tradução para termo inglês perfect phase match.
} 
eficientemente das ondas incidentes. Se a condição da Equação 44 não é satisfeita, então a intensidade da radiação gerada é menor do que para o caso $\Delta \mathrm{k}=0$. A amplitude da onda de soma de freqüências no plano de saída do meio não-linear é dada pela integração da Equação 40 de $z=0$ até $z=L$. O resultado pode ser expresso pela equação abaixo:

$$
I_{3}=\frac{256 \pi^{5}\left|\chi^{(2)}\right|^{2} I_{1} I_{2}}{n_{1} n_{2} n_{3} \lambda_{3}^{2} c} L^{2} \operatorname{sinc}^{2}\left(\frac{\Delta k \cdot L}{2}\right),
$$

Equação 45

onde $\lambda_{3}=2 \pi \mathrm{c} / \omega_{3}$ e $\operatorname{sinc}\left(\frac{\Delta k \cdot L}{2}\right) \equiv \frac{\sin \left(\frac{\Delta k \cdot L}{2}\right)}{\frac{\Delta k \cdot L}{2}}$, que é conhecido como fator diferença de fase. A Figura 4 mostra como esse fator varia com $\Delta \mathrm{k}$. A Equação 45 mostra que quando há casamento de fases, a intensidade da onda de freqüência $\omega_{3}$ gerada após a propagação de uma distância $L$ é proporcional ao quadrado de $L$, ao produto das intensidades das ondas incidentes e ao módulo quadrado de $\chi^{(2)}$.

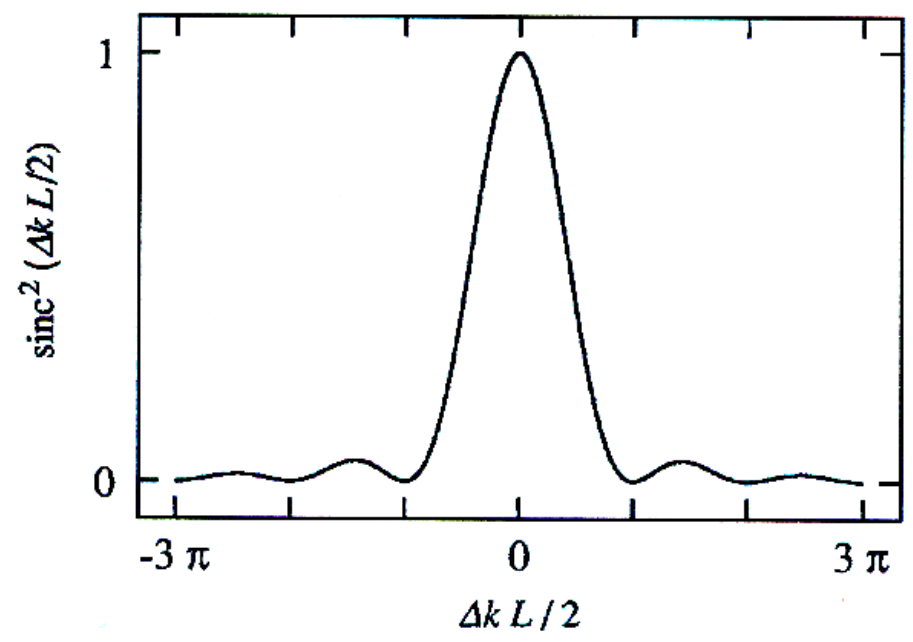

Figura 4: Efeito da diferença de vetor de onda $\Delta k$ na eficiência da Geração de Soma de Frequiências. 


\subsection{GERAÇÃO DE SOMA DE FREQÜÊNCIAS EM INTERFACES}

A Geração de Soma de Frequiências permite a investigação de interfaces entre meios distintos. Como vimos, o processo de Geração de Soma de Frequiências, por ser um processo óptico não-linear de segunda ordem, está diretamente ligado à susceptibilidade não-linear de segunda ordem $\chi^{(2)}$, e assim sujeito às suas relações de simetria.

Muitos grupos de pesquisa têm aplicado SFG para investigar diversos tipos de interfaces e superfícies. Assim, sua teoria já é bem definida ${ }^{[25,26,27,28]}$, desde o clássico trabalho de N. Bloembergen e P. S. Pershal sobre a teoria eletromagnética em interfaces de meios não-lineares ${ }^{[29]}$.

Sigamos então a um tratamento matemático ${ }^{[27,30]}$ mais específico sobre SFG em interfaces. Retomando a Equação 16, podemos escrever

$$
\overrightarrow{\mathrm{P}}^{(2)}\left(\omega_{3}=\omega_{1}+\omega_{2}\right)=\chi^{(2)}\left(\omega_{1}+\omega_{2}\right): \vec{E}\left(\omega_{1}\right) \vec{E}\left(\omega_{2}\right) .
$$

Equação 46

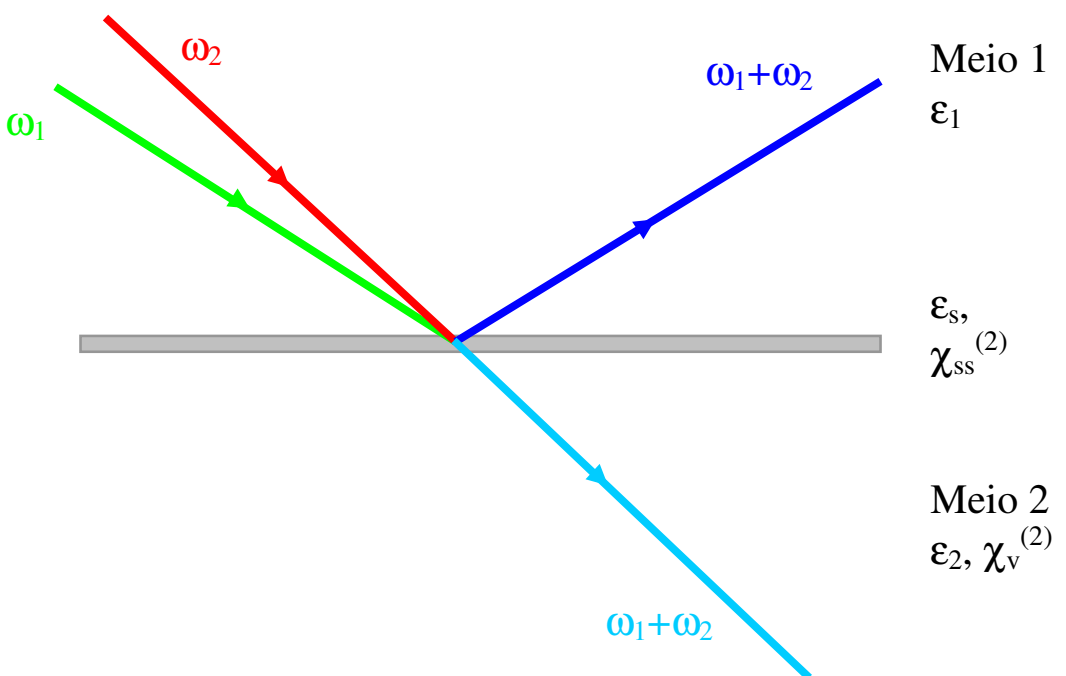

Figura 5: Geometria da Geração de Soma de Frequiência a partir da interface entre dois meios. A polarização $\mathrm{P}^{(2)}\left(\omega_{3}=\omega_{1}+\omega_{2}\right)$ surge da fina camada interfacial de constante dielétrica $\varepsilon_{\mathrm{s}}$, e das contribuições do volume do meio $2, \chi_{\mathrm{v}}{ }^{(2)}$. 
Como um termo fonte na equação de onda, $\mathrm{P}^{(2)}$ é responsável pela geração de uma nova onda com frequiência $\omega_{3}$ que é o sinal de SFG.

Consideremos o caso de SFG gerado a partir da reflexão em uma interface, como ilustra a Figura 5, onde o meio 1 é linear mas o meio 2 é não-linear. Consideremos também uma fina camada interfacial de constante dielétrica $\varepsilon_{\mathrm{s}}$ e susceptibilidade não-linear $\chi_{\text {ss }}^{(2)}$. A solução da equação de onda é calculada resultando em:

$$
\begin{aligned}
E_{s}\left(\omega_{3}\right)= & i\left(\frac{2 \pi k_{1}^{2}\left(\omega_{3}\right)}{k_{1 z}\left(\omega_{3}\right) \varepsilon_{1}\left(\omega_{3}\right)}\right) \\
& \times\left[L_{y y}\left(\omega_{3}\right) \chi_{s, y j k}^{(2)} L_{j j}\left(\omega_{1}\right) L_{k k}\left(\omega_{2}\right),\right. \\
& \left.\times E_{1 j}\left(\omega_{1}\right) E_{1 k}\left(\omega_{2}\right)\right]
\end{aligned}
$$

Equação 47

$$
\begin{aligned}
E_{p}\left(\omega_{3}\right) & =i\left(\frac{2 \pi \omega_{3}}{c}\right)\left[L_{x x}\left(\omega_{3}\right) \chi_{s, x j k}^{(2)} L_{j j}\left(\omega_{1}\right) L_{k k}\left(\omega_{2}\right)\right. \\
& +\left(\frac{k_{x}\left(\omega_{3}\right)}{k_{1 z}\left(\omega_{3}\right)}\right) L_{z z}\left(\omega_{3}\right) \chi_{s, z j k}^{(2)} L_{j j}\left(\omega_{1}\right) L_{k k}\left(\omega_{2}\right), \\
& \left.\times E_{1 j}\left(\omega_{1}\right) E_{1 k}\left(\omega_{2}\right)\right]
\end{aligned}
$$

Equação 48

onde os subscritos $s$ e $p$ se referem às polarizações dos feixes (perpendicular ao, e no plano de incidência, respectivamente), $\mathrm{k}_{1}\left(\omega_{3}\right)$ é o vetor de onda na freqüência $\omega_{3}$ no meio $1, \mathrm{E}_{1}\left(\omega_{\mathrm{i}}\right)$ é o campo incidente de freqüência $\omega_{\imath}$ no meio 1 , e $\mathrm{L}_{\mathrm{ii}}$ é coeficiente de transmissão de Fresnel, dado por

$$
\begin{aligned}
L_{x x}\left(\omega_{i}\right) & =\frac{2 \varepsilon_{1}\left(\omega_{i}\right) k_{2 z}\left(\omega_{i}\right)}{\varepsilon_{2}\left(\omega_{i}\right) k_{1 z}\left(\omega_{i}\right)+\varepsilon_{1}\left(\omega_{i}\right) k_{2 z}\left(\omega_{i}\right)}, \\
L_{y y}\left(\omega_{i}\right) & =\frac{2 k_{1 z}\left(\omega_{i}\right)}{k_{1 z}\left(\omega_{i}\right)+k_{2 z}\left(\omega_{i}\right)},
\end{aligned}
$$




$$
L_{z z}\left(\omega_{i}\right)=\frac{2 \varepsilon_{1}\left(\omega_{i}\right) k_{2 z}\left(\frac{\varepsilon_{2}}{\varepsilon_{s}}\right)}{\varepsilon_{2}\left(\omega_{i}\right) k_{1 z}\left(\omega_{i}\right)+\varepsilon_{1}\left(\omega_{i}\right) k_{2 z}\left(\omega_{i}\right)},
$$

Equação 49

O campo de Soma de Freqüência parece ser gerado da camada de constante dielétrica $\varepsilon_{\mathrm{s}}$ entre os meios 1 e 2 por uma polarização induzida (Equação 46). Entretanto, $\mathrm{P}_{\mathrm{s}}^{(2)}\left(\omega_{3}\right)$ ou $\chi_{\mathrm{s}}^{(2)}\left(\omega_{3}\right)$ têm contribuições tanto da interface quanto do volume, ou seja,

$$
\chi_{s, i j k}^{(2)}=\chi_{s s, i j k}^{(2)}+\frac{\chi_{V, i j k}^{(2)}}{k_{2 z}\left(\omega_{3}\right)+k_{2 z}\left(\omega_{1}\right)+k_{2 z}\left(\omega_{2}\right)}\left[F_{i}\left(\omega_{3}\right) F_{j}\left(\omega_{1}\right) F_{k}\left(\omega_{2}\right)\right],
$$

Equação 50

onde $F_{\alpha}(\Omega)=\left\{\begin{array}{c}\varepsilon_{2}(\Omega) / \mathcal{E}_{s}(\Omega), \text { para } \alpha=z \\ 1, \text { para } \alpha=x, y\end{array}\right.$

O primeiro termo na Equação 50 é a contribuição da interface, e o segundo é a contribuição do volume. É claro que a contribuição do volume dominará se $\chi_{\mathrm{v}}{ }^{(2)}$ é não-nulo (na aproximação do dipolo elétrico), num meio sem simetria de inversão. Assim, para estudos de superfície e interfaces com SFG, nós requeremos um meio cujo volume tenha simetria de inversão. Vale a pena observar que num cristal, por exemplo, o volume e a superfície têm diferentes simetrias estruturais. Isso leva a $\chi_{\mathrm{ss}}{ }^{(2)}$ e $\chi_{\mathrm{v}}{ }^{(2)}$ com diferentes tipos de simetria, isto é, elementos nulos para um, mas não-nulo para o outro. É então possível escolher uma combinação apropriada de polarização dos feixes que pode efetivamente suprimir a contribuição do volume e fazer $\chi_{s s}{ }^{(2)}$ específico a superfícies.

O sinal SFG refletido pode ser calculado a partir da Equação 47 e da Equação 48. Se os sinais de entrada são pulsados com duração do pulso $T$ e a secção 
reta da superposição dos feixes na interface é $A$, então a saída SFG em termos de fótons por pulso é dada por

$$
\begin{aligned}
& S\left(\omega_{3}\right)=\frac{8 \pi^{3} \omega_{3} \sec ^{2} \theta_{\omega_{3}}}{c^{3} \hbar\left[\varepsilon_{1}\left(\omega_{3}\right) \varepsilon_{1}\left(\omega_{1}\right) \varepsilon_{1}\left(\omega_{2}\right)\right]^{1 / 2}} \\
& \times\left|e^{\perp}\left(\omega_{3}\right) \bullet \chi_{s}^{(2)}: e\left(\omega_{1}\right) e\left(\omega_{2}\right)\right|^{2} \\
& \times I_{I}\left(\omega_{1}\right) I_{I}\left(\omega_{2}\right) A T,
\end{aligned}
$$

Equação 51

onde $e(\Omega)=\mathrm{L} \cdot \hat{e}(\Omega)$, e $\hat{e}(\Omega)$ é o vetor unitário que descreve a polarização do campo com freqüência $\Omega, \theta_{\omega}$ é o ângulo de reflexão do sinal SFG com relação à direção normal à superfície, e $I_{I}\left(\omega_{i}\right)$ é a intensidade do laser de entrada com freqüência $\omega_{\mathrm{i}}$.

Para se ter uma idéia a respeito da eficiência da geração de soma de freqüências num volume não-centrossimétrico e numa interface, podemos comparar os valores típicos de $\chi^{(2)}$. Para um campo elétrico atômico da ordem de $\mathrm{E}_{\mathrm{at}} \sim 10^{9}$ V/cm aplicado num volume, $\chi_{V}^{(2)}$ será da ordem de $1 / \mathrm{E}_{\mathrm{at}}$, ou $\chi_{V}^{(2)} \cong 10^{-10} \mathrm{~cm} / \mathrm{V}$. Com relação ao $\chi_{S}^{(2)}$ na interface, podemos aproximar $\left|\chi_{S}^{(2)}\right| \sim\left|\chi_{V}^{(2)} a\right|$, onde $a$ é a espessura da superfície ou interface (cerca de algumas dezenas de nanômetros), seu valor será da ordem de $\sim 10^{-17}-10^{-19} \mathrm{~cm} / \mathrm{V}$. No entanto, com o valor típico de $\chi_{S}^{(2)} \sim 10^{-18} \mathrm{~cm} / \mathrm{V}$, e com feixes de laser com potência da ordem de $\sim 10^{10} \mathrm{~W} / \mathrm{cm}^{2}$, a geração de fótons será de $\sim 10^{4}$ fótons/pulso, o que é facilmente detectável.

\subsection{IMPLICAÇÕES DO SFG EM INTERFACES}

Foi dito anteriormente (Seção 2.1) que a susceptibilidade não-linear de segunda ordem $\chi_{i j k}^{(2)}$ tem no máximo 27 componentes. No entanto, devido às 
condições de simetria, nem todas as componentes contribuem para o valor de $\chi_{i j k}^{(2)}$. Num meio centrossimétrico, todas as direções são equivalentes, e assim os valores de $\chi_{i j k}^{(2)}$ para duas direções opostas devem ser equivalentes:

$$
\chi_{i j k}^{(2)}=\chi_{-i-j-k}^{(2)} .
$$

Equação 52

Mas $\chi_{i j k}^{(2)}$ é um tensor de terceira ordem, e uma mudança no sinal dos índices indica simplesmente uma inversão do sistema de eixos, e o fenômeno físico que $\chi_{i j k}^{(2)}$ descreve deve mudar de sinal,

$$
\chi_{i j k}^{(2)}=-\chi_{-i-j-k}^{(2)}
$$

Equação 53

A Equação 53 é a regra de seleção para processos ópticos não-lineares de segunda ordem $^{[31]}$. Para satisfazer tanto a Equação 52 quanto a Equação $53, \chi_{i j k}^{(2)}$ deve ser identicamente nulo. Ou seja, para meios centrossimétricos, o SFG é proibido:

$$
\chi_{i j k}^{(2)}=0 . \quad(\text { meio centrossimétrico) }
$$

Equação 54

Para materiais líquidos e muitos materiais sólidos, o volume pode ser considerado como macroscopicamente aleatório ou randômico ${ }^{[31]}$ e assim possuindo simetria de inversão. $\mathrm{Na}$ interface, entretanto, essa simetria de inversão é quebrada. Este é o motivo de SFVS permitir obter informação de uma fina camada interfacial sem interferência do volume da amostra. Obviamente, em sólidos sem nenhuma simetria de inversão no volume, a técnica de SFVS não é mais sensível à superfície. A Equação 54 expressa a sensitividade a superfícies do SFG. 


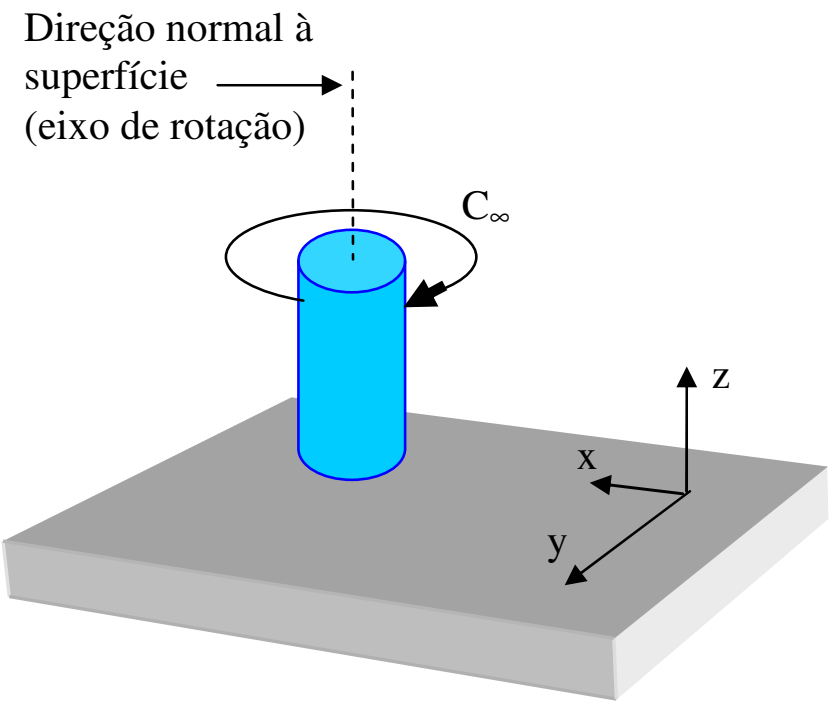

Figura 6: Uma superfície plana simétrica em torno da direção normal à superfície.

Consideremos agora uma superfície plana entre dois meios distintos, isotrópica e simétrica em torno da direção normal à superfície, possuindo assim um eixo de rotação $C_{\infty}$, conforme ilustra a Figura 6. Com esse tipo de simetria $\left(C_{\infty}\right)$, mudanças nas direções dos eixos $x$ e $y$ são indiferentes $(x=-x$ e $y=-y)$. Mas para o eixo $z$, o mesmo não acontece, ou seja, $z \neq-z$. Para uma superfície com simetria $C_{\infty}$, as componentes não-nulas de $\chi_{i j k}^{(2)}$ não devem ser alteradas se o sinal de $x$ e $y$ são trocados, mas a regra de seleção mostrada na Equação 53 deve ainda permanecer válida. A consequiência é que somente um número limitado de combinações vetoriais dos feixes incidente e saída pode satisfazer estas regras. A Tabela I mostra as componentes não-nulos para uma superfície isotrópica ${ }^{[34]} C_{\infty}$.

Tabela I: Elementos não-nulos de $\chi_{i j k}^{(2)}$ para o caso de uma superfície isotrópica.

\begin{tabular}{|} 
Componentes que potencialmente geram sinal SFG \\
$\qquad \chi_{z x x}^{(2)} \equiv \chi_{z y y}^{(2)}$ \\
\hline$\chi_{x z x}^{(2)} \equiv \chi_{y z y}^{(2)}$ \\
\hline
\end{tabular}




\begin{tabular}{|c|}
\hline$\chi_{x x z}^{(2)} \equiv \chi_{y y z}^{(2)}$ \\
\hline$\chi_{z z z}^{(2)}$ \\
\hline
\end{tabular}

Se considerarmos a direção $x$ paralela à superfície e contida no seu plano de incidência, o feixe de polarização $p$ pode ser decomposto em componentes $x \mathrm{e} z$, e o feixe de polarização $s$ só pode ser resolvido e uma única componente na direção $y$. Com a combinação específica de polarização dos feixes, é possível selecionar as componentes da susceptibilidade apropriadas. A polarização do sinal gerado de SFG é determinada pelas componentes não-nulas de $\chi_{i j k}^{(2)}$ que geram o sinal de SFG. A Tabela II mostra todas as possíveis combinações de polarização possíveis para o caso de uma superfície com eixo de simetria $C_{\infty}$. As polarizações são escritas seguindo a ordem sinal SFG, feixe visível, feixe infravermelho. Com relação às polarizações pss e sps, se os feixes de SFG e visível estiverem afastados de ressonâncias eletrônicas, elas são equivalentes.

Tabela II: As possíveis combinações de polarizações e elementos de $\chi_{i j k}^{(2)}$ que podem contribuir para o espectro SFG

\begin{tabular}{|c|c|}
\hline Combinação de polarização & Elementos de $\chi_{i j k}^{(2)}$ \\
\hline$p s s$ & $\chi_{z x x}^{(2)} \equiv \chi_{z y y}^{(2)}$ \\
\hline$s p s$ & $\chi_{x z x}^{(2)} \equiv \chi_{y z y}^{(2)}$ \\
\hline$s s p$ & $\chi_{x x z}^{(2)} \equiv \chi_{y y z}^{(2)}$ \\
\hline$p p p$ & $\chi_{z z z}^{(2)}, \chi_{z x x}^{(2)}, \chi_{x z x}^{(2)}, \chi_{x x z}^{(2)}$ \\
\hline
\end{tabular}




\subsection{HIPERPOLARIZABILIDADE DE SEGUNDA ORDEM $\beta$.}

A susceptibilidade não-linear de segunda ordem é uma média macroscópica da polarizabilidade (ou hiperpolarizabilidade) não-linear de segunda ordem $\beta$. Esta pode ser definida como o termo que descreve a interação não-linear da molécula com o campo óptico, além de descrever o comportamento refrativo e absorvedor da molécula ${ }^{[32]}$. A relação entre $\chi^{(2)}$ e $\beta$ pode ser expressa pela equação abaixo:

$$
\chi_{i j k}^{(2)}=\frac{N}{\varepsilon_{0}} \sum\langle R(\psi) R(\theta) R(\varphi)\rangle \beta_{\alpha \beta \gamma} .
$$

Equação 55

Nesta equação, $N$ é o número de moléculas por unidade de volume, e $R(\psi) R(\theta) R(\varphi)$ é o produto de três matrizes de rotação que relacionam o sistema de coordenadas do laboratório e o sistema de coordenadas da molécula. O símbolo \langle\rangle representa uma média orientacional. Da mesma forma que os índices ijk se referem aos eixos $x, y, z$ no referencial do laboratório, os índices $\alpha \beta \gamma$ se referem aos eixos $x, y, z$, no referencial da molécula. Se o tensor $\beta$ das moléculas é conhecido, as medidas dos elementos de $\chi^{(2)}$ podem fornecer informações a respeito da orientação dessas moléculas.

Fazendo uso novamente da Teoria da Perturbação ${ }^{[33]}$, pode-se obter uma expressão para $\beta_{\alpha \beta \gamma}$. Uma simplificação é apresentada quando se consideram freqüências $\omega_{\mathrm{IR}}$ próximas de uma freqüência de ressonância da molécula $\omega_{0}$, e $\omega_{\mathrm{VIS}}$ estando longe das freqüências de transições eletrônicas ${ }^{[34]}$ : 


$$
\beta_{\alpha \beta \gamma}=\frac{1}{2 \hbar} \frac{M_{\alpha \beta} A_{\gamma}}{\left(\omega_{I R}-\omega_{q}+i \Gamma_{q}\right)},
$$

Equação 56

onde $\Gamma^{-1}$ representa a largura da transição. Os termos $M_{\alpha \beta}$ e $A_{\gamma}$ são os momentos de transição Raman e infravermelha, respectivamente, e são dadas por

$$
M_{\alpha \beta}=\sum_{s}\left[\frac{\left\langle g\left|\hat{\mu}_{\alpha}\right| s\right\rangle\left\langle s\left|\hat{\mu}_{\beta}\right| v\right\rangle}{\hbar\left(\omega_{S F}-\omega_{s g}\right)}-\frac{\left\langle g\left|\hat{\mu}_{\beta}\right| s\right\rangle\left\langle s\left|\hat{\mu}_{\alpha}\right| v\right\rangle}{\hbar\left(\omega_{V I S}+\omega_{s g}\right)}\right],
$$

Equação 57

$$
A_{\gamma}=\left\langle v\left|\hat{\mu}_{\gamma}\right| g\right\rangle
$$

Equação 58

Aqui, $\hat{\mu}$ é o operador dipolo elétrico, $|g\rangle$ é o estado fundamental, $|v\rangle$ é o estado excitado, e $|s\rangle$ é um outro estado qualquer.

Para mais de uma ressonância da amostra, a Equação 25 pode ser simplificada como segue ${ }^{[25,26,33,34]}$ :

$$
\begin{aligned}
\chi^{(2)} & =\chi_{N R}^{(2)}+\chi_{R}^{(2)} \\
& =\chi_{N R}^{(2)}+\sum_{q} \frac{\left(M_{\alpha \beta} A_{\gamma}\right)_{q}}{\omega_{I R}-\omega_{q}+i \Gamma_{q}}, \\
& =\chi_{N R}^{(2)}+\sum_{q} \frac{B_{q}}{\omega_{I R}-\omega_{q}+i \Gamma_{q}}
\end{aligned}
$$

Equação 59

onde o índice $q$ se refere ao q-ésimo modo ressonante. Quando $\omega_{\mathrm{IR}}$ está longe da ressonância, a Equação 59 dá $\chi_{N R}^{(2)}$, que inclui a contribuição (não-ressonante) de todas as outras ressonâncias da amostra que não seja a q-ésima. 


\subsection{INTERPRETAÇÃO DO ESPECTRO DE SOMA DE FREQUÊNCIAS}

As ressonâncias nos espectros de SFG possuem quatro características marcantes, que são a posição do pico $\left(\omega_{q}\right)$, a sua largura $\left(\Gamma_{q}\right)$, sua intensidade $\left(B_{q}\right)$ e a fase do sinal com relação a $\chi_{N R}^{(2)}$. Essas características podem fornecer informações a respeito da conformação molecular de um filme na interface. Para a geração de um sinal de SFG, há a necessidade de que as moléculas da interface sejam ativas no Infravermelho e no Raman, conforme se pode concluir da Equação 55 e da Equação 56. Por isso, entre outros motivos, grande parte do trabalho realizado com SFG tem sido focado nos modos vibracionais $\mathrm{CH}$. A Figura 7 ilustra alguns desses modos. As setas indicam a direção do deslocamento interno dos estiramentos $\mathrm{C}-\mathrm{H}$. Algumas das frequiências de ressonância desses modos estão mostradas na Tabela III.

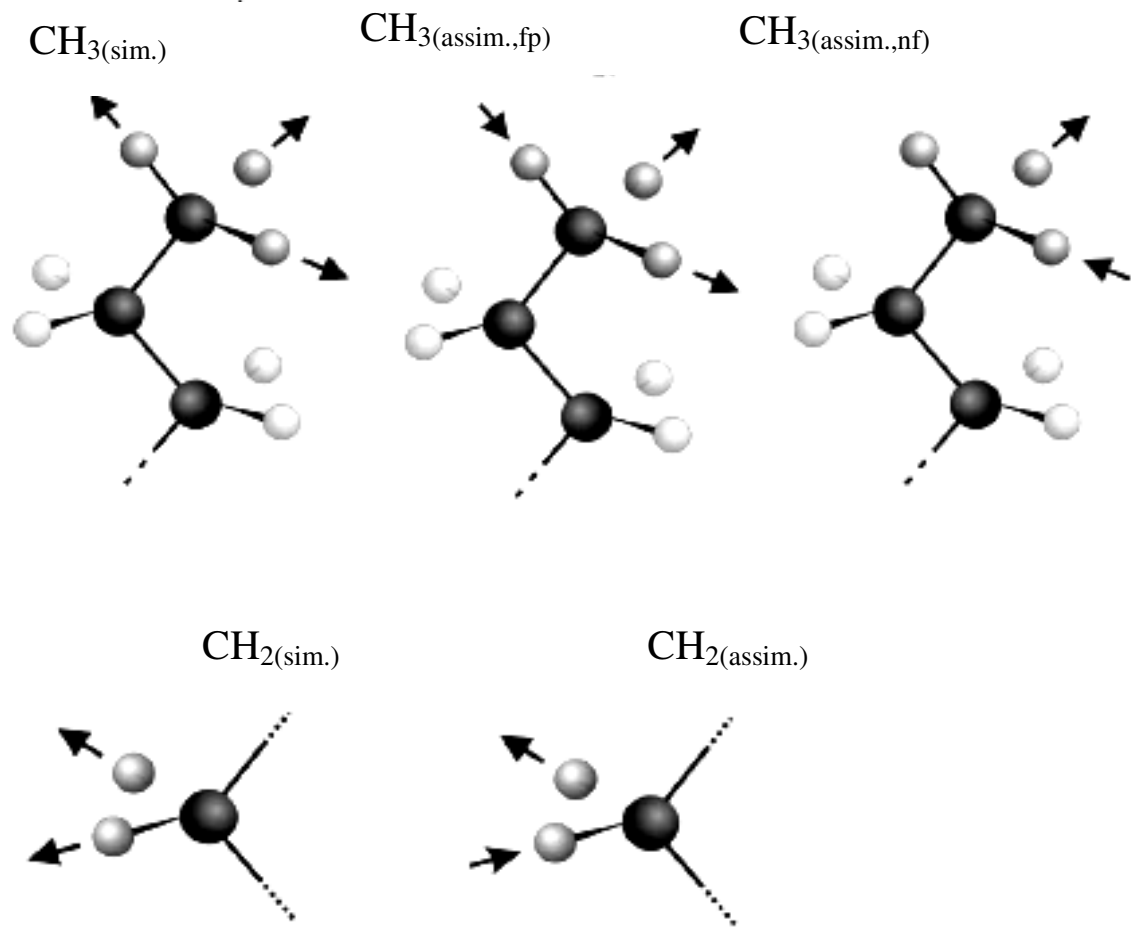

Figura 7: Modos vibracionais do metil e do metileno. Os índices $n p$ e $f p$ significam no plano e fora do plano, respectivamente, onde o plano é definido pelas ligações $\mathrm{C}$-C. Por simplicidade, somente o deslocamento dos átomos de hidrogênio são mostrados ${ }^{[34]}$. 
Tabela III: Atribuições ressonantes e números de onda dos modos estiramentos dos grupos C-H observados por SFG ${ }^{[38,39,40,41]}$.

\begin{tabular}{|c|c|c|}
\hline Modo & Descrição & Freqüência \\
\hline $\mathrm{CH}_{3 \text { (sim.) }}$ & Estiramento simétrico do $\mathrm{CH}_{3}$ & $\sim 2878 \mathrm{~cm}^{-1}$ \\
\hline $\mathrm{CH}_{3 \text { (sim, FR) }}$ & $\begin{array}{c}\text { Estiramento simétrico do } \mathrm{CH}_{3} \\
\text { (ressonância de Fermi) }\end{array}$ & $\sim 2945$ \\
\hline $\mathrm{CH}_{2 \text { (assim., np) }}$ & Estiramento anti-simétrico no plano & $\sim 2962$ \\
\hline $\mathrm{CH}_{2 \text { (assim., fp) }}$ & $\begin{array}{c}\text { Estiramento anti-simétrico fora do } \\
\text { plano }\end{array}$ & $\sim 2952$ \\
\hline $\mathrm{CH}_{2 \text { (sim.) }}$ & Estiramento simétrico do $\mathrm{CH}_{2}$ & $\sim 2846$ \\
\hline $\begin{array}{c}\mathrm{CH}_{2 \text { (sim., FR) }} \\
\begin{array}{c}\text { Estiramento simétrico do } \mathrm{CH}_{2} \\
\text { (ressonância de Fermi) }\end{array}\end{array}$ & $\sim 2890$ \\
\hline $\begin{array}{c}\mathrm{CH} \\
\text { (assim.) }\end{array}$ & Estiramento anti-simétrico do $\mathrm{CH}_{2}$ & $\sim 2915$ \\
\hline $\begin{array}{c}\mathrm{CH} \\
\text { aromático }\end{array}$ & Estiramento C-H aromático & $\sim 3060$ \\
\hline
\end{tabular}

Conforme o empacotamento das moléculas, e considerando as condições de simetria da amostra, tem-se uma determinada configuração de picos referentes aos modos $\mathrm{CH}$. Isto é aproveitado para fornecer informação sobre a cadeia principal de moléculas poliméricas.

Um simples pico ressonante pode ser expresso por

$$
\chi_{R}^{(2)}=\frac{\left(M_{\alpha \beta} A_{\gamma}\right)}{\left(\omega_{I R}-\omega_{0}+i \Gamma\right)}=\frac{B}{\left(\omega_{I R}-\omega_{0}+i \Gamma\right)},
$$

Equação 60

Expressando essa susceptibilidade ressonante numa forma complexa, temos:

$$
\begin{aligned}
& \frac{B}{\left(\omega_{I R}-\omega_{0}+i \Gamma\right)} \frac{\left(\omega_{I R}-\omega_{0}-i \Gamma\right)}{\left(\omega_{I R}-\omega_{0}-i \Gamma\right)}=\frac{B\left(\omega_{I R}-\omega_{0}-i \Gamma\right)}{\left(\left(\omega_{I R}-\omega_{0}\right)^{2}+\Gamma^{2}\right)} \\
& =\frac{B\left(\omega_{I R}-\omega_{0}\right)}{\left(\left(\omega_{I R}-\omega_{0}\right)^{2}+\Gamma^{2}\right)}-i \frac{B \Gamma}{\left(\left(\omega_{I R}-\omega_{0}\right)^{2}+\Gamma^{2}\right)}
\end{aligned}
$$


$\mathrm{Na}$ equação acima se destacam as partes real e imaginária de $\chi_{R}{ }^{(2)}$. Em coordenadas polares, $\chi_{\mathbf{R}}{ }^{(2)}$ pode ser escrito como

$$
\chi_{R}^{(2)}=\left|\chi_{R}^{(2)}\right| e^{i \delta}
$$

Equação 62

onde $\left|\chi_{R}^{(2)}\right|$ e $\delta$ são o módulo e a fase (mais especificamente, a mudança de fase com relação ao feixe incidente), respectivamente, da susceptibilidade ressonante.
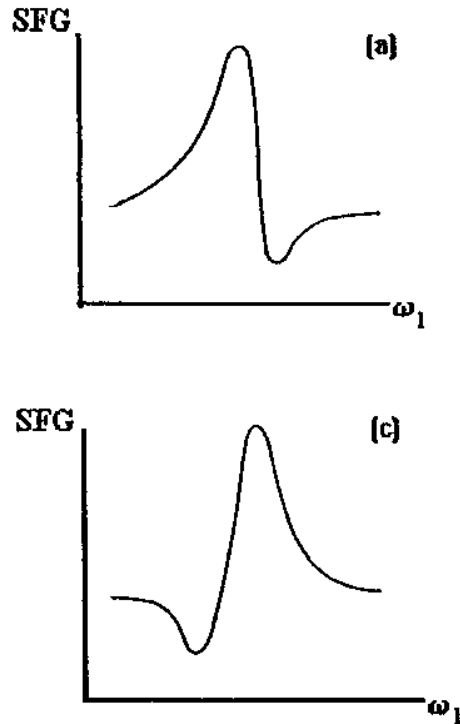

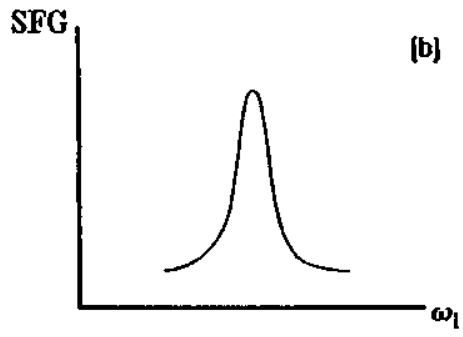

SFG

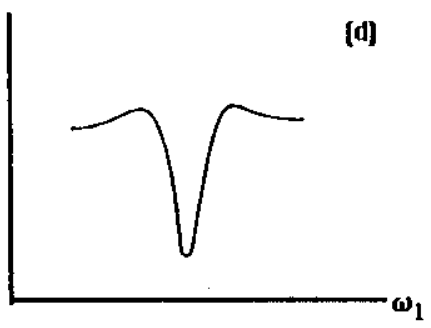

Figura 8: Possíveis formas espectrais de uma ressonância. O sinal é proporcional a $\left|\chi_{N R}^{(2)}+B /\left(\omega_{I R}-\omega_{0}+i \Gamma\right)\right|^{2}$. Nos gráficos temos: a) $\chi_{N R}^{(2)}$ é real e tem o mesmo sinal que B; b) $\left|\chi_{N R}^{(2)}\right|\left\langle\left\langle|B / \Gamma|\right.\right.$; c) $\chi_{N R}^{(2)}$ é real, mas com sinal oposto a B; d) $\chi_{N R}^{(2)}$ é imaginário e tem sinal oposto a $|B / \Gamma|$, e ainda $\left.\left|\chi_{N R}^{(2)}\right|\right\rangle|B / \Gamma|$ [A partir da Ref. 27].

A fase do sinal ressonante é útil na interpretação do espectro SFG, pois os vários picos vizinhos podem interferir entre si e entre a susceptibilidade nãoressonante, dando origem a formas espectrais características e diferentes daquelas observadas em espectroscopia convencional (ver Figura 8). Por exemplo, tomemos a 
Equação 59 para uma ressonância apenas. A susceptibilidade não-linear de segunda ordem pode ser expressa por

$$
\chi^{(2)}=\chi_{N R}^{(2)}+\chi_{R}^{(2)}=\chi_{N R}^{(2)}+\frac{B_{q}}{\omega_{I R}-\omega_{q}+i \Gamma_{q}}
$$

Equação 63

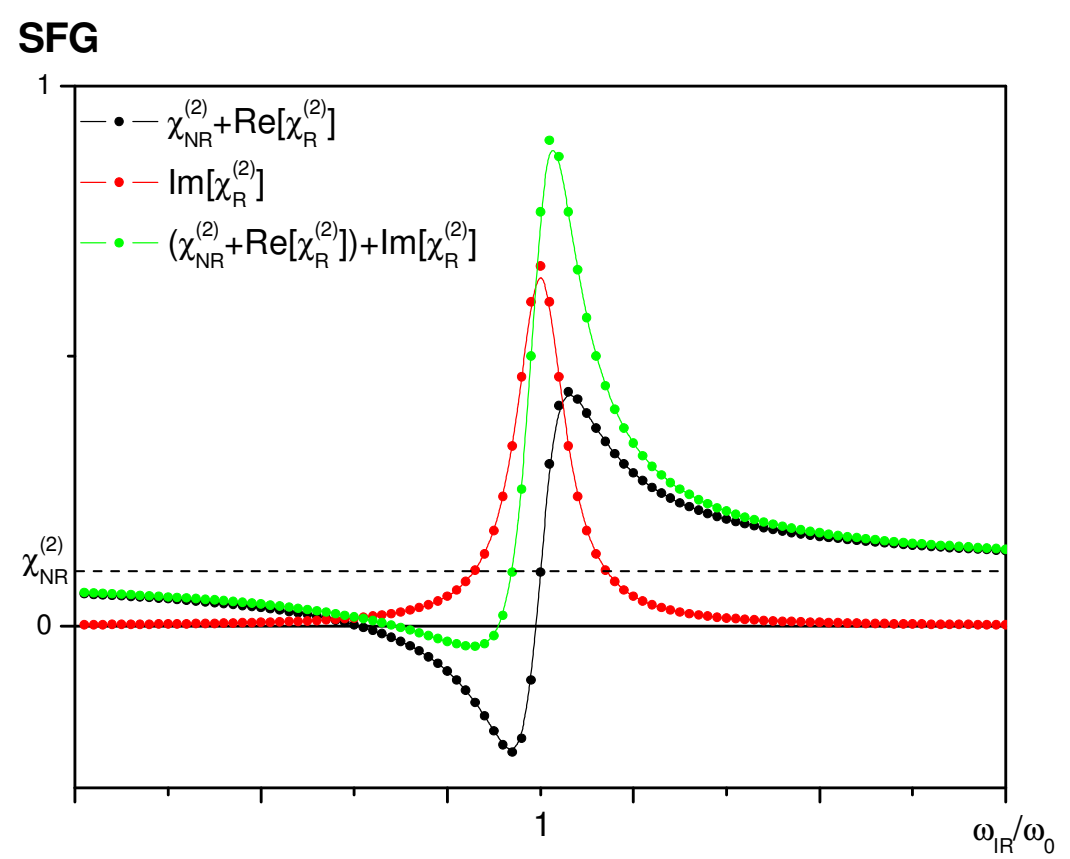

Figura 9: Gráficos de $\chi_{N R}^{(2)}+\operatorname{Re}\left[\chi_{R}^{(2)}\right]$, de $\operatorname{Im}\left[\chi_{R}^{(2)}\right]$, e de $\chi_{N R}^{(2)}+\operatorname{Re}\left[\chi_{R}^{(2)}\right]+\operatorname{Im}\left[\chi_{R}^{(2)}\right]$ em função de $\omega_{\mathrm{IR}} / \omega_{0}$.

Para um melhor entendimento, construímos os gráficos da parte real, imaginária, e da soma das duas partes em função da razão $\omega_{\mathrm{IR}} / \omega_{0}$ de $\chi_{S}^{(2)}=\chi_{N R}^{(2)}+\chi_{R}^{(2)}$, e supusemos a situação do gráfico $c$ da Figura 8 , onde $\chi_{N R}^{(2)}$ é real e com sinal oposto a $\chi_{R}^{(2)}$. Os gráficos estão mostrados na Figura 9. Como pode ser visto, a parte imaginária $\chi_{R}^{(2)}$ é simétrica (função par), mas a parte real de $\chi_{R}^{(2)}$ é assimétrica (função ímpar) e deslocada do eixo $x$ por causa de $\chi_{N R}^{(2)}$. Como visto anteriormente, o sinal SFG é proporcional ao quadrado de $\chi_{S}^{(2)}=\chi_{N R}^{(2)}+\chi_{R}^{(2)}$. Como 
$\chi_{N R}^{(2)}$ é aproximadamente constante, a forma de linha espectral do sinal SFG é determinada principalmente pelo sinal de $\chi_{R}^{(2)}$. Da Figura 9, podemos notar a origem da assimetria do pico de SFG através do quadrado do gráfico verde. 


\section{PARTE EXPERIMENTAL}

\subsection{PREPARAÇÃO DAS AMOSTRAS}

Os filmes automontados foram preparados a partir de soluções de policátion PAH (Aldrich, $\left.\mathrm{M}_{\mathrm{W}}=15.000\right)$ e de poliânion PSS (Aldrich, $\left.\mathrm{M}_{\mathrm{W}}=70.000\right)$, com concentrações de $0,5 \mathrm{mg} / \mathrm{mL}$, e $\mathrm{pH} 4$ ou $\mathrm{pH}$ 12. Para o ajuste do $\mathrm{pH}$, foram utilizadas soluções de $\mathrm{HCl}$ (Qhemis, 37\% PA) e $\mathrm{NaOH}$ (Aldrich, 99.99\% de pureza). Todas as soluções foram feitas utilizando-se água ultrapura (Milli-Q), com resistência maior do que $18 \mathrm{M} \Omega \cdot \mathrm{cm}$.

Os substratos utilizados foram janelas de quartzo amorfo $\left(\mathrm{SiO}_{2}\right)$ e também de fluoreto de cálcio $\left(\mathrm{CaF}_{2}\right)$, tanto para medidas de filmes in situ quanto de filmes $e x$ situ. As janelas de quartzo foram limpas com solução de ácido sulfúrico e peróxido de hidrogênio $\left(\mathrm{H}_{2} \mathrm{SO}_{4}+\mathrm{H}_{2} \mathrm{O}_{2}\right)$ na proporção de 7:3 ("solução piranha"), por um período de 30 minutos, seguido por extenso enxágüe com água pura e secagem com jato de nitrogênio. Quanto ao $\mathrm{CaF}_{2}$, a limpeza se deu através de solução de permanganato de potássio (numa concentração onde a solução apresentava uma coloração arroxeada ou púrpura). $\mathrm{O} \mathrm{CaF}_{2}$ ficou em banho nessa solução por um período de aproximadamente 12 horas, sendo em seguida banhado em solução de $\mathrm{H}_{2} \mathrm{O}_{2}+\mathrm{H}_{2} \mathrm{SO}_{4}$, na proporção de 20:1, por aproximadamente 20 min. 


\subsection{INSTRUMENTAÇÃO DE SFG}

Para a obtenção de espectro de SFG foi utilizado um espectrômetro da EKSPLA cujo arranjo experimental está ilustrado na Figura 10. Nele, um laser pulsado (30ps) de $\mathrm{Nd}^{+3}$ :YAG emite luz de comprimento de onda $\lambda=1064 \mathrm{~nm} \mathrm{e}$ excita uma Unidade Geradora de Harmônicos (HGU). Essa unidade produz feixes de $2^{\circ}$ harmônico a $\lambda=532 \mathrm{~nm}$ (visível) e de $3^{\circ}$ harmônico a $\lambda=355 \mathrm{~nm}$ (UV), além de ainda permitir um sinal de saída no fundamental $(1064 \mathrm{~nm})$. Este fundamental e o UV excitam um Oscilador/Amplificador Paramétrico Óptico (OPO/OPA), responsável pela geração do feixe infravermelho (IR) sintonizável que incidirá na $\operatorname{amostra}\left(\lambda_{\mathrm{IR}}\right)$. O feixe no visível $\left(\lambda_{\mathrm{VIS}}=532 \mathrm{~nm}\right)$ será o outro feixe incidente.

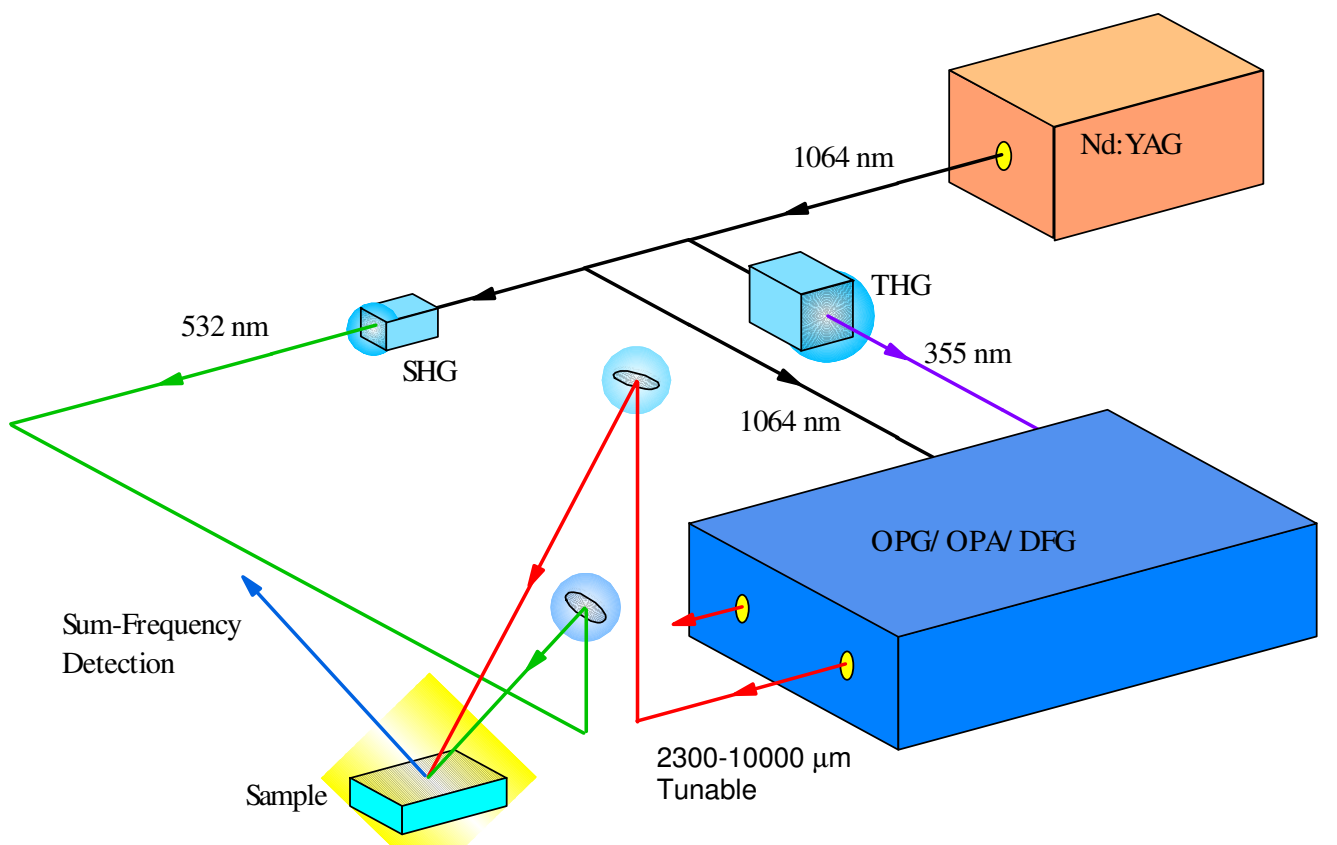

Figura 10: Layout do sistema de SFG. O sistema e composto por um laser de $\mathrm{Nd}^{+3}$ :YAG que emite no comprimento de onda de $1064 \mathrm{~nm}$ e bombeia uma Unidade Geradora de Harmônicos e um Gerador/Amplificador Paramétrico Óptico. 
O OPO/OPA pode então gerar luz IR numa faixa 2300-10000 nm através de um estágio Gerador de Diferença de Freqüências $(D F G)$. O IR gerado pode variar num intervalo pré-determinado conforme a faixa de varredura que se deseja estudar. Portanto, o sinal de Soma de Freqüências varia conforme a combinação dos feixes $\omega_{\text {IR }}$ do OPA e do feixe $\omega_{\mathrm{VIS}}$ da HGU. O sinal SFG é então detectado por um conjunto monocromador/fotomultiplicadora e, através de um programa em LABVIEW e sistema de aquisição de dados, estes são coletados num PC. Todo o aparato é montado em uma mesa óptica com sistema de isolamento pneumático de vibrações, a fim de evitar que vibrações externas interfiram nas medidas. A Figura 11 são fotos Laboratório de Espectroscopia Não-linear de Interfaces - LENI, mostrando o espectrômetro de SFG utilizado para a obtenção dos espectros. À esquerda pode-se ver o laser de $\mathrm{Nd}^{+3}$ :YAG, a Unidade Geradora de Harmônicos, e o OPO/OPA. À direita temos o estágio de detecção.
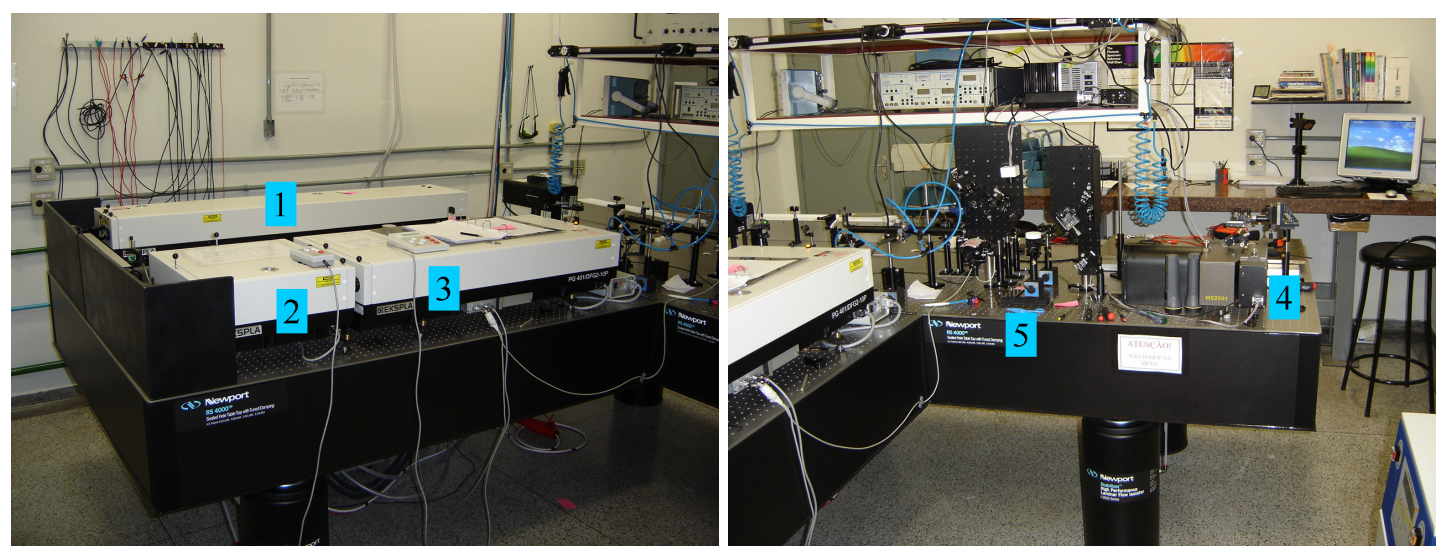

Figura 11: Fotos do LENI. À esquerda: 1- laser pulsado de $\mathrm{Nd}^{+3}$ :YAG, 2- Unidade Geradora de Harmônicos, e 3- Gerador/Amplificador Paramétrico Óptico. À direita: 4- monocromadora/fotomultiplicadora, 5- estágio da amostra.

Os ângulos de incidência dos feixes de entrada foram $\phi_{\mathrm{VIS}} \cong 61,4^{\circ}, \phi_{\mathrm{IR}} \cong$ 54,8 . Assim, pela relação de casamento de fase (Equação 41), temos $\vec{k}_{S F G}=\vec{k}_{V I S}+\vec{k}_{I R}$, ou $k_{S F G} \sin \phi_{S F G}=k_{V I S} \sin \phi_{V I S}+k_{I R} \sin \phi_{I R}$, resultando num sinal de 
soma de freqüências com ângulo $\phi_{\text {SOMA }} \cong 60,5^{\circ}$. O ponto da superposição dos feixes visível e infravermelho sobre as amostras tinha área de aproximadamente $2 \mathrm{~mm}^{2}$, e a combinação de polarização utilizada em todas as medidas foi a SSP, para os feixes SFG, visível e infravermelho, respectivamente.

\subsection{ARRANJO EXPERIMENTAL PARA ESTUDO IN SITU E EX SITU}

Para as medidas em filmes in situ e filmes ex situ, o arranjo experimental é diferente em virtude de suas particularidades. As amostras secas automontadas sobre o substrato (ex situ) foram medidas segundo arranjo experimental descrito na Figura 12-a. Nela, os dois feixes se superpõem na face superior do substrato onde se encontra o filme adsorvido.

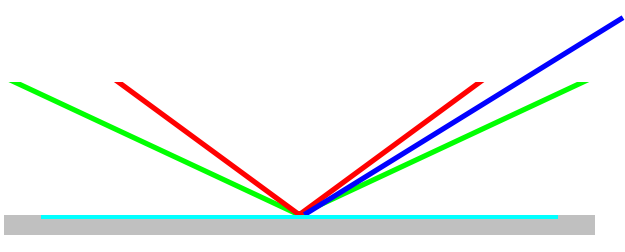

a)

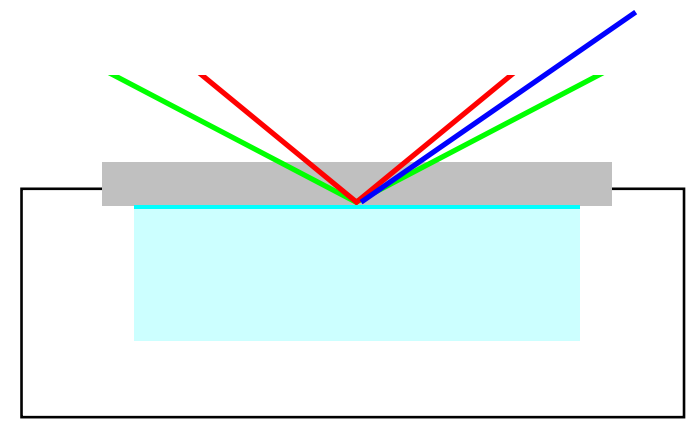

b)

Figura 12: Arranjo experimental para medidas. Em a) temos o arranjo geométrico para as medidas ex situ. Aqui, a superposição dos feixes ocorre na face superior do substrato, onde está localizado o filme previamente adsorvido. Em b), o arranjo geométrico para as medidas in situ. Neste arranjo, a superposição dos feixes ocorre na face inferior do substrato (janela de quartzo ou de $\mathrm{CaF}_{2}$ ).

Entretanto, para o estudo in situ, utilizou-se uma célula de Teflon para o suporte do substrato (quartzo ou fluoreto de cálcio). A célula está representada na Figura 12-b, onde temos em cinza a janela de quartzo ou $\mathrm{CaF}_{2}$ (substrato), e em azul, o espaço para a solução de polieletrólito. Como pode ser observado, os feixes incidentes se superpõem agora na face inferior da janela, uma vez que se pretende 
estudar a adsorção do filme no substrato ainda molhado. A Figura 13 abaixo é uma foto da célula de Teflon utilizada neste trabalho. A solução de polieletrólito é colocada na câmara interna da célula através do orifício que aparece em primeiro plano. Os quatro orifícios laterais são utilizados para que o ar na câmara possa sair. No centro da câmara está um filtro de cor que serve para eliminar o espalhamento do feixe de luz visível que atravessa a janela e incide no fundo da célula de Teflon.

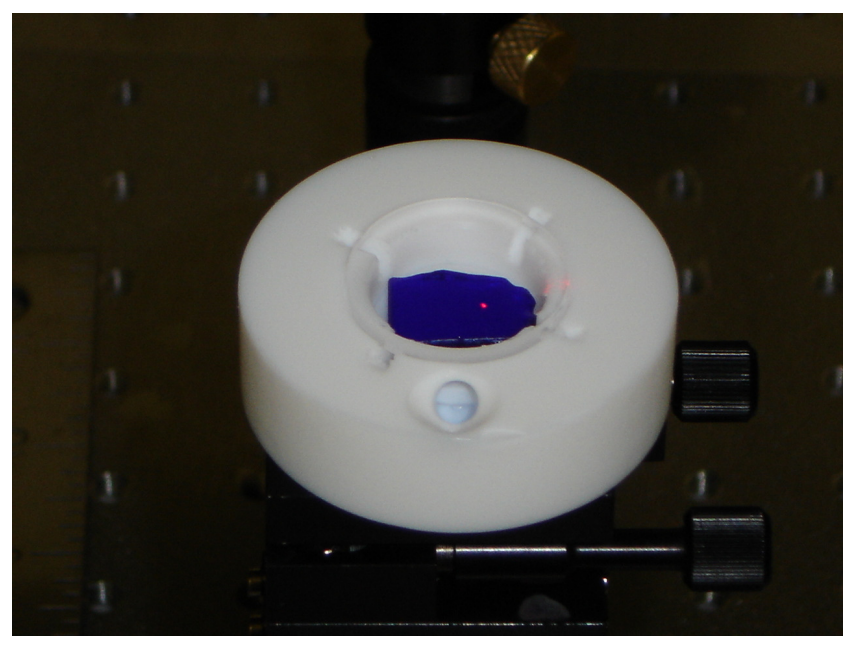

Figura 13: Célula de teflon utilizada nas medidas in situ.

Os filmes ex situ também foram construídos na mesma célula. Para simular o mergulho vertical da lâmina de vidro dentro de cada béquer de soluções, após cada inserção de solução na câmara da célula e passado o tempo para que a adsorção ocorresse ( $\sim 3 \mathrm{~min})$, retirou-se a janela de forma inclinada, de maneira a erguê-la cuidadosamente por uma borda (e sempre a mesma borda) até a sua completa retirada da célula.

Todos os espectros SFG foram normalizados utilizando-se como referência um substrato de quartzo cristalino. Assim, inicialmente faz-se uma medida na referência, e em seguida divide-se o sinal da Soma pelo produto das intensidades dos feixes infravermelho e visível. Depois, para cada amostra, repete-se o mesmo 
procedimento e então se divide o resultado obtido com a amostra com o obtido com a referência. A expressão abaixo ilustra o procedimento.

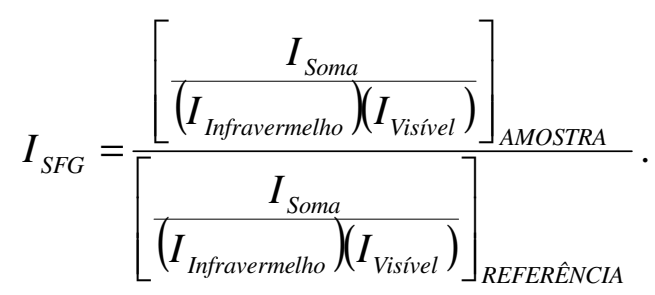

Equação 64

Com isso, eliminam-se as flutuações do sinal SFG devidas às flutuações de intensidade do feixe visível $(\sim 1$ a $2 \%)$ e do feixe IR ( 10 a 30\%). Além disso, variações da superposição dos feixes incidentes e da eficiência do sistema de detecção enquanto o IR é sintonizado também são normalizadas com esse procedimento. 


\section{FILMES AUTOMONTADOS SOBRE O QUARTZO}

Apresentaremos a seguir os resultados obtidos a partir da Espectroscopia Vibracional por SFG de filmes automontados de polieletrólitos. Os espectros foram obtidos medindo-se as amostras em duas regiões espectrais em particular: i) região de estiramentos C-H, de 2800-3000 $\mathrm{cm}^{-1}$ (alifáticos), e 3000-3100 $\mathrm{cm}^{-1}$ (aromáticos), e ii) região de estiramentos $\mathrm{O}-\mathrm{H}$, de $3100-3800 \mathrm{~cm}^{-1}$. As medidas na região de estiramentos C-H alifático foram realizadas com uma aquisição de pontos a cada 3 $\mathrm{cm}^{-1}$. Para a região de estiramento $\mathrm{C}-\mathrm{H}$ aromático e $\mathrm{O}-\mathrm{H}$, o espaçamento foi de 10 $\mathrm{cm}^{-1}$

Inicialmente os resultados mostrados são de filmes obtidos a partir de $\mathrm{pH}$ 4 e pH 12 sobre o quartzo fundido, tanto in situ quanto ex situ. No Capítulo 5, investigamos o efeito do tipo de substrato no processo de automontagem realizando medidas em filmes automontados sobre o fluoreto de cálcio $\left(\mathrm{CaF}_{2}\right)$. Todas as medidas foram normalizadas segundo o procedimento descrito na Seção 3.3.

\subsection{A INTERFACE QUARTZO/ÁGUA}

Antes de discutirmos os espectros SFG das soluções poliméricas em contato com o substrato de quartzo, vamos apresentar os espectros da interface quartzo/água com diversos valores de $\mathrm{pH}$ no volume da água, a fim de facilitar nossa

discussão posterior. Esses espectros já foram extensivamente discutidos ${ }^{[35,36,37]}$, e são 
mostrados na Figura 14. Além disso, o espectro SFG da interface quartzo/gelo também é mostrado. A combinação da polarização dos feixes de entrada/saída é ssp.
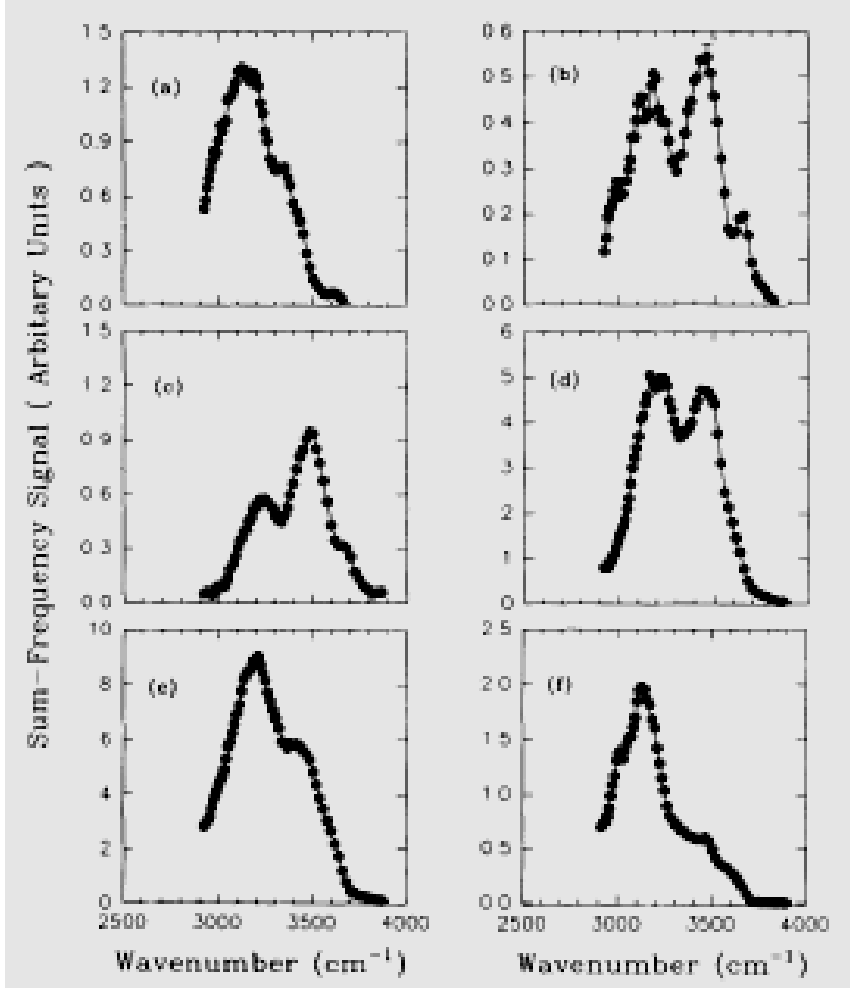

Figura 14: Espectros SFG da interface quartzo/água com diferentes valores de pH no volume. Os pH são: a) 1,5 ; b) 3,8 ; c) 5,6 ; d) 8,0 ; e) 12,3 . A letra f) é o espectro SFG da interface quartzo/gelo. [A partir da Ref. 35]

Dois picos característicos aparecem próximos a $3200 \mathrm{~cm}^{-1}$ e a $3450 \mathrm{~cm}^{-1}$, respectivamente, e ainda um terceiro menos visível em torno de $3600 \mathrm{~cm}^{-1}$. O pico a $3200 \mathrm{~cm}^{-1}$ é geralmente atribuído ao modo estiramento simétrico de ligações $\mathrm{OH}$ de moléculas de água tetraedricamente coordenadas, como no caso do gelo. O pico a $3450 \mathrm{~cm}^{-1}$ é controverso sendo que alguns pesquisadores ${ }^{[35]}$ atribuem-no ao estiramento simétrico de moléculas de água assimetricamente ligadas, ou seja, moléculas de água com algumas ligações de hidrogênio fortes e outras ligações de hidrogênio fracas em suas vizinhanças, como no caso da água líquida. Estas serão as posições assumidas na interpretação desses picos. Outros pesquisadores ainda sugerem que o pico a $3400 \mathrm{~cm}^{-1}$ ocorra devido a ligações de hidrogênio bifurcadas. 
De qualquer forma, o pico em $3200 \mathrm{~cm}^{-1}$ indica uma rede ordenada de ligações de $\mathrm{H}$, enquanto que o pico a $3400 \mathrm{~cm}^{-1}$ está relacionado à desordem na rede de ligações de $\mathrm{H}$ das moléculas de água. Finalmente, o pico em torno de $3600 \mathrm{~cm}^{-1}$ é geralmente atribuído a estiramentos anti-simétricos da ligação O-H de moléculas de água ligadas assimetricamente ${ }^{[35]}$ ou ainda a "O-H livres" ${ }^{[36]}$.

A Figura 14 mostra como os dois picos a $3200 \mathrm{~cm}^{-1}$ e $3450 \mathrm{~cm}^{-1}$ variam com o valor do $\mathrm{pH}$ da água. A Figura 14.a. mostra que a $\mathrm{pH} 1,5$, a interface quartzo/água se comporta como a interface quartzo/gelo (Figura 14.f.), indicando que grande parte das moléculas de água na interface estão arranjadas com coordenação tetraédrica com o oxigênio apontando para o substrato devido à formação de ligações de hidrogênio Si-OH…O-H. À medida que o pH aumenta (Figura 14.b. até Figura 14.e.), a intensidade relativa dos dois picos varia. No intervalo de $\mathrm{pH}$ de 1,5 a 5,6, a intensidade do primeiro pico diminui enquanto a do segundo aumenta. A partir do $\mathrm{pH} 5,6$, o primeiro volta a aumentar e o segundo torna a diminuir, e a $\mathrm{pH} 12,3$ temos novamente a aparência do espectro SFG para a interface quartzo/gelo, porém com intensidade bem maior que a $\mathrm{pH} 1,5$.

A química de superfície do quartzo indica a ocorrência de grupos Si-OH que podem ser negativamente carregados pela desprotonação na água com uma concentração suficientemente baixa de prótons, ou seja, em altos valores de $\mathrm{pH}$. Para $\mathrm{pH} \sim 2$, a superfície do quartzo é neutra, mas pode ser levemente positiva para $\mathrm{pH}$ menores que 2. No entanto, a superfície do quartzo é totalmente ionizada para $\mathrm{pH}$ maiores que 10. Assim, as cargas negativas podem dar origem a um forte campo elétrico na superfície. Este campo pode então orientar algumas monocamadas de moléculas de água interfaciais com seus momentos de dipolo apontando em direção ao quartzo ( $\mathrm{H}$ apontando para o substrato) e formando uma rede de ligações de $\mathrm{H}$ 
ordenada. Dessa forma, o $\mathrm{pH}$ do volume de água pode determinar a intensidade do campo elétrico na interface, o que afeta diretamente a orientação das moléculas de água na interface e por consequiência, a intensidade do sinal SFG. Em pH intermediário $(3<\mathrm{pH}<8)$, há uma competição entre o ordenamento devido ao campo elétrico e as ligações de $\mathrm{H}$ com o substrato, resultando em uma rede de ligações de $\mathrm{H}$ desordenada e um sinal SFG mais fraco.

\subsection{FILMES PREPARADOS A PARTIR DE SOLUÇÕES COM pH 4}

$\mathrm{O}$ espectro da interface quartzo/água pura a $\mathrm{pH} 4$ obtido em nosso laboratório está mostrado na Figura 15. Pode-se constatar que está em acordo com a literatura (Figura 14). As intensidades dos dois picos na Figura 15 indicam que há moléculas simetricamente ordenadas coexistentes com moléculas de água em uma rede desordenada de ligações de $\mathrm{H}$.

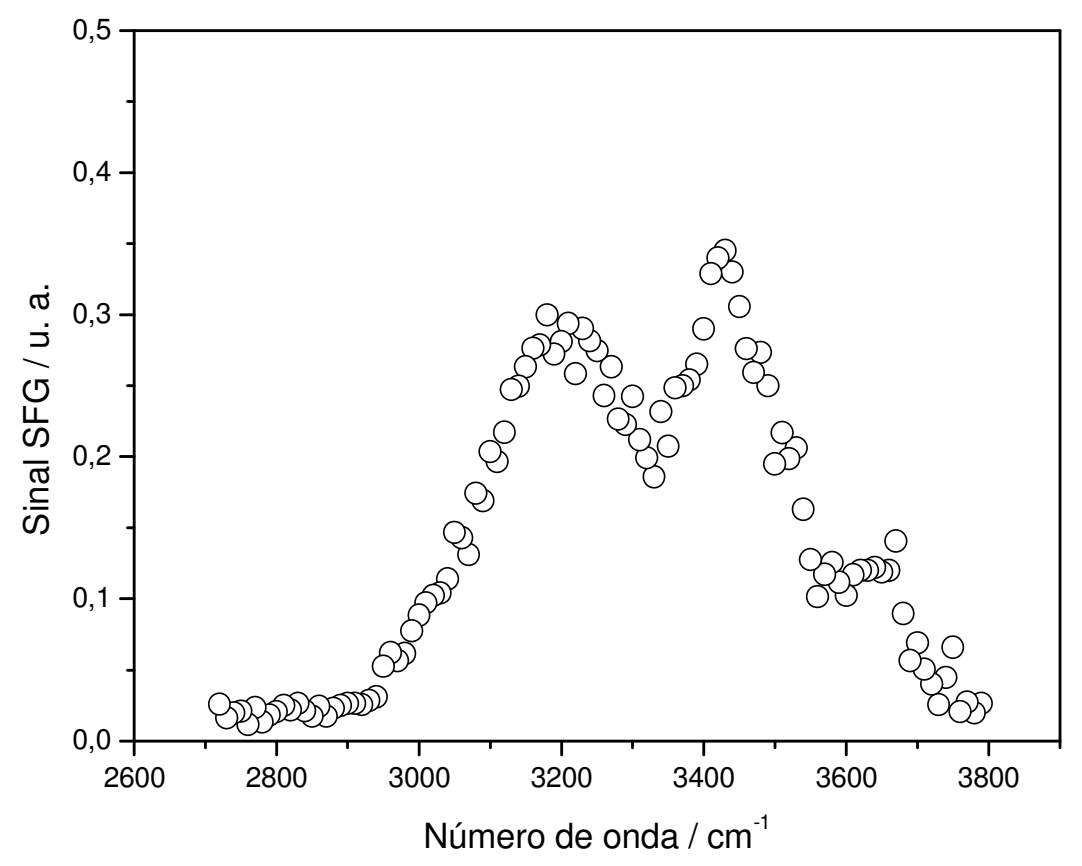

Figura 15: Espectro SFG da interface quartzo/água a pH 4. 

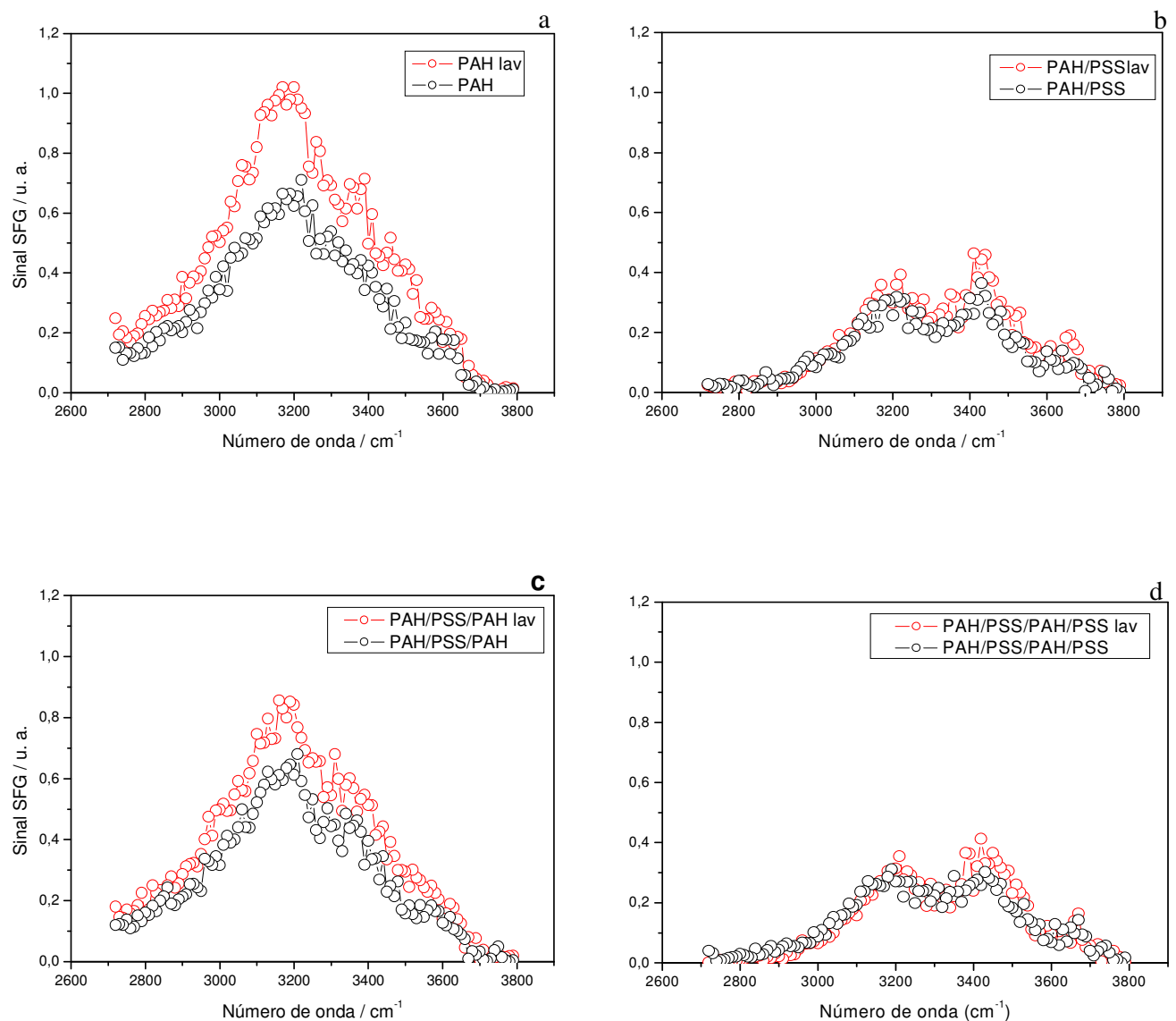

Figura 16: Espectros SFG de filmes in situ de PAH/PSS sobre o quartzo a partir de soluções com pH 4. SFG da interface: a) quartzo/(solução de PAH); b) quartzo/PAH/(solução de PSS); c) quartzo/PAH/PSS/(solução de PAH); d) quartzo/PAH/PSS/PAH/(solução de PSS).

Na Figura 16.a, temos o espectro da interface quartzo/(solução de PAH), onde podemos verificar que não ocorre sinal de ligações $\mathrm{C}-\mathrm{H}$ na cadeia principal do polímero. Nota-se somente uma banda larga referente a estiramentos O-H. Entretanto, a intensidade relativa dos dois picos mudou. O pico a $3200 \mathrm{~cm}^{-1}$ teve sua intensidade quase dobrada com relação à Figura 15. Isso indica que o campo elétrico na interface quartzo/PAH/água é maior que o campo elétrico na interface quartzo/água; ou seja, a densidade de carga elétrica total na camada de PAH e do substrato é maior que a densidade de carga no quartzo quando em equilíbrio a pH 4. Como houve adsorção de uma camada catiônica sobre um substrato negativamente 
carregado, esse aumento do módulo do campo elétrico só pode ser possível com uma significativa sobre-compensação de cargas após a adsorção do PAH, resultando numa superfície altamente carregada positivamente.

Quando se adsorve uma camada de PSS sobre a interface quartzo/PAH, temos então o espectro mostrado na Figura 16.b. Novamente temos a forma da Figura 15. Isto sugere que o campo elétrico na interface quartzo/PAH/(solução de PSS) é aproximadamente igual ao campo na interface quartzo/água. A semelhança está tanto na intensidade dos picos quanto na razão entre essas intensidades. Portanto, as densidades de carga das camadas de PAH e PSS são aproximadamente de mesma magnitude, e após a automontagem de uma bicamada, a carga total da interface é ligeiramente negativa.

Por fim, nas Figura 16.c e Figura 16.d temos respectivamente medidas in

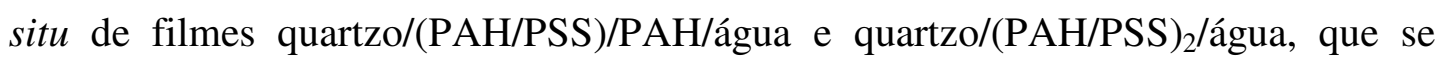
assemelham às Figura 16.a e b. Isso mostra que a cada bicamada automontada todo o processo descrito anteriormente se reproduz.

Vale ainda notar que as intensidades do sinal de SFG nas medidas in situ durante o passo de lavagem com solução de pH 4 (Figura 16, curvas em vermelho) são ligeiramente mais intensas do que quando em solução de polieletrólito antes da lavagem. O efeito é maior na interface que apresenta o maior campo elétrico, ou seja, nas interfaces quartzo/PAH/água e quartzo/(PAH/PSS)/PAH/água. Isso pode ser causado devido à remoção de contra-íons contidos na solução de polieletrólito e que blindavam o campo total na interface, reduzindo o campo elétrico. Em outras palavras, por não conter polieletrólitos, a solução lavagem possui força iônica menor que a solução de polieletrólitos. Assumindo que a lavagem não remove 
polieletrólitos, isso resulta em um menor efeito de blindagem do campo elétrico e num maior ordenamento das moléculas de água na interface.

Para resumir os resultados da Figura 16, propomos um modelo que está representado na Figura 17. Nela, as setas dão o sentido e intensidade relativa do campo elétrico na interface. Esse campo é o responsável pelo ordenamento das moléculas de água, que dão origem aos sinais da Figura 16, e se deve à combinação entre as densidades de carga do quartzo e as das moléculas já adsorvidas.
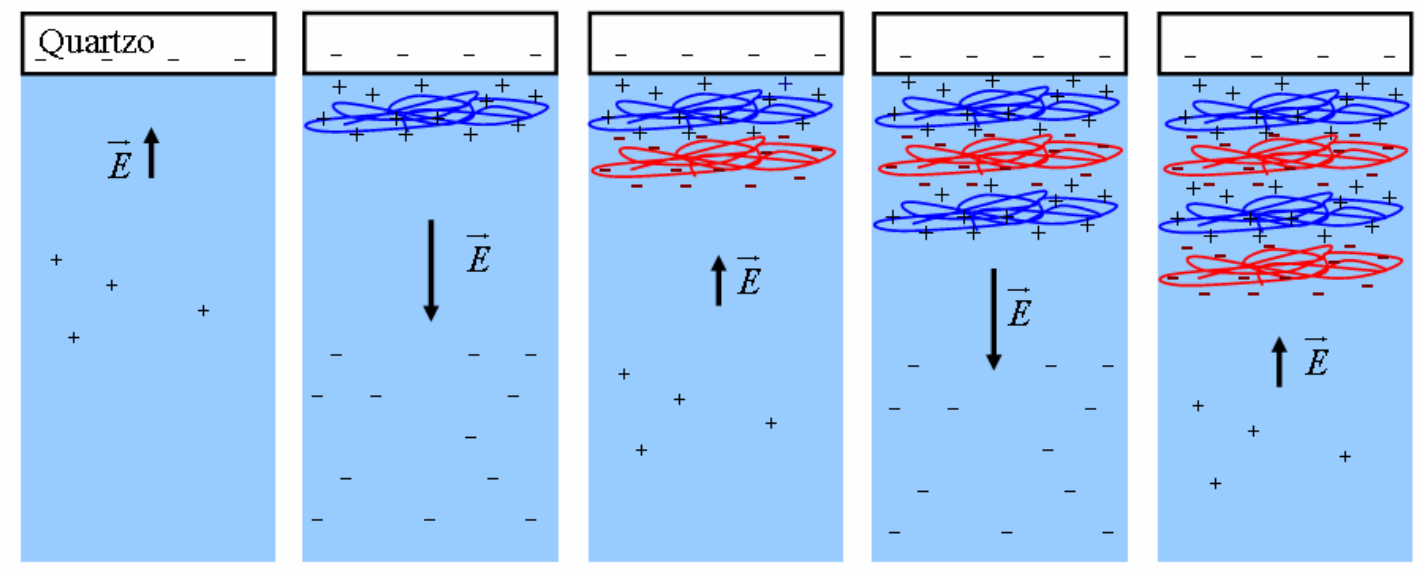

Figura 17: Modelo da camada adsorvida a partir das medidas in situ de PAH e PSS sobe o quartzo a pH 4. O traçado azul representa moléculas de PAH, e o vermelho, as de PSS. Os sinais + e - na solução representam os contra-íons.

Medidas de potencial Zeta ${ }^{[17]}$ também indicam alternância entre a densidade de cargas positivas e negativas para filmes automontados de PAH/PSS, que pode variar em algumas dezenas de milivolts.

Os resultados referentes a filmes ex situ de PAH/PSS secados espontaneamente, ou seja, sem jato de nitrogênio ou qualquer outro artifício, como estufa etc., estão apresentados na Figura 18. Os resultados para os filmes secados com jato de $\mathrm{N}_{2}$ serão apresentados à parte, no Capítulo 6, onde será discutido o efeito desse tipo de secagem. 
As medidas foram realizadas em três pontos diferentes sobre o filme. A secagem ocorreu por evaporação espontânea por cerca de dois dias em ambiente com umidade do ar variando entre 38 e $41 \%$. Verificam-se nos filmes ex situ que há picos intensos na região de estiramento $\mathrm{C}-\mathrm{H}\left(2800-3100 \mathrm{~cm}^{-1}\right)$, indicando que ocorre ordenamento orientacional das cadeias dos polímeros. Além disso, os espectros da Figura 18 indicam que o filme é bastante homogêneo. Deve ainda ser observado que esse ordenamento não cresce conforme aumenta o número de camadas adsorvidas, mas varia conforme a última camada seja o PAH ou o PSS, isto é, os filmes nos quais a última camada é o PAH têm sinal ligeiramente maior do que aqueles que terminam com PSS.
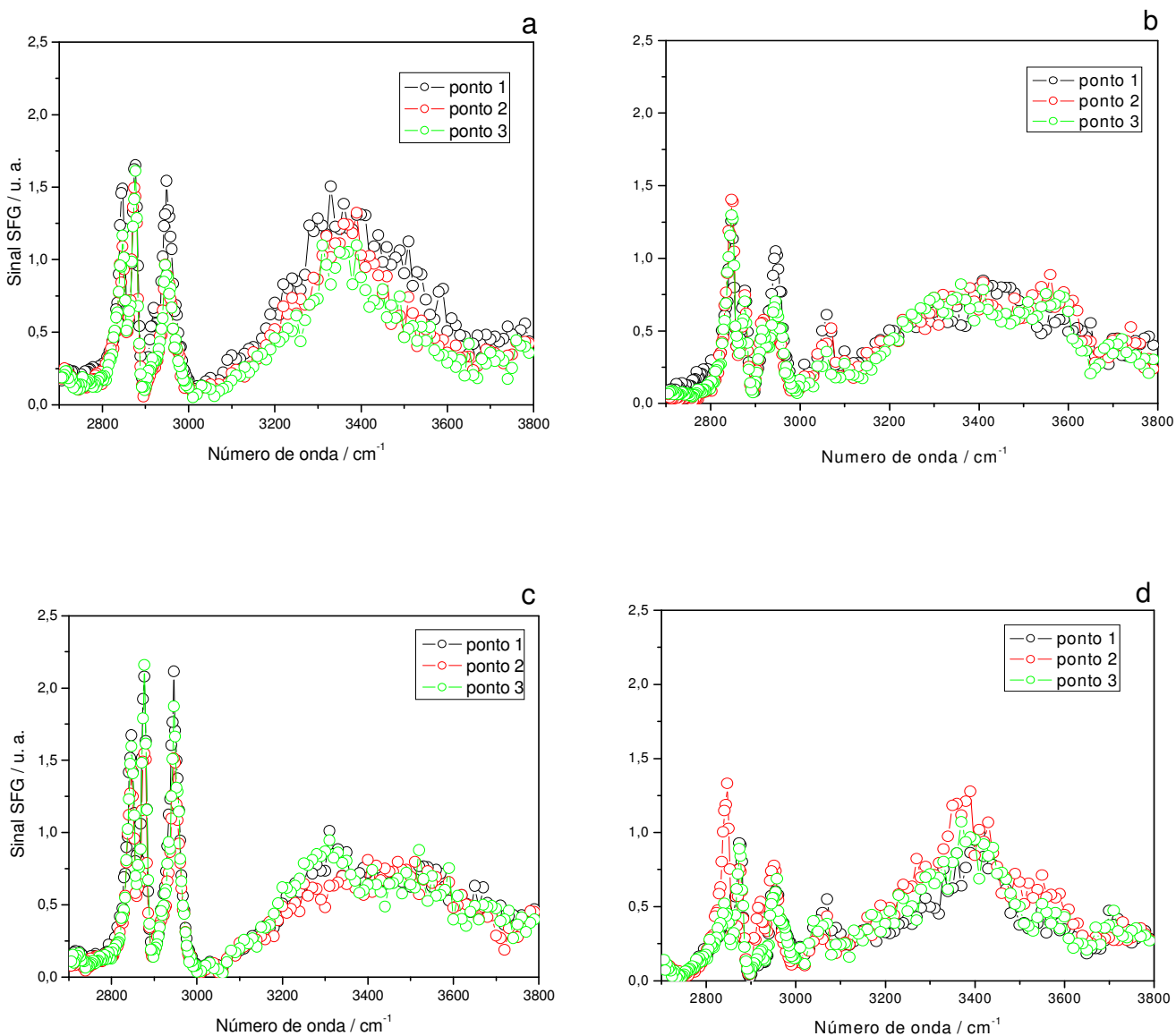

Figura 18: Espectro SFG de filmes ex situ de PAH/PSS (pH 4) sobre o quartzo com secagem espontânea. Os gráficos são medidas em três pontos do filme de: a) $\mathrm{PAH}$; b) PAH/PSS; c) (PAH/PSS)/PAH; e d) $(\mathrm{PAH} / \mathrm{PSS})_{2}$. 
Vê-se também que mesmo após aproximadamente 48 horas de secagem ainda existe água adsorvida no filme, pois ocorre uma banda larga e intensa na região de estiramento O-H. Essa água adsorvida é de difícil remoção e exigiria um tratamento térmico mais rigoroso para a remoção como, por exemplo, o uso de uma estufa.

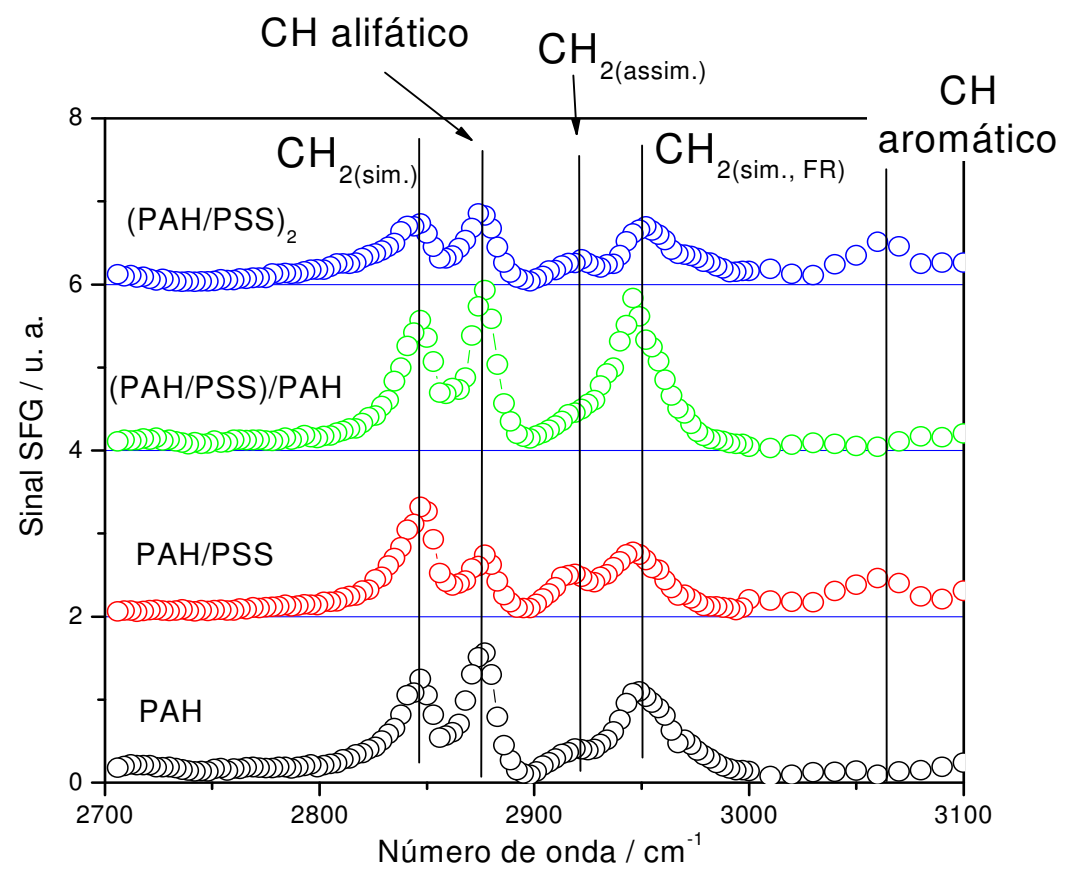

Figura 19: Espectros SFG de filmes $e x$ situ de PAH/PSS a pH 4 com secagem espontânea sobre o quartzo. Os gráficos são as médias das três medidas da: a) $\mathrm{PAH}$; b) PAH/PSS; c) (PAH/PSS)/PAH; d) (PAH/PSS) $)_{2}$.

A fim de facilitar a identificação das freqüências dos picos na região de estiramento C-H, construiu-se o gráfico da Figura 19. Cada um dos gráficos é uma média das três medidas da Figura 18. Os picos são referentes a estiramentos $\mathrm{C}-\mathrm{H}$, podendo-se identificar cinco picos em torno de 2847, 2877, 2919, 2949, e $3060 \mathrm{~cm}^{-1}$. Os picos a 2847 e $2919 \mathrm{~cm}^{-1}$ são atribuídos a estiramento simétrico do $\mathrm{CH}_{2 \text { (sim.) }}$ e estiramento assimétrico do $\mathrm{CH}_{2 \text { (assim.), }}$, respectivamente ${ }^{[38,39,40]}$. O pico em $\sim 3060 \mathrm{~cm}^{-}$ ${ }^{1}$ é atribuído a vibrações do anel aromático dissubstituído ${ }^{[41]}$ (CH aromático). O pico 
em $2949 \mathrm{~cm}^{-1}$ pode ser atribuído à ressonância de Fermi entre o estiramento simétrico com o sobretom ${ }^{\dagger \dagger}$ da deformação do $\mathrm{CH}_{2 \text { (sim.,FR) }}{ }^{[42]}$. O pico a $\sim 2877 \mathrm{~cm}^{-1}$ tem sido atribuído ao grupo metil em cadeias alifáticas ${ }^{[19,20,38,39,40]}$. No entanto, as cadeias dos polímeros PAH e PSS não possuem o grupo metil, a não ser os grupos terminais da cadeia e, portanto, com densidade muito baixa para ser detectável nos espectros SFG. O estiramento $\mathrm{CH}$ geralmente é muito fraco e ocorre em torno de $2900 \mathrm{~cm}^{-1}{ }^{[43]}$. O pico em $\sim 2877 \mathrm{~cm}^{-1}$ pode ser estiramento $\mathrm{CH}$, embora a atribuição correta desse pico requeira um estudo mais detalhado, talvez com polímeros com esse grupo deuterado.

O espectro das cadeias alterna-se em intensidade e forma entre dois tipos, um característico de filmes terminados por PAH e outro de filmes terminados por PSS. Além disso, nota-se da Figura 19 que somente em filmes onde a última camada adsorvida é o PSS é que notamos o pico em torno de $3070 \mathrm{~cm}^{-1}$, o que é razoável por se tratar de uma ressonância característica de anel aromático e que só o PSS possui. No filme de (PAH/PSS)/PAH, esse pico desaparece, indicando que o ordenamento do anel notado para o filme PAH/PSS desapareceu devido à presença da camada subseqüente de PAH. Assim, pode-se concluir que a camada de PSS tem seus anéis reorientados, numa tendência deste de neutralizar a densidade de carga positiva das camadas adjacentes de PAH, gerando assim um saldo orientacional nulo do anel aromático. É, portanto, razoável supor que os grupos $\mathrm{CH}_{2}$ e $\mathrm{CH}$ das cadeias também sejam reorientados, de tal maneira que as camadas anteriores têm o seu ordenamento alterado quando a camada seguinte é adsorvida sobre o filme. Assim, possivelmente o espectro observado na região $\mathrm{C}-\mathrm{H}$ parece resultar de contribuições apenas da última camada de polieletrólito adsorvida.

\footnotetext{
† Tentativa de tradução para o termo inglês overtone.
} 


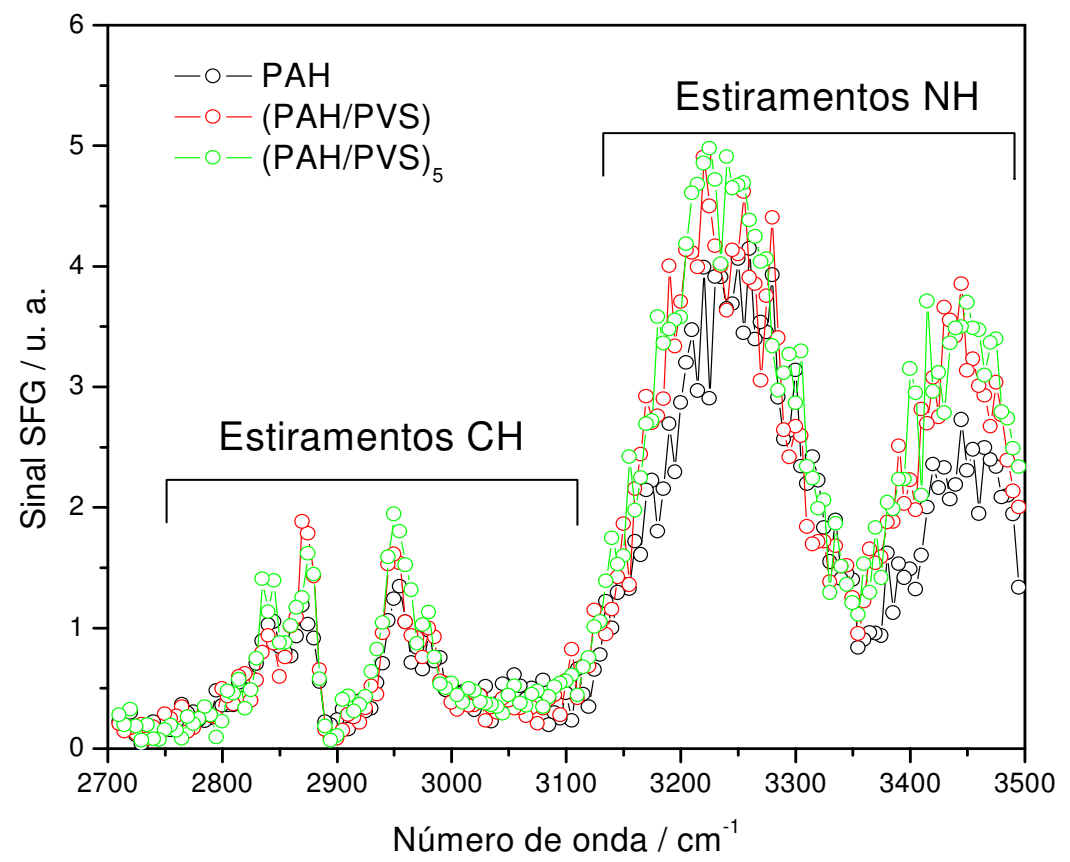

Figura 20: Espectro SFG de filmes automontado de PAH/PVS.

Deve ser observado que nenhuma informação a respeito da orientação preferencial do grupo $\mathrm{NH}_{3}{ }^{+}$foi obtida dos resultados acima. A fim de verificar também o ordenamento do PAH, observou-se a região entre 2800 e $3200 \mathrm{~cm}^{-1}$ onde comumente se observa estiramentos simétricos e assimétricos do $\mathrm{NH}_{3}{ }^{+[24,44,45]}$. Isso, entretanto não foi possível devido ao grande sinal da água ainda presente nos filmes, que podem estar mascarando uma pequena contribuição dos grupos $\mathrm{NH}_{2} / \mathrm{NH}_{3}{ }^{+}$. Entretanto, um ordenamento dos grupos NH não é consistente com nossos espectros, pois uma monocamada de grupos $\mathrm{NH}$ bem ordenados seria facilmente detectável. Isso está ilustrado na Figura 20, que mostra o espectro SFG de filmes com uma monocamada de PAH, e de uma e cinco bicamadas de (PAH/PVS), todos preparados em pH neutro ( $\mathrm{pH} \sim 6,8$ ). Observa-se uma forte contribuição dos estiramentos $\mathrm{NH}$ em 3200 e $3450 \mathrm{~cm}^{-1}$, e a nítida diferença entre os picos referentes a estiramentos N-H e estiramentos O-H da Figura 18. 
Portanto, a partir do que foi dito acima, propomos também um modelo para ilustrar a estrutura dos filmes secados por evaporação espontânea sobre substrato de quartzo. Esse modelo está mostrado na Figura 21. Deve-se observar a orientação preferencial dos anéis aromáticos do PSS, que se alterna à medida que o filme cresce. Como não foi possível observar sinais do $\mathrm{NH}_{3}{ }^{+}$, admitimos aqui que ele se arranje de maneira centrossimétrica, com parte dos grupos apontando para o substrato e a outra parte em direção oposta. Esta configuração minimiza a repulsão eletrostática entre os grupos $\mathrm{NH}_{3}{ }^{+}$. No caso do PSS, a interação entre os anéis aromáticos pode estar estabilizando a orientação preferencial dos grupos $\mathrm{SO}_{3}{ }^{-}$.

$\mathbf{a}$
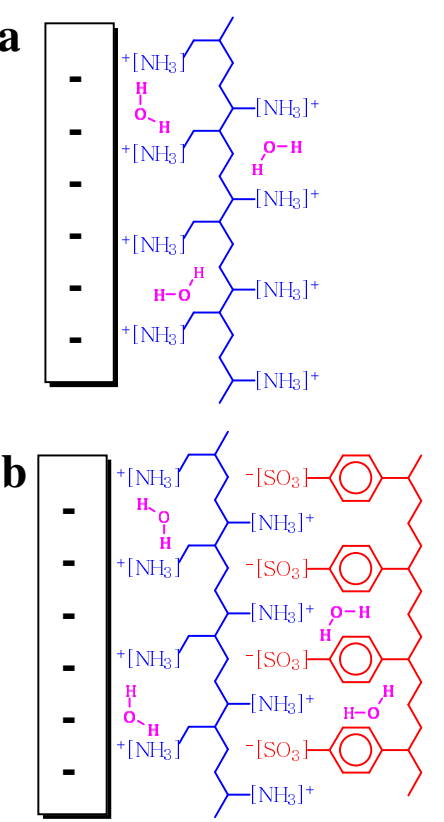

c
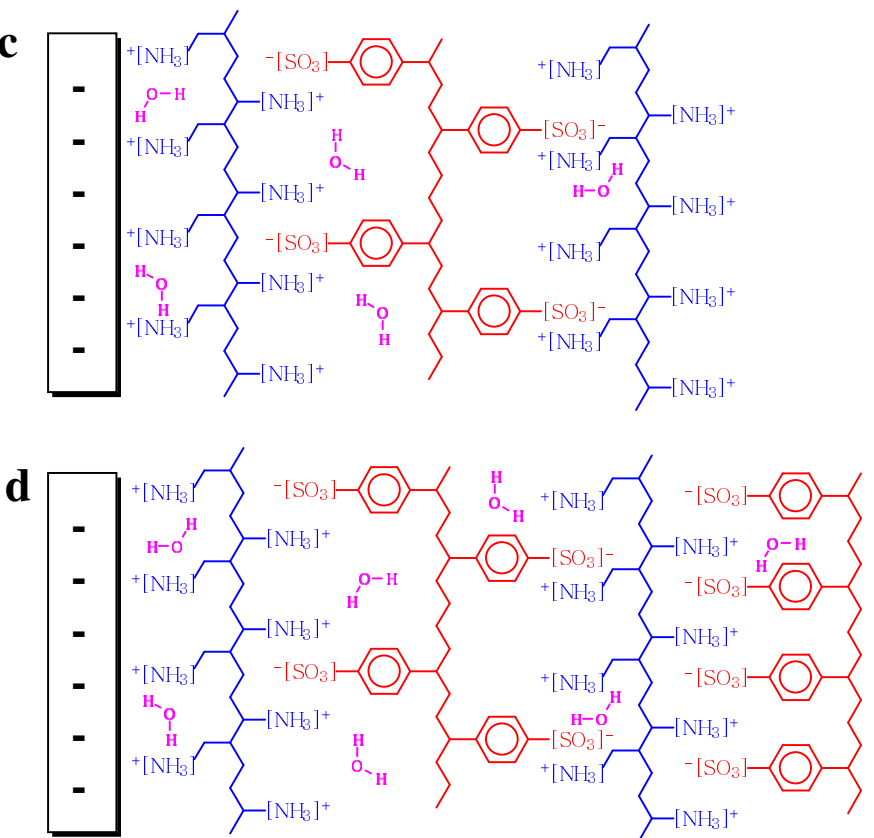

Figura 21: Modelo proposto para as medidas ex situ de PAH e PSS sobe o quartzo a pH 4. As moléculas em azul representam o PAH, e as vermelhas, o PSS: a) $\mathrm{PAH}$; b) (PAH/PSS); c) (PAH/PSS)/PAH; d) (PAH/PSS) .

\subsection{FILMES PREPARADOS A PARTIR DE SOLUÇÕES COM pH 12}

Na Figura 22, temos o espectro da interface quartzo/água pura a $\mathrm{pH} 12$, também obtido em nosso laboratório. Pode-se constatar que está em coerência com a 
Figura 14. É evidente o pico a $3200 \mathrm{~cm}^{-1}$. Além disso, é possível observar um outro pico mais suave, na forma de um “ombro” próximo a $3400 \mathrm{~cm}^{-1}$.

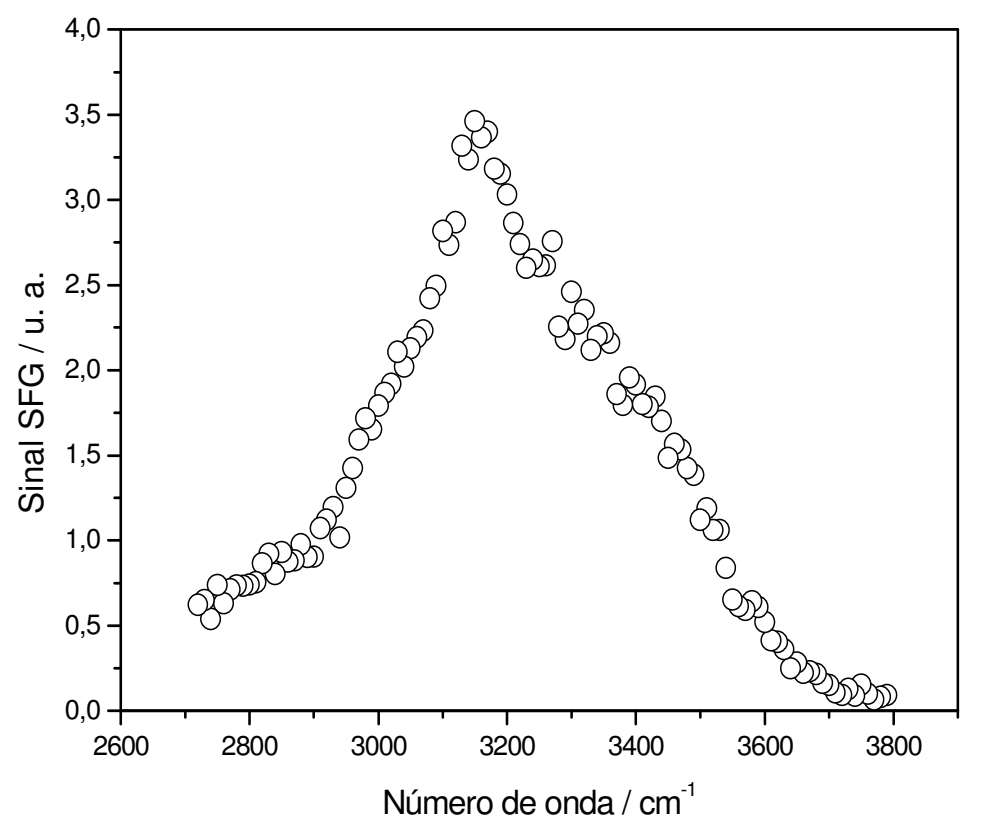

Figura 22: Espectro SFG da interface quartzo/água a pH 12. Vê-se um primeiro pico em $3200 \mathrm{~cm}^{-1}$, e o outro mais suave próximo de $3400 \mathrm{~cm}^{-1}$.

A seguir, os espectros das soluções de polieletrólitos a pH 12 em interface com o quartzo estão apresentados na Figura 23. Nela, é possível verificar, a exemplo das medidas in situ no quartzo a pH 4, que não ocorre sinal (picos) decorrentes das cadeias principais dos polieletrólitos, mas apenas o sinal proveniente da orientação das moléculas de água. Conforme foi discutido nos resultados a $\mathrm{pH} 4$ sobre o quartzo, durante o passo de mergulho em soluções de PAH e PSS e de lavagem, também nas soluções a pH 12 ocorre adsorção das moléculas poliônicas, mas elas permanecem em média desordenadas em virtude da grande dinâmica conformacional das cadeias quando em solução. Nota-se ainda que a intensidade do sinal de SFG varia quando a solução é de PAH ou de PSS. Comparando-se essas intensidades com 
o da interface quartzo/água a $\mathrm{pH} 12$, pode-se verificar que o campo elétrico (e a densidade total de carga) na interface quartzo/PAH/água é menor do que na interface quartzo/água. No entanto, quando o filme é terminado por PSS, a densidade de carga total é aproximadamente igual à densidade de carga no quartzo (Figura 23.b e d.).
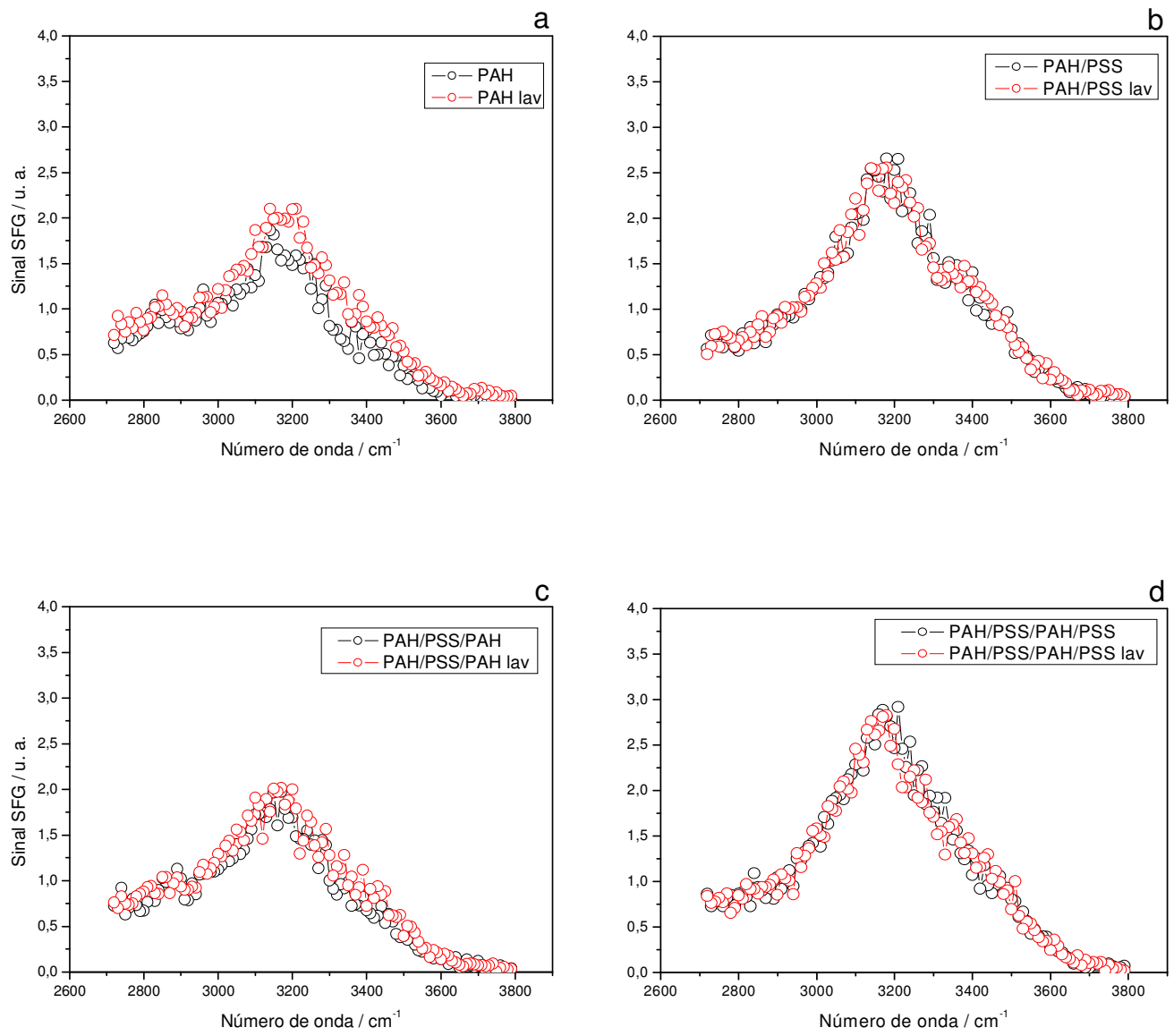

Figura 23: Espectros SFG de filmes in situ de PAH/PSS sobre o quartzo a partir de soluções com pH 12. SFG da interface: a) quartzo/(solução de $\mathrm{PAH}$ ); b) quartzo/PAH/(solução de PSS); c) quartzo/PAH/PSS/(solução de PAH); d) quartzo/PAH/PSS/PAH/(solução de PSS).

As intensidades dos espectros SFG in situ durante o passo de lavagem foram ligeiramente maiores do que os espectros SFG das soluções de polieletrólitos, como também fora observado para as soluções a pH 4 (Figura 16). Como dito anteriormente, esse efeito pode ser causado pela remoção dos contra-íons das 
soluções de polieletrólitos responsáveis por uma blindagem do campo total da interface.

O modelo para estas medidas in situ está Figura 24. Como na Figura 17, a intensidade e o sentido do campo elétrico varia em função da densidade de carga elétrica na interface devido à adsorção das camadas de polieletrólitos. O espectro SFG gerado pela interface quartzo/água é relativamente grande (Figura 22). Na interface quartzo/PAH, a intensidade do espectro SFG é ainda intenso, embora menor, mas agora a densidade de carga é positiva, devido à adsorção do $\mathrm{PAH}$, e o sentido do campo elétrico se inverte. Quando a interface é quartzo/PAH/PSS, a densidade de carga é negativa, devido à adsorção do PSS, e o espectro SFG é aproximadamente tão grande quanto o da interface quartzo/água, e o campo elétrico retoma sua orientação inicial.
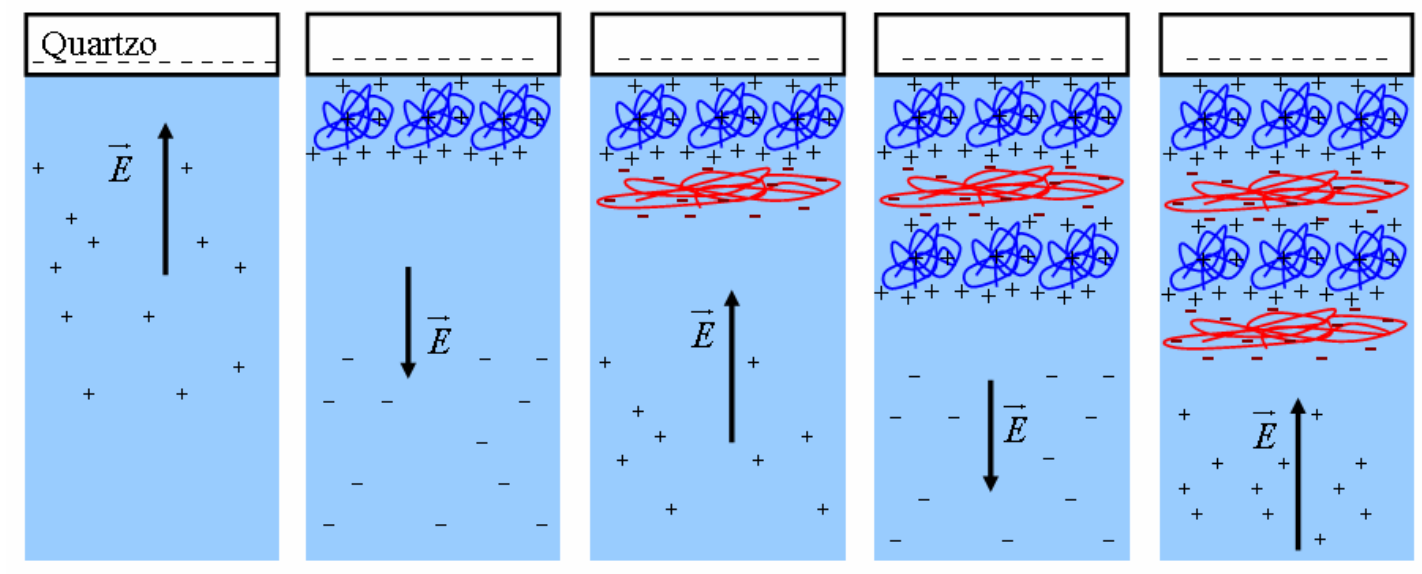

Figura 24: Modelo proposto para as medidas in situ de PAH e PSS sobe o quartzo a pH 12. Como na Figura 17, o traçado azul representa moléculas de PAH, e o vermelho, as de PSS. Os sinais + e - na solução representam os contra-íons.

Para os filmes ex situ de PAH/PSS adsorvidos sobre o quartzo, a partir de soluções com pH 12, os resultados estão na Figura 25. Como nas medidas anteriores, os filmes foram secados por evaporação espontânea da água também por um período de 48 horas, mas também pode ser constatado que ainda há água nos filmes. 
Entretanto, comparando-se com os filmes produzidos em $\mathrm{pH} 4$, a água adsorvida é mais desordenada e com ligações de $\mathrm{H}$ mais fracas (deslocamento da freqüência de estiramento $\mathrm{O}-\mathrm{H}$ em direção à região de "OH livre”). Além disso, também foram realizadas medidas em três pontos para verificar a homogeneidade das amostras. Assim como no caso anterior de filmes produzidos a partir de $\mathrm{pH} 4$, esse método de secagem produz filmes bastante homogêneos para filmes produzidos a partir de $\mathrm{pH}$ 12.
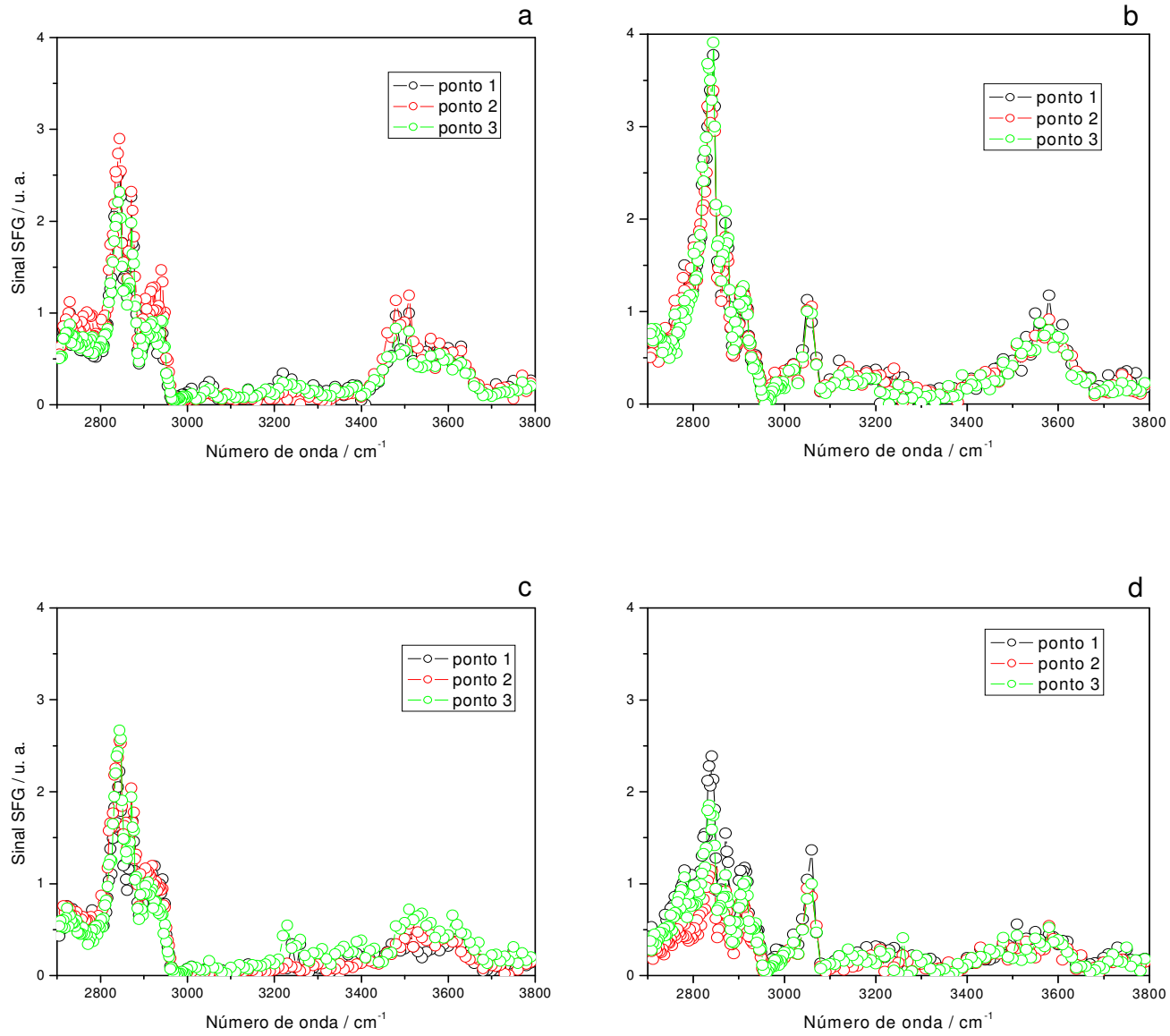

Figura 25: Espectro SFG de filmes ex situ de PAH/PSS (pH 12) sobre o quartzo com secagem espontânea. Os gráficos são medidas em três pontos do filme de: a) $\mathrm{PAH}$; b) PAH/PSS; c) (PAH/PSS)/PAH; e d) (PAH/PSS) $)_{2}$.

As ressonâncias dos espectros na região de estiramentos $\mathrm{CH}$ podem ser vistas em mais detalhes pela média das três medidas dos gráficos da Figura 25, 
construindo-se assim a Figura 26. É possível verificar a presença dos mesmos picos da Figura 19, referentes a estiramentos C-H. Temos novamente a alternância do pico próximo a $3060 \mathrm{~cm}^{-1}$. Esse pico, conforme discutido acima, está associado ao anel aromático dissubstituído. Entretanto, ele fica mais evidente na Figura 26 que naquela, mostrando uma significativa diferença nos espectros dos filmes quando a última camada adsorvida é o PAH ou o PSS. Como na Figura 19, esse pico só aparece quando a última camada é o PSS, reforçando o que foi dito acima de que quando ele adsorve sobre a camada previamente adsorvida de PAH (gráficos vermelho e azul na Figura 26), os anéis tomam uma orientação preferencial, que provavelmente é em direção ao PAH (devido à atração eletrostática). Isso é razoável, pois esses anéis estão ligados rigidamente ao grupo carregado $\left[\mathrm{SO}_{3}{ }^{-}\right]$, responsável pela interação eletrostática entre os polieletrólitos.

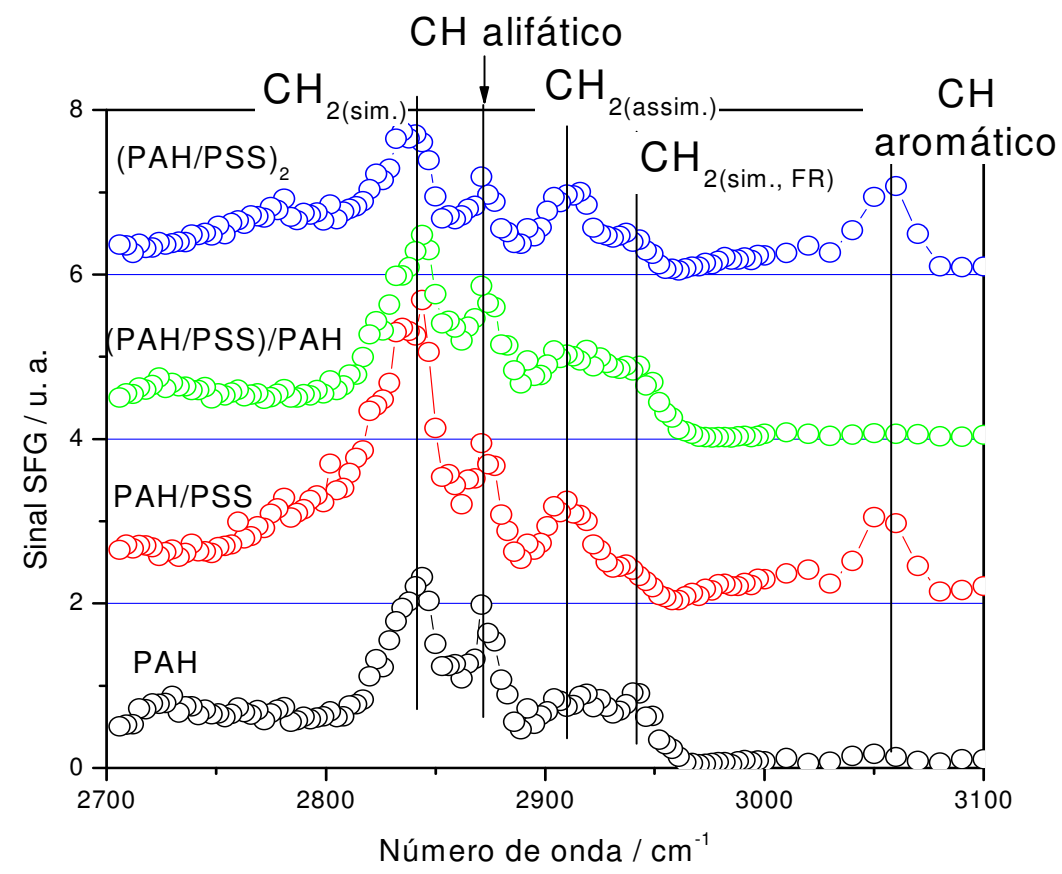

Figura 26: Espectros SFG de filmes $e x$ situ de PAH/PSS a pH 12 com secagem espontânea sobre o quarto. Os gráficos são as médias das três medidas da Figura 25. 
Pode-se observar que quando o PSS recebe uma camada de PAH (gráfico verde da Figura 26), ele se encontra entre duas camadas de densidades de carga aproximadamente iguais. Assim, os anéis aromáticos do PSS tendem a se orientar de maneira a compensar igualmente a atração eletrostática entre as duas camadas de PAH, o que resulta num saldo orientacional nulo, causando a extinção do sinal a $\sim 3060 \mathrm{~cm}^{-1}$, no filme de (PAH/PSS)/PAH, conforme discutido a respeito dos filmes produzidos a $\mathrm{pH} 4$.

Nesse $\mathrm{pH}$, o $\mathrm{PAH}$ tem a maioria de seus grupos $\mathrm{NH}_{3}{ }^{+}$convertidos em $\mathrm{NH}_{2}$, mas novamente nenhum sinal referente a estiramentos do grupo $\mathrm{NH}$ foi observado.

Em vista do que foi verificado para filmes ex situ de PAH/PSS sobre o quartzo a pH 12, uma representação dos filmes sobre o quartzo a pH 12 seria semelhante ao da Figura 21, com a observação de que o PAH deve ter um grau de ionização muito menor e, portanto, cadeias bem mais enoveladas, resultando em filmes mais espessos ${ }^{[17]}$. 


\section{FILMES AUTOMONTADOS SOBRE FLUORETO DE CÁLCIO}

\subsection{A INTERFACE $\mathrm{CaF}_{2} / \mathrm{ÁGUA}$}

A exemplo do que foi feito no Capítulo 4 , apresentaremos inicialmente os espectros SFG da interface $\mathrm{CaF}_{2}$ /água para vários valores de $\mathrm{pH}$ no volume da água $^{[46]}$, mostradas na Figura 27. Para estes espectros, a interpretação dos picos é semelhante à da interface quartzo/água, descrito no Capítulo anterior: o pico em torno de $3200 \mathrm{~cm}^{-1}$ é atribuído a moléculas de água mais fortemente ordenadas na interface com ligações de $\mathrm{H}$ simétricas e tetraédricas; e o pico em torno de $3450 \mathrm{~cm}^{-1}$ é atribuído a moléculas de água formando uma rede de ligações de $\mathrm{H}$ desordenadas. Ocorre também o pico entre $3600-3700 \mathrm{~cm}^{-1}$, geralmente atribuído a osciladores " $\mathrm{OH}$ livres".

Para $\mathrm{pH}$ baixos $(\mathrm{pH}<6)$, a superfície do $\mathrm{CaF}_{2}$ é carregada positivamente e o espectro SFG é intenso e característico de uma rede de ligações de H ordenada pela influencia de um elevado campo elétrico na interface. Para $\mathrm{pH} \sim 6,5$, a superfície do $\mathrm{CaF}_{2}$ torna-se neutra (ponto de carga zero) e a água não tem nenhuma orientação preferencial na interface.

A pH alto, o $\mathrm{CaF}_{2}$ interage com a água numa reação de transferência iônica dos íons na superfície do $\mathrm{CaF}_{2}$ com íons $\mathrm{OH}^{-}$na solução, ou ainda gerados pela adsorção dissociativa de moléculas de água sobre a superfície do $\mathrm{CaF}_{2}$, segundo a reação $\mathrm{CaF}_{2}+2 \mathrm{H}_{2} \mathrm{O} \Leftrightarrow \mathrm{Ca}(\mathrm{OH})_{2}+2 \mathrm{HF}$, resultando numa camada de grupos 
$\mathrm{Ca}(\mathrm{OH})_{2}$ na interface $\mathrm{CaF}_{2} /$ água $^{[47]}$. A Ref. [46] atribui o pico em $3650 \mathrm{~cm}^{-1}$ a esses grupos $\mathrm{Ca}-\mathrm{OH}$ e argumenta que essa freqüência (característica de grupos "OH livres" na interface ar/água) implica em grupos $\mathrm{Ca}-\mathrm{OH}$ interagindo fracamente por meio de ligações de H. Entretanto, essa interpretação é meio controversa pelo fato ser pouco provável que os grupos $\mathrm{OH}$ do $\mathrm{Ca}(\mathrm{OH})_{2}$ não formem ligações de $\mathrm{H}$ com a água circundante. Com efeito, medidas de infravermelho do $\mathrm{Ca}(\mathrm{OH})_{2}$ cristalino têm mostrado uma absorção próximo a $3639 \mathrm{~cm}^{-1}$ e que varia com a temperatura ${ }^{[48]}$. É mais razoável então acreditar que o $\mathrm{Ca}(\mathrm{OH})_{2}$ formado segundo a reação descrita acima esteja ligado via ligações de $\mathrm{H}$ na interface, originando o pico em $\sim 3650 \mathrm{~cm}^{-1}$.

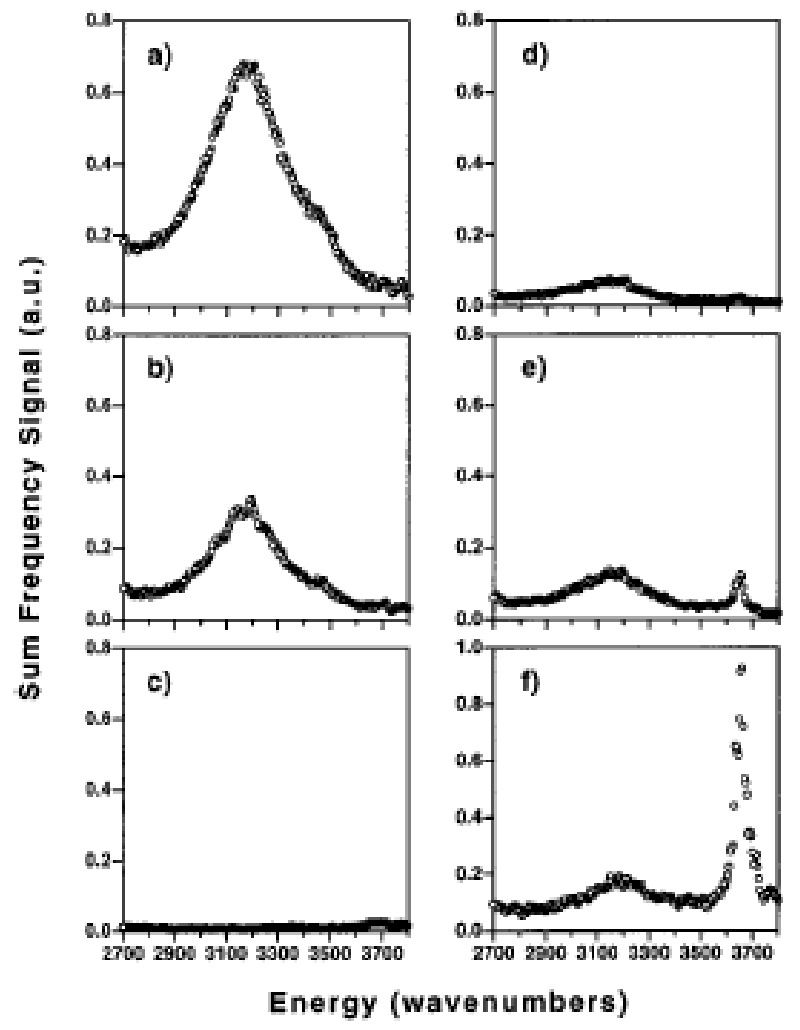

Figura 27: Espectros SFG da interface $\mathbf{C a F}_{2}$ /água com diferentes valores de $\mathbf{p H}$ no volume. Os pH são: a) 2,9; b) 5,1; c) 6,4; d) 9,3; e) 12,3; f) 13,7. [A partir da Ref. 46]

Portanto, $\mathrm{o} \mathrm{CaF}_{2}$ difere do quartzo no que diz respeito à química de superfície, pois embora ambos tenham suas características superficiais fortemente 
dependentes do $\mathrm{pH}$, a carga superficial do $\mathrm{CaF}_{2}$ pode ser positiva ( $\mathrm{pH}$ baixos) ou negativa ( $\mathrm{pH}$ altos), enquanto que o quartzo tem a superfície carregada negativamente num intervalo grande de $\mathrm{pH}$.

\subsection{FILMES PREPARADOS A PARTIR DE SOLUÇÕES COM pH 4}

Apresentaremos agora as medidas de filmes feitos a partir de solução de $\mathrm{pH}$ 4, sobre o $\mathrm{CaF}_{2}$, que nesse $\mathrm{pH}$ adquire carga superficial positiva ${ }^{[]}$. Dessa forma, o primeiro polieletrólito a ser adsorvido é o PSS. Para efeito de comparação, temos na Figura 28 o espectro SFG da interface $\mathrm{CaF}_{2}$ /água em $\mathrm{pH}$ 4. Pode-se notar a concordância com a literatura ${ }^{[46]}$. $\mathrm{O}$ espectro da interface $\mathrm{CaF}_{2}$ /água indica que ocorre orientação das moléculas de água devido ao campo elétrico local gerado pelo $\mathrm{CaF}_{2}$. É interessante destacar ainda que, assim como ocorre na interface quartzo/água, ocorrem dois picos, o primeiro próximo a $3200 \mathrm{~cm}^{-1}$, referente a moléculas altamente ordenadas com ligações de $\mathrm{H}$ tetraédricas e simétricas, e o segundo, bem mais fraco, próximo a $3400 \mathrm{~cm}^{-1}$, referente a ligações de $\mathrm{H}$ mais desordenadas, e que se assemelha ao espectro da interface quartzo/água a pH 12.

Em seguida, na Figura 29, temos os espectros SFG de filmes in situ de PSS e PAH. Com relação ao quartzo, algumas semelhanças e diferenças são notadas. Novamente, nenhum sinal SFG proveniente das vibrações $\mathrm{CH}$ das cadeias é observado. Da mesma forma que no quartzo, isso pode ser causado pela desordem das cadeias devido à agitação molecular na solução, resultando assim numa orientação resultante nula. Entretanto, diferentemente da automontagem sobre o quartzo, não temos mais sinal referente à água quando a interface é $\mathrm{CaF}_{2} /$ (solução de PSS), indicando que o campo elétrico nesta interface é aproximadamente nulo. Isso 
sugere que uma monocamada de PSS foi adsorvida e que a sua densidade de carga é aproximadamente igual ao do $\mathrm{CaF}_{2}$, mas com sinal oposto, de modo que o campo elétrico resultante na interface é aproximadamente nulo.

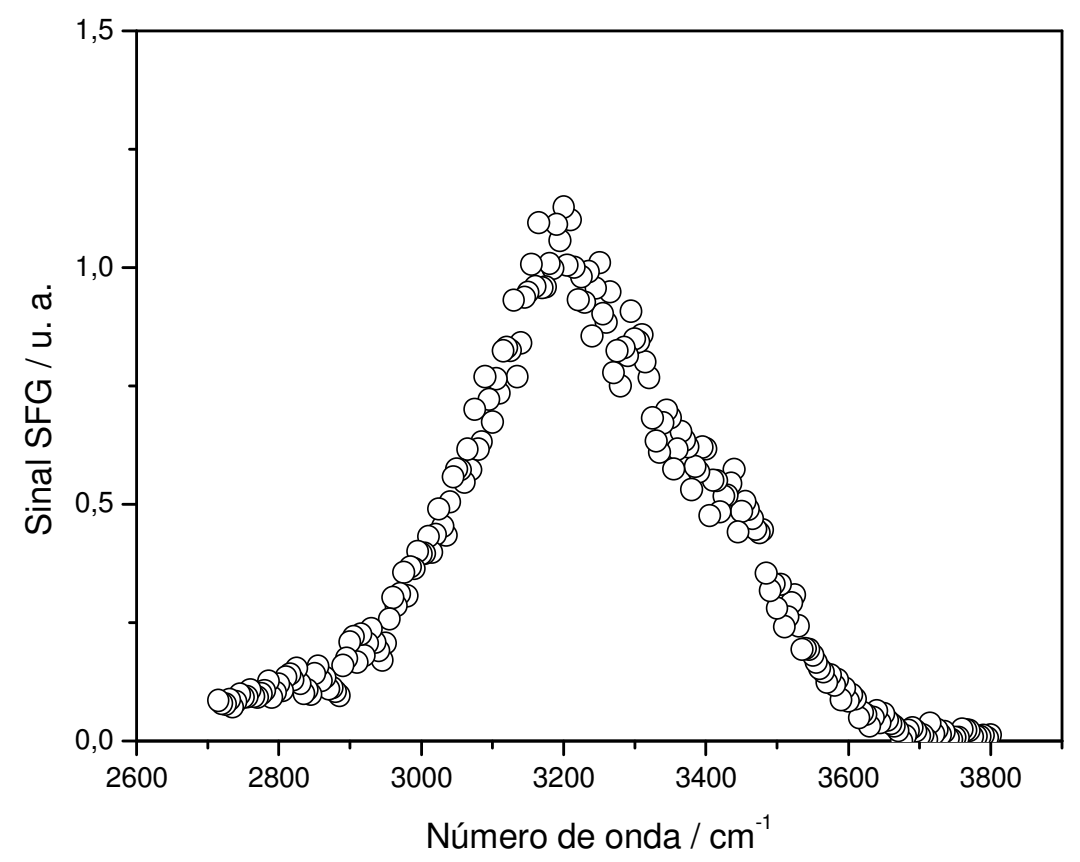

Figura 28: Espectro SFG da interface $\mathrm{CaF}_{2} / a ́ g u a$ a pH 4. É possível observar um primeiro pico em $3200 \mathrm{~cm}^{-1}$, e um "ombro" em $\sim 3400 \mathrm{~cm}^{-1}$.

Entretanto, ao adsorver-se a segunda monocamada, agora de PAH (Figura 29.b) temos novamente a banda larga referente à orientação das moléculas de água, com picos em $3200 \mathrm{~cm}^{-1}$ e $3400 \mathrm{~cm}^{-1}$, indicando a presença de moléculas de água na interface altamente ordenadas pelo alto campo elétrico interfacial. Mas pode-se ainda notar que a intensidade do sinal é maior no filme $\mathrm{CaF}_{2} /(\mathrm{PSS} / \mathrm{PAH}) / a ́ g u a$ do que na interface $\mathrm{CaF}_{2} /$ água. Esse fato indica que mais moléculas de água estão orientadas, sugerindo que o campo local na interface $\mathrm{CaF}_{2} / \mathrm{PSS} / \mathrm{PAH} / a ́ g u a$ é maior que na interface $\mathrm{CaF}_{2}$ /água. Em outras palavras, pode-se concluir que a densidade de carga superficial da camada de PAH é maior do que a do $\mathrm{CaF}_{2}$, em pH 4. 

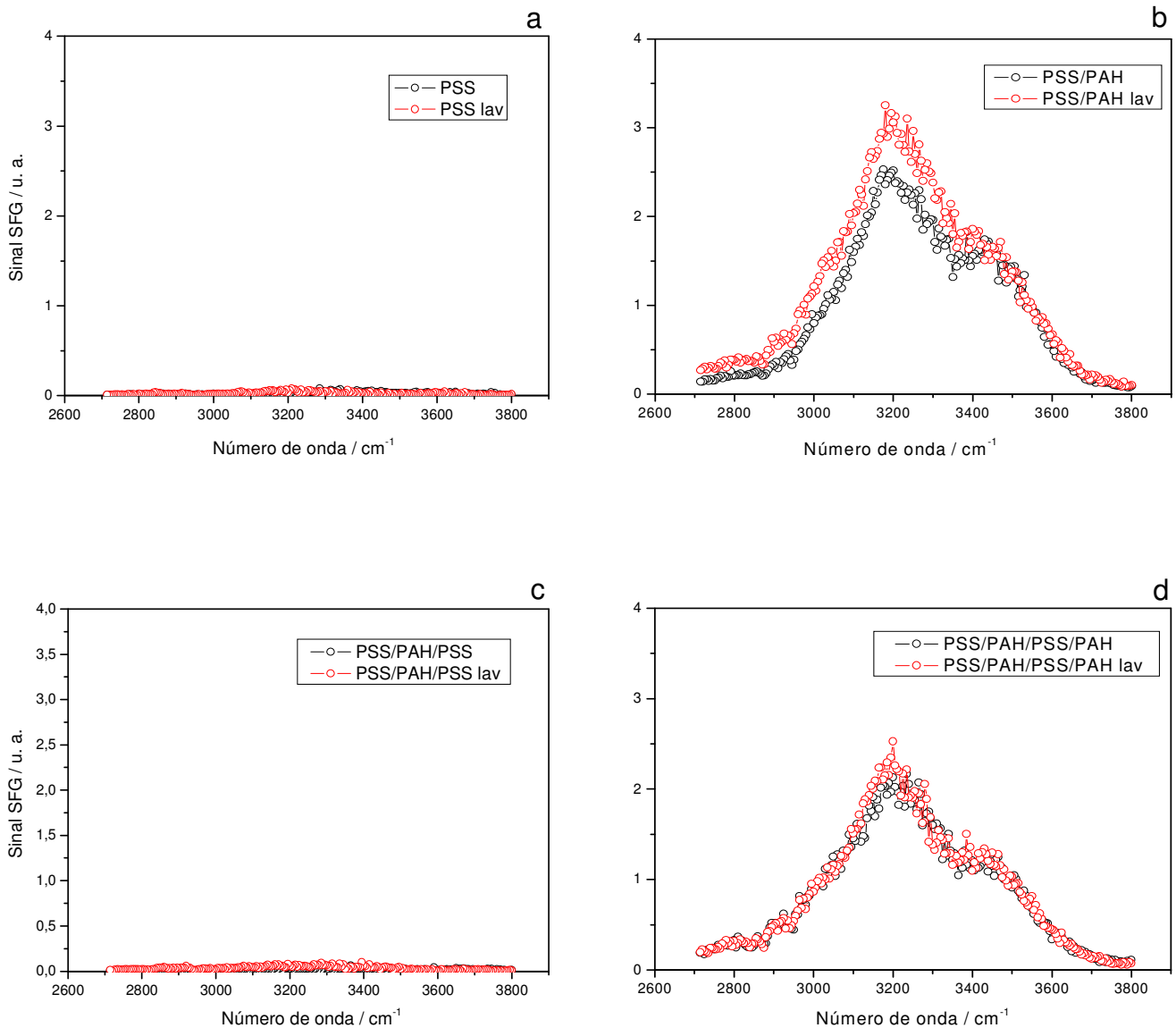

Figura 29: Espectros SFG de filmes in situ de PAH/PSS sobre o $\mathrm{CaF}_{2}$ a partir de soluções com pH 4. Os gráficos são: a) $\mathrm{CaF}_{2} /($ solução de $\mathrm{PSS}$ ); b) $\mathrm{CaF}_{2} / \mathrm{PSS} /($ solução de $\mathrm{PAH}) ; \quad$ c) $\mathrm{CaF}_{2} / \mathrm{PSS} / \mathrm{PAH} /($ solução de $\mathrm{PSS}$ ); d) $\mathrm{CaF}_{2} / \mathrm{PSS} / \mathrm{PAH} / \mathrm{PSS} /($ solução de PAH).

Nos gráficos c e d da Figura 29, temos respectivamente filmes $\mathrm{CaF}_{2} /(\mathrm{PSS} / \mathrm{PAH}) / \mathrm{PSS} / a ́ g u a$ e $\mathrm{CaF}_{2} /(\mathrm{PSS} / \mathrm{PAH})_{2} /$ água. Pode-se notar que os espectros se repetem na automontagem das camadas sucessivas de PSS e PAH. É importante destacar que, a exemplo do quartzo, em todas as medidas in situ, o sinal da solução lavagem é ligeiramente maior do que o sinal da própria solução polimérica devido à mudança da força iônica da solução de polieletrólito para a solução lavagem (excetuando-se é claro o caso onde a última camada é o PSS, quando o campo elétrico na interface é nulo). 
De forma análoga às medidas in situ mostradas anteriormente, propomos também um modelo que ajuda a compreender o passo de mergulho e lavagem do substrato na solução de polieletrólitos (Figura 30). Vê-se que a densidade de carga superficial que gera o campo elétrico sentido pela água varia devido à adsorção das cadeias de polieletrólitos no filme, mesmo que estas estejam em solução e experimente uma dinâmica conformacional que não permita que elas adquiram uma orientação preferencial no filme in situ.
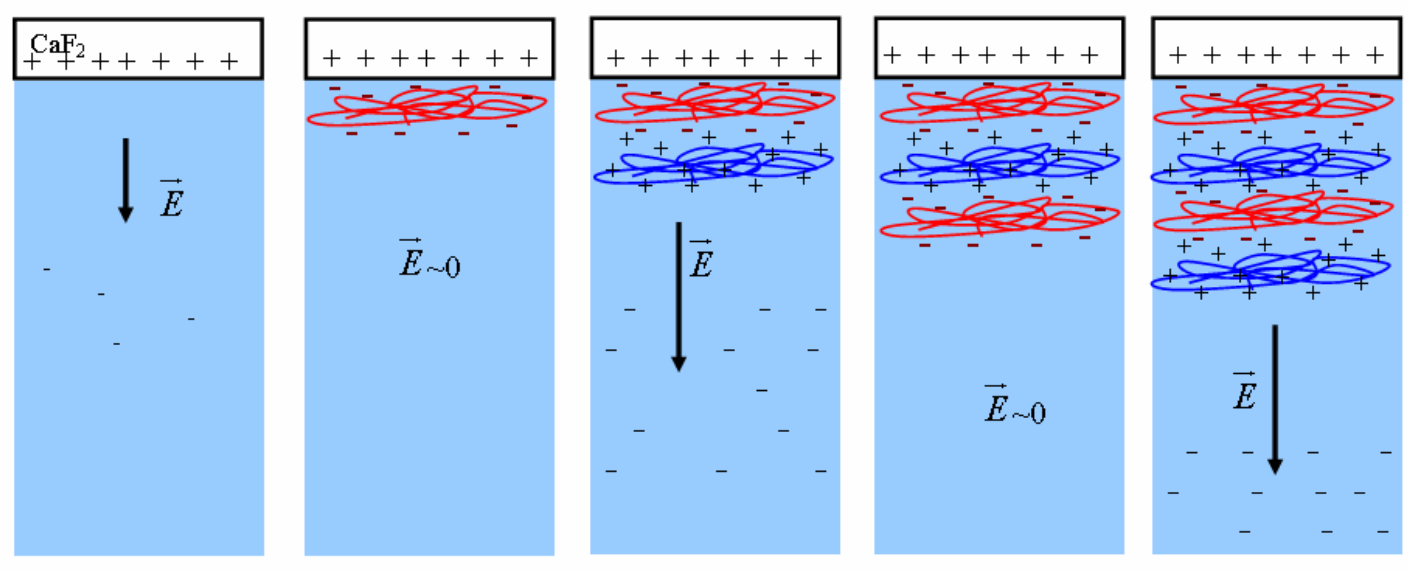

Figura 30: Modelo proposto para as medidas in situ de PAH e PSS sobe o fluoreto de cálcio a pH 4. O traçado azul representa moléculas de PAH, e o vermelho, as de PSS. Os sinais + e - na solução representam os contra-íons.

Para os filmes ex situ de PAH/PSS sobre $\mathrm{CaF}_{2}$, todos eles foram secos por evaporação espontânea da água. Os espectros SFG desses filmes estão mostrados na Figura 31. É possível notar que eles retêm ainda certa quantidade de água, embora bem menor que no quartzo, quase não ocorrendo em certos filmes (gráfico b da Figura 31, por exemplo).

Essa ausência de sinal referente a estiramentos $\mathrm{OH}$ indica uma evaporação da água mais fácil nos filmes automontados em $\mathrm{CaF}_{2}$, possivelmente devido a uma menor interação da água com o substrato. Novamente os filmes foram postos para secar por um período de 48 horas, e como essa secagem ocorreu de modo 
relativamente lento, a água presente sobre o $\mathrm{CaF}_{2}$ pôde dissolvê-lo levemente em sua superfície, já que a solubilidade do $\mathrm{CaF}_{2}$ em água é baixa, mas não nula $(\sim 0,0016 \mathrm{~g}$ de $\mathrm{CaF}_{2} / 100 \mathrm{~g}$ de água, a $25^{\circ} \mathrm{C}$ ) ${ }^{[46,47]}$. Na Figura 32 , temos duas fotos de filmes de PAH e de PSS secados por evaporação espontânea da água. Na foto da esquerda, uma monocamada de PAH foi adsorvida sobre o quartzo. Vê-se que não há manchas perceptíveis sobre o substrato. Ao contrário, na foto da direita temos um filme de (PSS/PAH)/PSS sobre o $\mathrm{CaF}_{2}$ onde é fácil notar manchas esbranquiçadas, possivelmente devido à recristalização do $\mathrm{CaF}_{2}$ durante a evaporação da água.
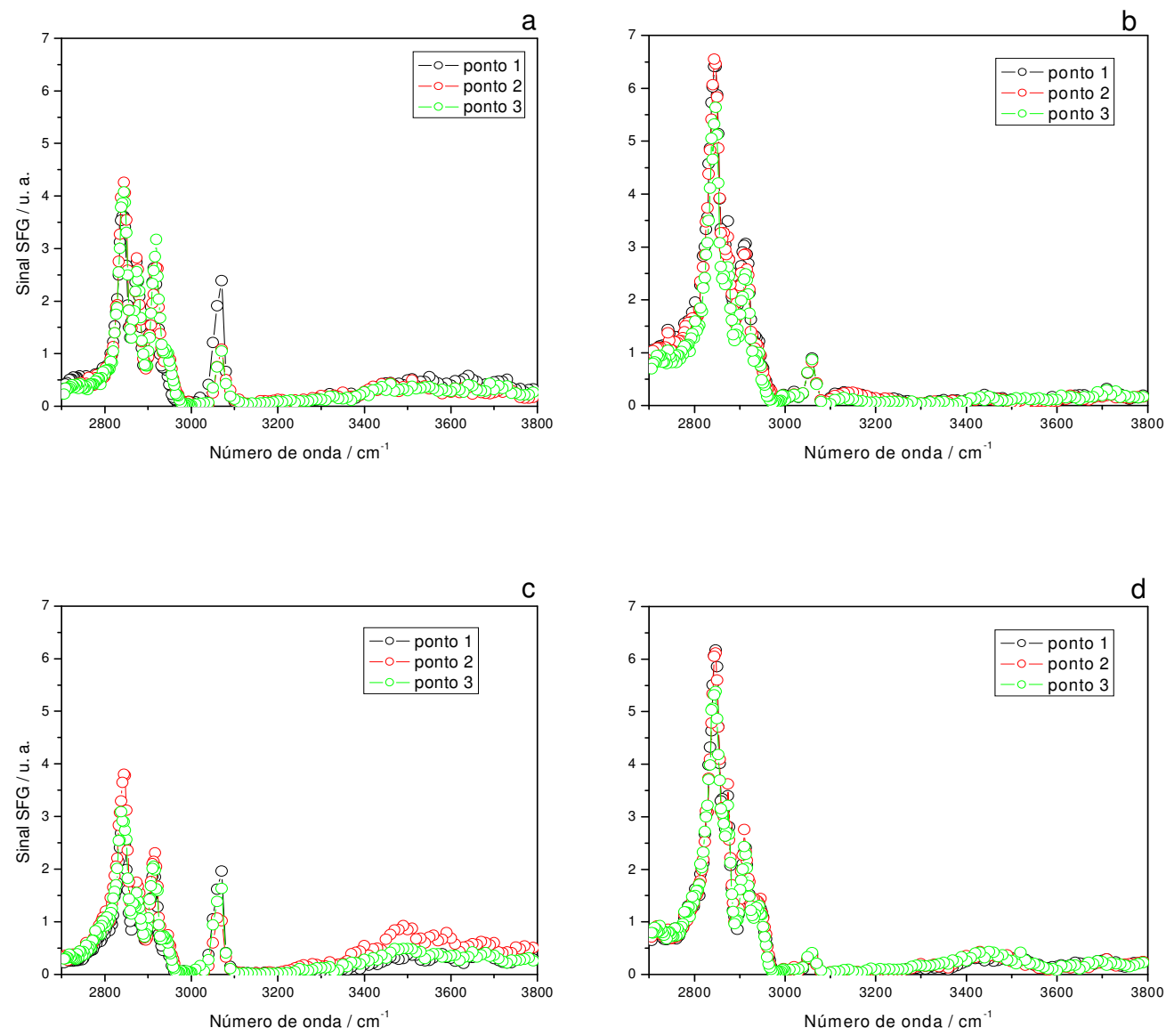

Figura 31: Espectro SFG de filmes ex situ de PAH/PSS (pH 4) sobre o $\mathrm{CaF}_{2}$ com secagem espontânea. Os gráficos são medidas em três pontos do filme de: a) PSS; b) PSS/PAH; c) (PSS/PAH)/PSS; e d) $(\mathrm{PSS} / \mathrm{PAH})_{2}$. 
Entretanto, mesmo com essas manchas, notamos que o ordenamento das cadeias tem certa homogeneidade, conforme mostra os espectros da Figura 31. Vê-se ainda que o ordenamento varia conforme a última camada adsorvida, sendo mais intenso o sinal para filmes que terminam com o PAH e menos intenso se terminam com PSS.
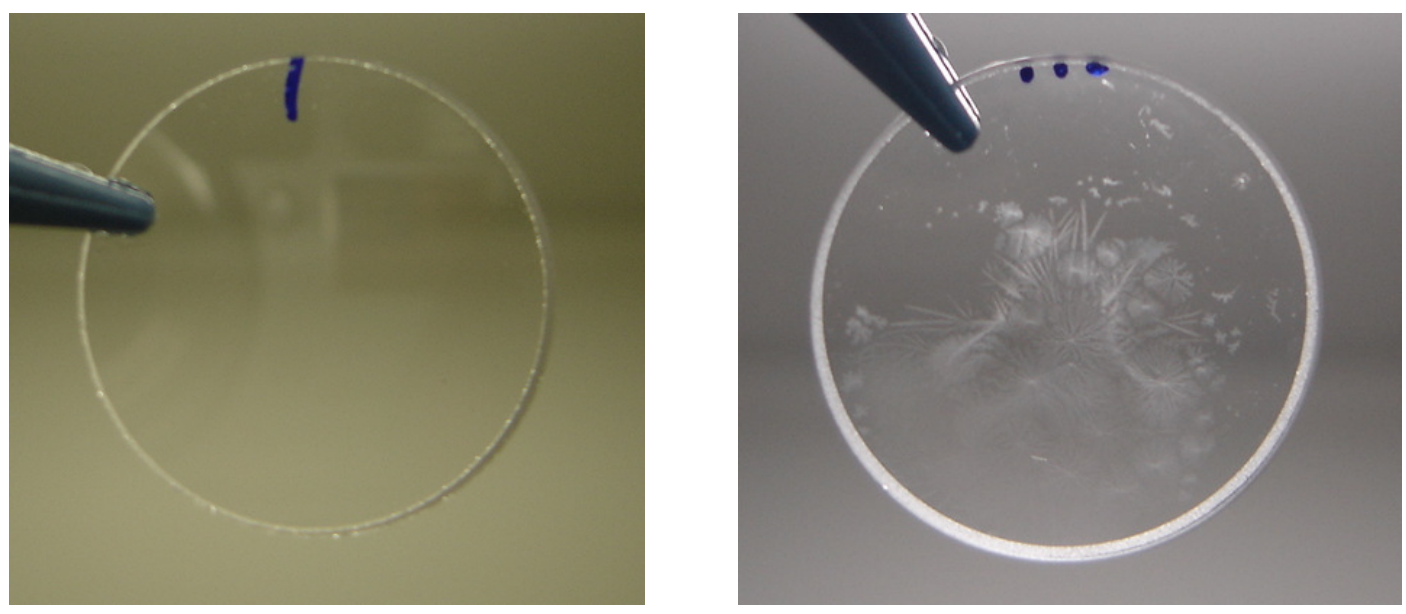

Figura 32: Aspecto dos filmes sobre o quartzo e sobre o $\mathbf{C a F}_{2}$. Na foto da esquerda temos o substrato de quartzo com uma monocamada de $\mathrm{PAH}$; e na da direita, a foto do $\mathrm{CaF}_{2}$ com um filme (PSS/PAH)/PSS. Ambos os filmes foram secados por evaporação espontânea da água.

A média dos espectros SFG da Figura 31 é mostrada na Figura 33, para a região de estiramentos $\mathrm{CH}$. As freqüências dos picos são as mesmas da Figura 19. Com relação ao sinal $\sim 3070 \mathrm{~cm}^{-1}$ atribuído ao anel dissubstituído do PSS, nota-se que ele é proeminente na primeira camada de PSS, mas que não há seu completo aniquilamento quando se adsorve a camada de PAH. Isso pode ser uma conseqüência do fato de que a primeira camada de PSS é "sanduichada" pelo fluoreto de cálcio e por uma camada de PAH (camadas diferentes), indicando que ainda ocorre ordenamento preferencial em direção a uma dessas densidades de carga. Do modelo da Figura 30, podemos observar que o campo elétrico gerado pela camada de PAH é maior que o campo elétrico gerado pelo $\mathrm{CaF}_{2}$. Isso sugere que na primeira monocamada de PSS, os anéis aromáticos assumem uma orientação preferencial em 
direção ao $\mathrm{CaF}_{2}$, mas quando a monocamada de $\mathrm{PAH}$ (que é mais positivo que o $\mathrm{CaF}_{2}$ ) é adsorvida sobre o PSS, ocorre a orientação preferencial a favor do PAH.

Na camada seguinte de PSS, o sinal dos anéis torna a aumentar em virtude dessa terceira camada interagir somente com a camada anterior de PAH. Por fim, quando a última camada de PAH é adsorvida sobre o PSS, temos novamente a diminuição do sinal dos anéis sem a sua total extinção. Assim, a segunda camada de PSS se encontra entre duas camadas de PAH e, pelo que foi discutido sobre as medidas ex situ no quartzo, o saldo orientacional dos anéis aromáticos dessa última camada de PSS deve ser nulo, restando somente a contribuição da primeira camada. É importante ressaltar que o efeito do substrato se propaga pelas camadas adjacentes.

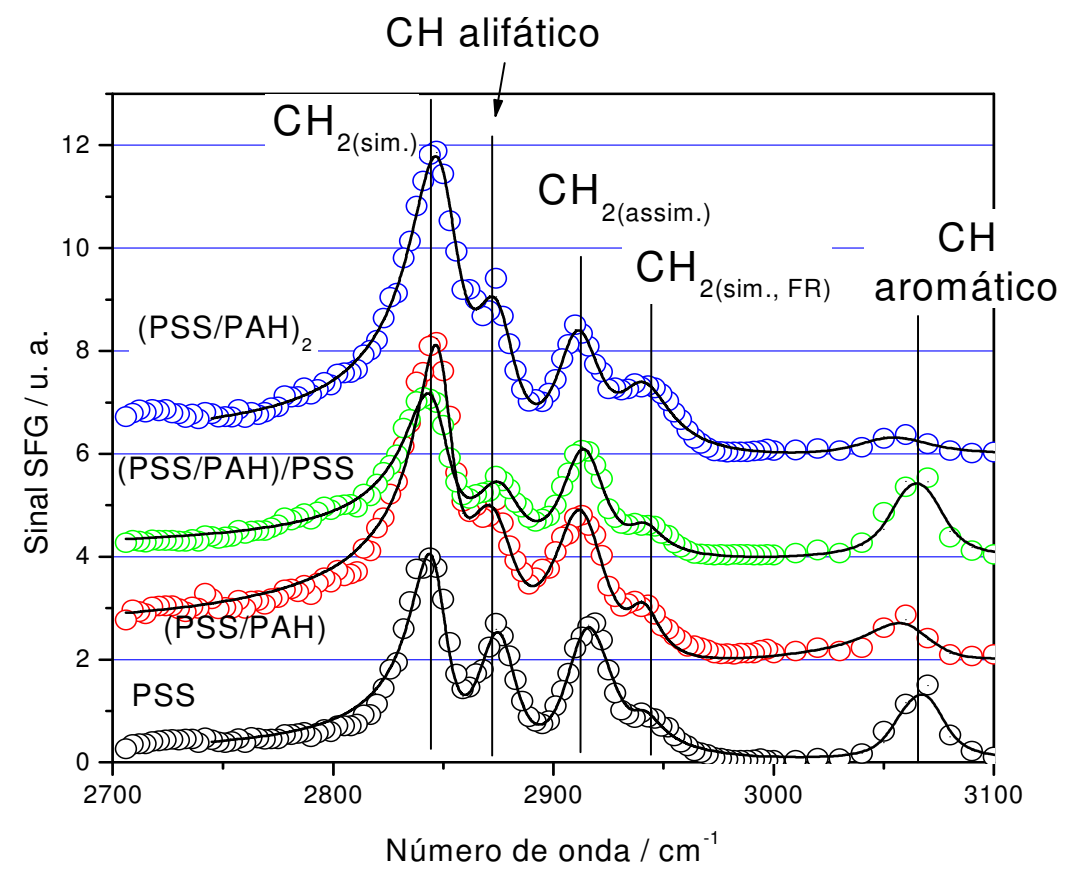

Figura 33: Espectros SFG de filmes ex situ de PAH/PSS com secagem espontânea. Os gráficos são as médias das três medidas da Figura 31.

Entretanto, para confirmar esta interpretação, deve-se ter o sinal da contribuição dos anéis invertidos quando o filme é terminado por PSS ou PAH. Fezse então o ajuste dos gráficos da Figura 33 segundo a Equação 59. Os parâmetros 
obtidos desses ajustes estão apresentados na Tabela IV. Pôde-se comprovar que o pico em torno de $3060 \mathrm{~cm}^{-1}$ tem se seu sinal alternado com relação ao sinal de base não-ressonante (ver detalhe em vermelho na Tabela IV). Na primeira monocamada de PSS, o sinal do pico é negativo $(-11,40821)$, que indica uma orientação preferencial em direção ao substrato, mas positivo $(11,79912)$ quando a segunda monocamada (PAH) é adsorvida, indicando uma orientação preferencial do grupo estireno em sentido contrário ao anterior, isto é, em direção à monocamada de PAH. O sinal torna a ficar negativo $(-13,23698)$ quando a terceira monocamada é adsorvida (PSS), indicando uma orientação preferencial em direção à monocamada anterior de PAH. Por fim, quando a quarta monocamada é adsorvida (PAH), o sinal do pico do anel aromático é positivo $(10,04043)$, indicando que a orientação total resultante dos anéis aromáticos do filme é em direção contrária ao substrato.

Tabela IV: Resultados do ajuste dos espectros da Figura 33. As colunas indicam as monocamadas adsorvidas. $B_{i}$ representa a amplitude, $\omega_{i}$ representa a frequiência da ressonância, e $\Gamma_{i}$ é a largura do pico. Os números identificam os picos, lidos na Figura 33, da esquerda para a direita.

\begin{tabular}{|c|c|c|c|c|}
\cline { 2 - 5 } \multicolumn{1}{c|}{} & PSS & (PSS/PAH) & $($ PSS/PAH $) / P S S$ & $(\mathrm{PSS} / \mathrm{PAH})_{2}$ \\
\hline B1 & 14.06975 & 12.36092 & 14.34159 & 22.21835 \\
B2 & 14.13789 & 17.21052 & 11.75885 & 13.83232 \\
B3 & 19.34611 & 21.58007 & 15.61607 & 15.40078 \\
B4 & 1.52514 & 5.08766 & 3.85168 & 11.3483 \\
B5 & -11.40821 & 11.79912 & -13.23698 & 10.04043 \\
& & & & \\
$\omega 1$ & 2847.62911 & 2850.32348 & 2847.2885 & 2850.42393 \\
$\omega 2$ & 2876.05194 & 2874.52071 & 2877.06281 & 2874.80552 \\
$\omega 3$ & 2914.29927 & 2913.88597 & 2914.09001 & 2911.43506 \\
$\omega 4$ & 2940.63159 & 2940.66177 & 2940.21175 & 2939.43329 \\
$\omega 5$ & 3066.0475 & 3061.9933 & 3065.196 & 3053.0302 \\
& & & & \\
\hline
\end{tabular}




\begin{tabular}{|c|c|c|c|c|}
\hline$\Gamma 1$ & 9.58406 & 8.94271 & 11.6713 & 13.05881 \\
$\Gamma 2$ & 11.17701 & 15.13734 & 14.04981 & 11.88838 \\
$\Gamma 3$ & 13.09489 & 15 & 12.20017 & 12.79298 \\
$\Gamma 4$ & 5.41827 & 8.4514 & 8.99862 & 14.37107 \\
$\Gamma 5$ & 8.38875 & 15.07867 & 9.54964 & 18.06496 \\
$\chi_{\mathrm{NR}}{ }^{(2)}$ & & & & -0.33578 \\
\hline
\end{tabular}

A partir das medidas acima, propomos um modelo para a estrutura dos filmes ex situ de PAH/PSS sobre o $\mathrm{CaF}_{2}$, que está mostrado Figura 34. Levou-se em consideração as diferentes densidades de carga superficial do $\mathrm{CaF}_{2}$ e do PAH para mostrar o não cancelamento total do sinal devido ao anel no filme com uma bicamada (PSS/PAH).

a
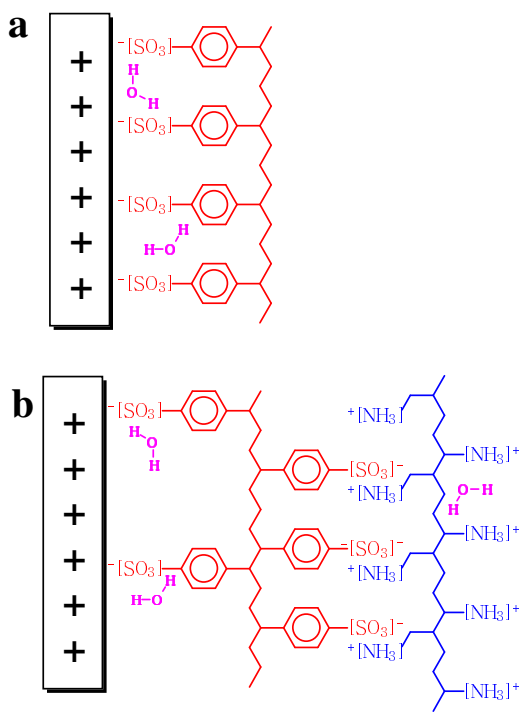
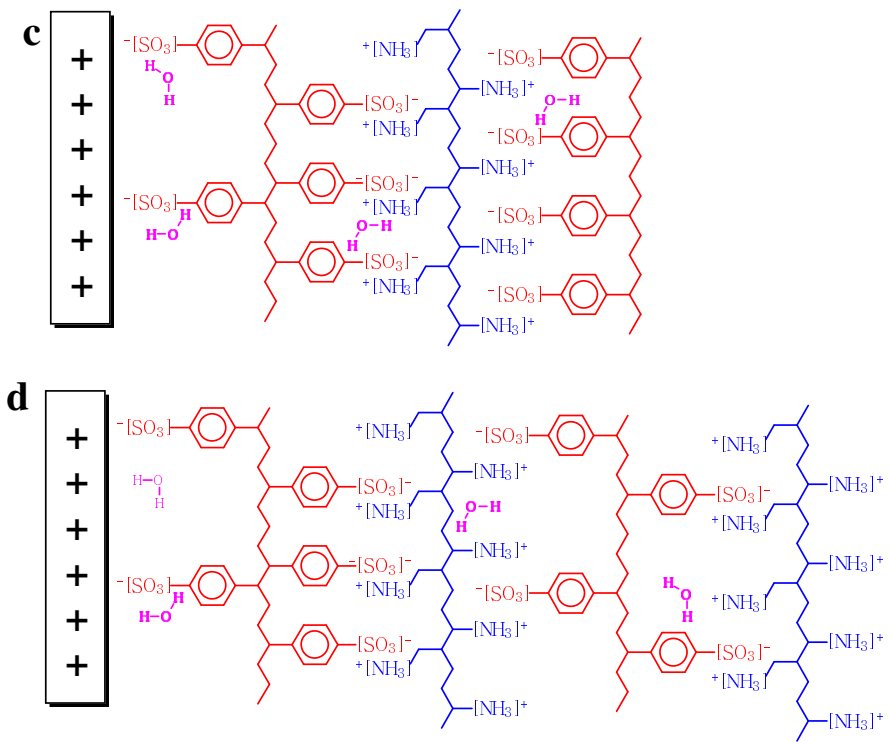

Figura 34: Modelo proposto para as medidas ex situ de PAH/PSS sobe o $\mathrm{CaF}_{2}$, a pH 4. As moléculas em azul representam o PAH, e as vermelhas, o PSS: a) PSS; b) $(\mathrm{PSS} / \mathrm{PAH}) ; \mathrm{c})(\mathrm{PSS} / \mathrm{PAH}) / \mathrm{PSS} ; \mathrm{d})(\mathrm{PSS} / \mathrm{PAH})_{2}$. 


\subsection{FILMES PREPARADOS A PARTIR DE SOLUÇÕES COM pH 12}

Por fim, passamos aos resultados de filmes in situ e ex situ sobre o $\mathrm{CaF}_{2}$ preparados a partir de soluções com pH 12. Na Figura 35 temos o espectro da interface $\mathrm{CaF}_{2}$ /água a pH 12 .

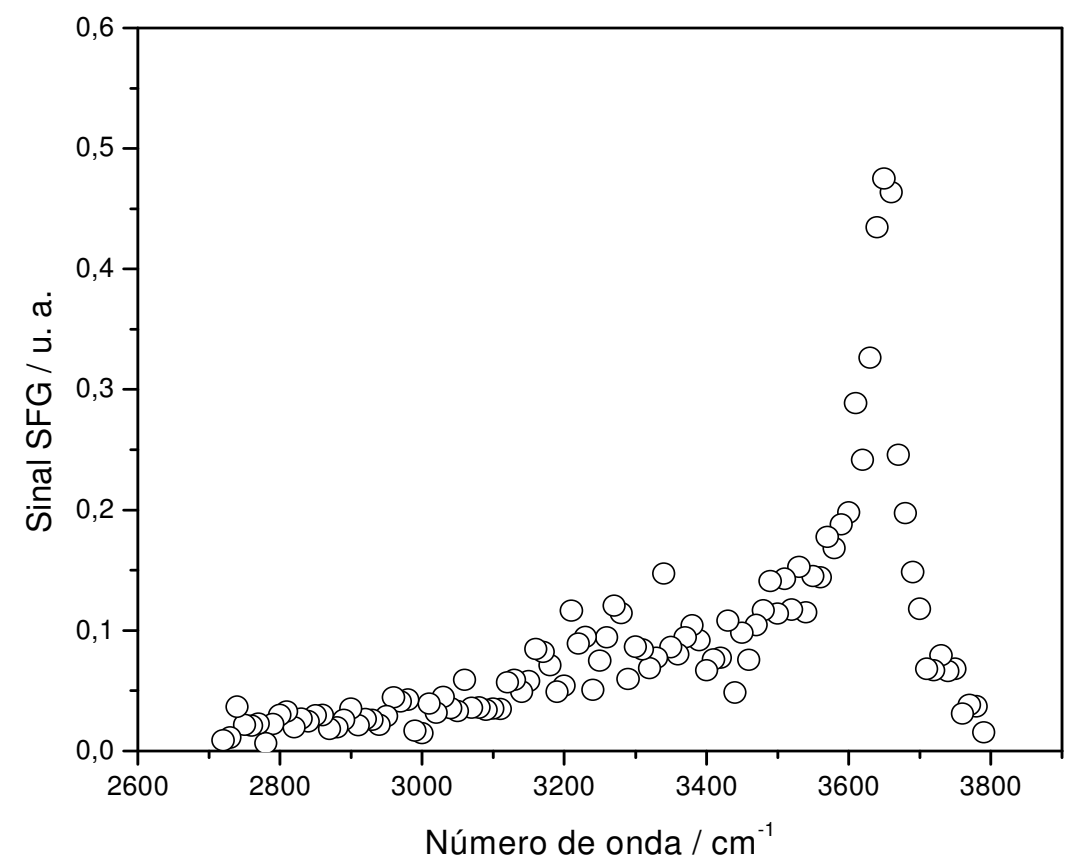

Figura 35: Espectro SFG da interface $\mathbf{C a F}_{2} /$ água a pH 12. Nota-se o pico a 3650 $\mathrm{cm}^{-1}$, referente a ligações O-H livres. Pouco se nota picos a $3200 \mathrm{~cm}^{-1}$ e a $3400 \mathrm{~cm}^{-1}$.

Esse espectro apresenta desacordo com os espectros da Figura 27. A diferença está no fato de que o espectro da Figura 35 (obtido em nosso laboratório) se assemelha ao espectro da Figura 27-f, cujo pH da água na interface é relatado como 13,7. Esse espectro foi medido várias vezes, inclusive revendo-se os procedimentos de limpeza a fim de evitar qualquer efeito de uma possível contaminação. No entanto, nenhum resultado que estivesse de acordo com a Figura 27, pôde ser obtido. Acreditamos que essa diferença possa ser devida à medida do $\mathrm{pH}$ ou ao arranjo experimental, pois enquanto aquelas medidas foram realizadas num 
aparato de reflexão total interna através do uso de um prisma de $\mathrm{CaF}_{2}$, nós utilizamos a segunda reflexão de uma janela de $\mathrm{CaF}_{2}$ (ver Figura 12, na Seção 3.3). Com relação à medida do pH, a Ref.: 46 relata que o controle do $\mathrm{pH}$ foi monitorado durante todo o tempo de obtenção dos espectros. No entanto, o eletrodo do pHmetro pode ser alterado se ele permanecer muito tempo em contato com soluções a pH alto. Quanto à origem do pico em $\sim 3650 \mathrm{~cm}^{-1}$, ela já foi discutida na Seção 5.1 .
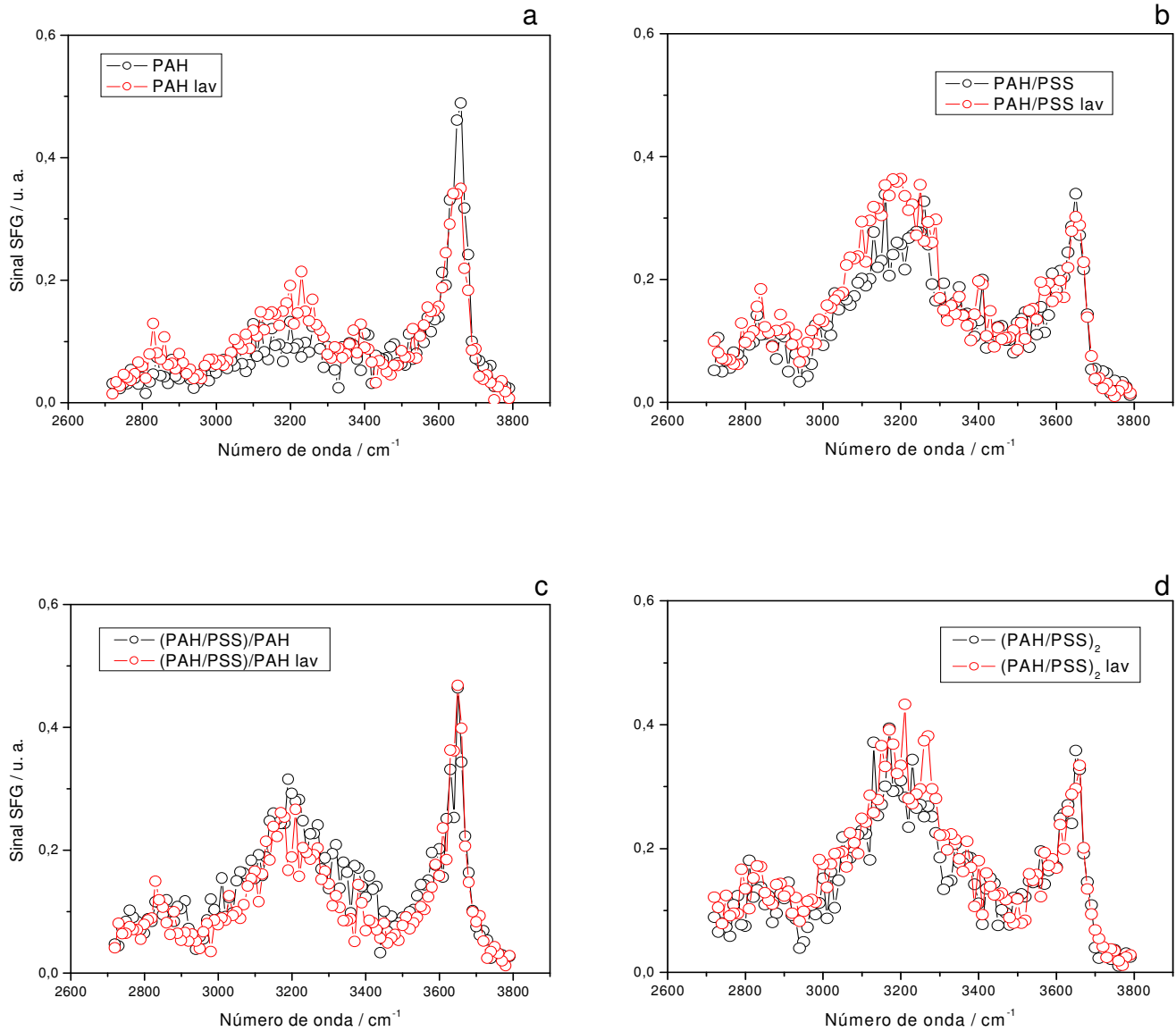

Figura 36: Espectros SFG de filmes in situ de PAH/PSS sobre o $\mathrm{CaF}_{2}$ a partir de soluções com pH 12. Os gráficos são: a) $\mathrm{CaF}_{2} /($ solução de $\mathrm{PAH})$; b) $\mathrm{CaF}_{2} / \mathrm{PAH} /($ solução de $\mathrm{PSS}) ; \quad$ c) $\mathrm{CaF}_{2} / \mathrm{PAH} / \mathrm{PSS} /($ solução de $\mathrm{PAH}$ ); d) $\mathrm{CaF}_{2} / \mathrm{PAH} / \mathrm{PSS} / \mathrm{PAH} /($ solução de PSS).

Entretanto, a densidade de carga não é muito alta (Figura 35), haja vista que as moléculas de água não estão altamente ordenadas na interface. Na Figura 36, temos as medidas in situ de filmes de PAH e PSS. A pH alto, o fluoreto de cálcio 
adquire densidade superficial de carga negativa ${ }^{[46]}$. Assim, o polieletrólito a ser adsorvido primeiro é o PAH. Nestas medidas, nota-se certo sinal na região de ressonância do $\mathrm{CH}$, que pode ser vista como uma leve depressão em torno de 2950 $\mathrm{cm}^{-1}$. No entanto, a aparência desse sinal difere muito do sinal observado nas medidas ex situ vistas até aqui, pois elas não aparecem como picos bem definidos, mas como uma banda "negativa" devido à interferência do sinal ressonante com o não-ressonante. Esse sinal é muito mais fraco e indica que as cadeias não estão "perfeitamente" alinhadas, devido a um enovelamento das cadeias de polieletrólitos sobre o $\mathrm{CaF}_{2}$. Isso é esperado, uma vez que o PAH, por ser um polieletrólito fraco, não tem a sua cadeia completamente carregada, permitindo assim seu enovelamento.

$\mathrm{O}$ fato de o mesmo não ter acontecido em filmes sobre o quartzo pode ser devido ao tipo de interação substrato-camada, pois a química de superfície do quartzo e do fluoreto de cálcio diferem também no fato de que este último é menos hidrofílico que o primeiro.
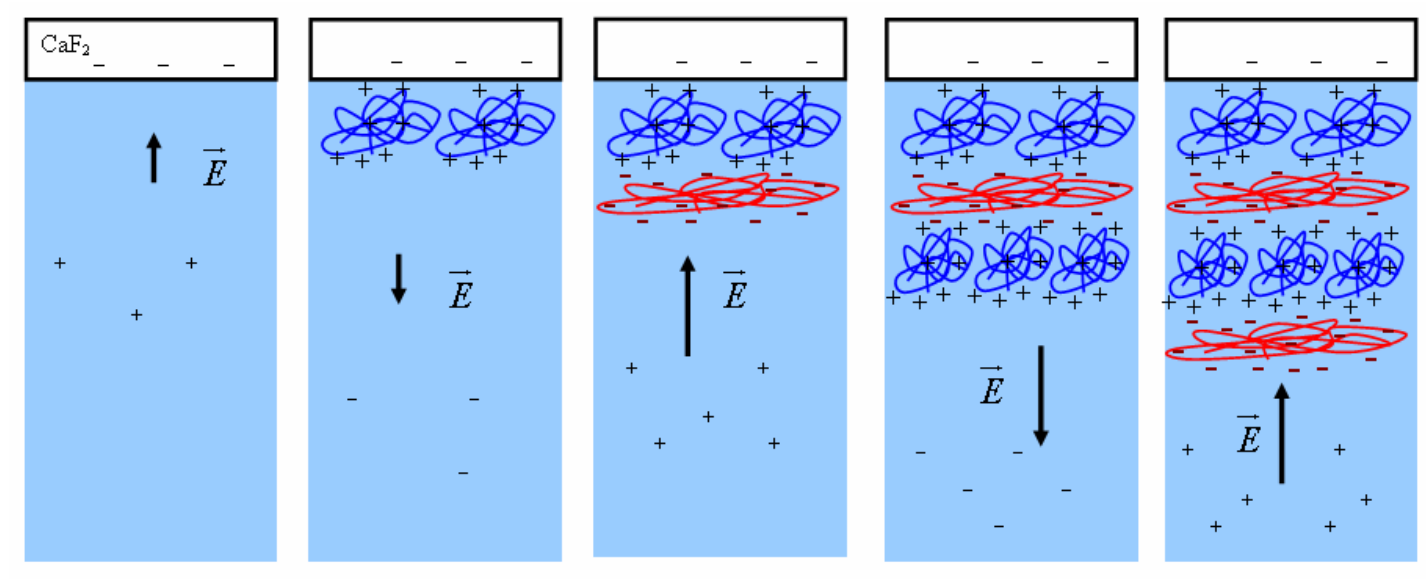

Figura 37: Modelo proposto para as medidas in situ de PAH e PSS sobe o fluoreto de cálcio a pH 12. O traçado azul representa moléculas de PAH, e o vermelho, as de PSS. Os sinais + e - na solução representam os contra-íons.

Com relação às intensidades do sinal da Figura 36, deve ser observado que na solução de PAH a intensidade do sinal da água na interface em $\sim 3200 \mathrm{~cm}^{-1}$ é 
relativamente pequena em comparação aos demais gráficos. Já no gráfico b, esse sinal cresce na solução de PSS, voltando a diminuir um pouco com a camada seguinte de PAH, e por fim, aumentando novamente na última camada de PSS. O modelo para a estrutura dos filmes in situ de PAH/PSS a pH 12 sobre o $\mathrm{CaF}_{2}$ está na Figura 37.

Por fim, temos os espectros SFG de filmes ex situ sobre o $\mathrm{CaF}_{2}$ preparados a partir de soluções a pH 12. Os resultados estão representados na Figura 38. Nos espectros é possível observar certa quantidade de água, embora essa quantidade seja pequena e sua estrutura desordenada, como mencionadas anteriormente no caso da automontagem em $\mathrm{CaF}_{2}$ a $\mathrm{pH} 4$.
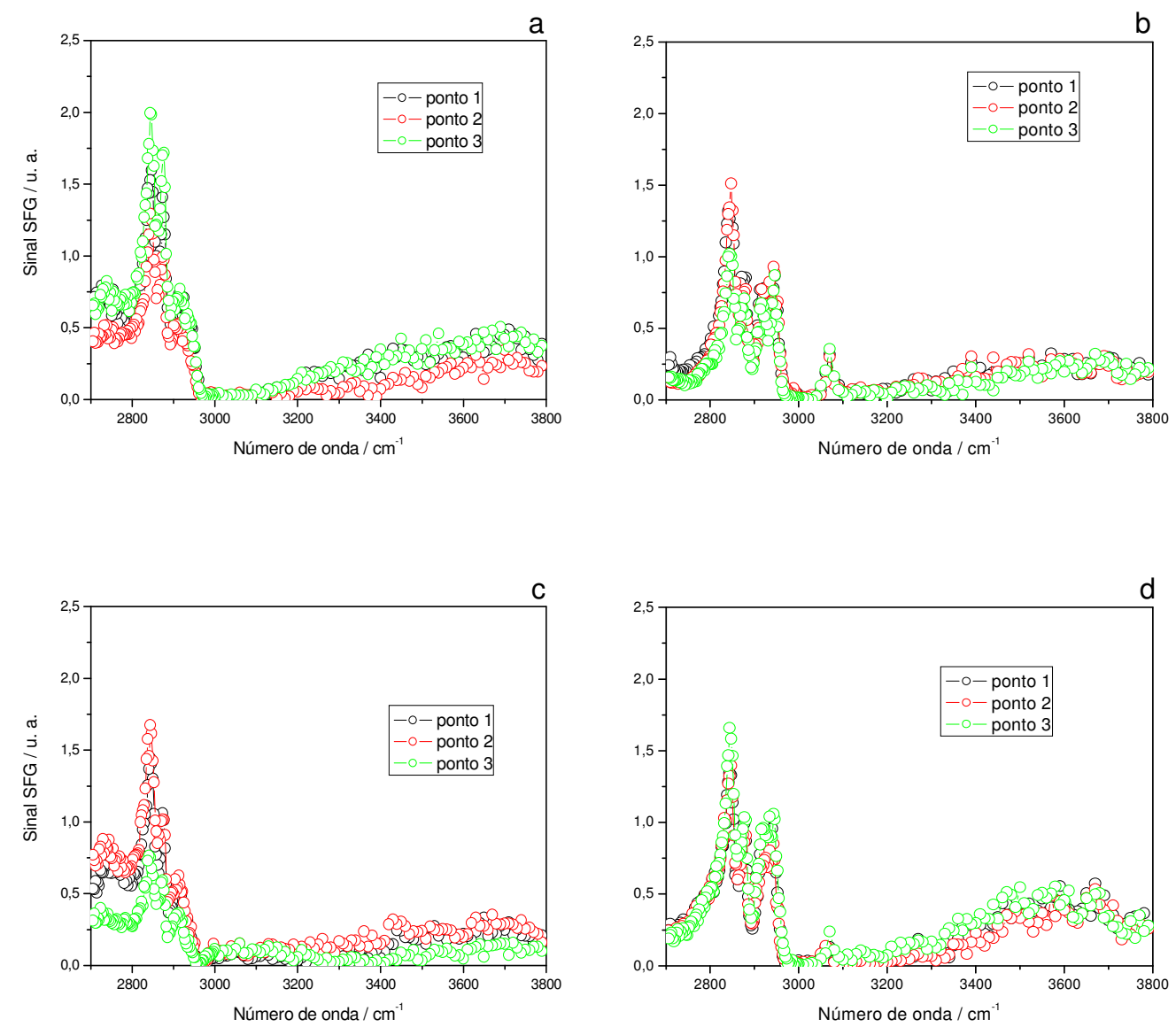

Figura 38: Espectro SFG de filmes ex situ de PAH/PSS (pH 12) sobre o $\mathrm{CaF}_{2}$ com secagem espontânea. Os gráficos são medidas em três pontos do filme de: a) $\mathrm{PAH}$; b) PAH/PSS; c) (PAH/PSS)/PAH; e d) $(\mathrm{PAH} / \mathrm{PSS})_{2}$. 
Pode-se perceber também na Figura 38 a homogeneidade dos filmes. Vêse o mesmo comportamento das medidas anteriores. É possível verificar ainda que quando a última camada a ser adsorvida é o PAH (gráficos a e c), o filme se torna um pouco menos homogêneo, ao contrário de quando a última camada é o PSS. Isso pode também ser devido à densidade de carga na cadeia do PAH e à interação substrato-camada neste $\mathrm{pH}$.

A média das medidas da Figura 38 estão mostradas na Figura 39 na região dos estiramentos $\mathrm{CH}$. Vêem-se os mesmos picos de estiramento $\mathrm{CH}$ encontrados nos filmes anteriores. Como naqueles casos, ocorre a alternância na intensidade dos picos da cadeia quando se alterna a última camada, e ainda a alternância do pico a 3060 $\mathrm{cm}^{-1}$ nos filmes onde a última camada é o PSS, extinguindo-se onde a última camada é o PAH.

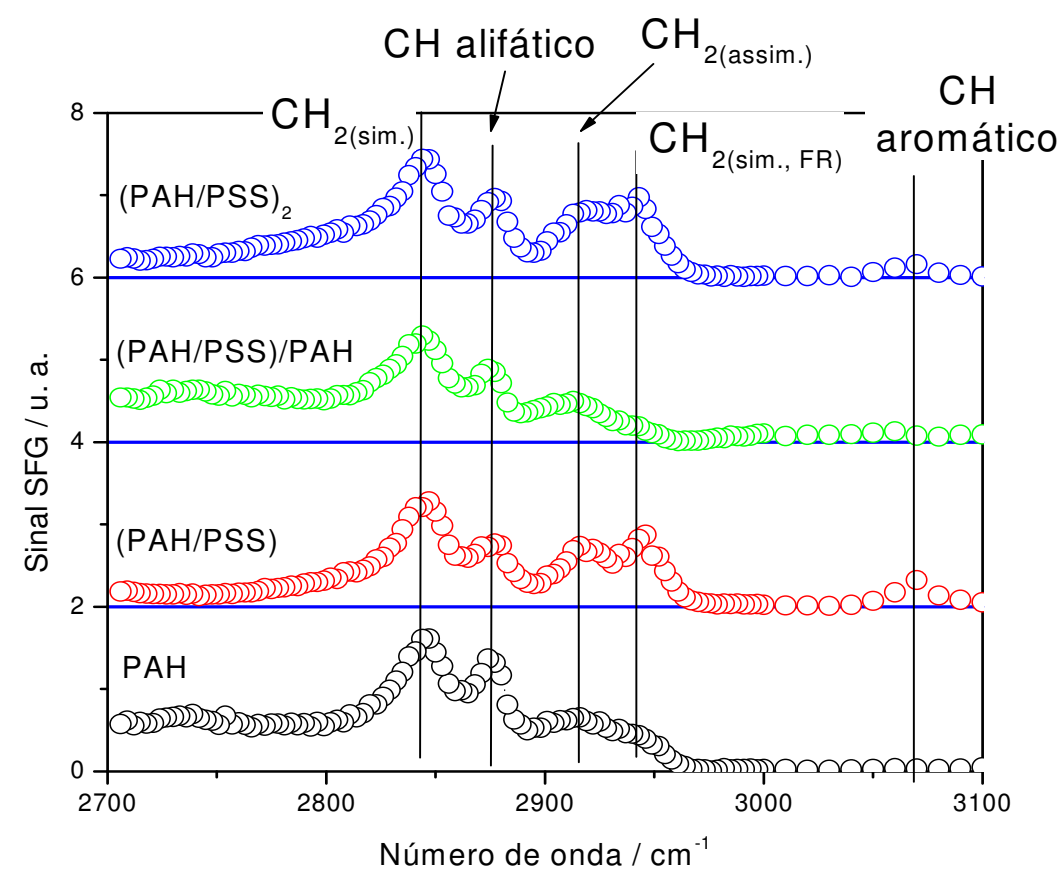

Figura 39: Espectros SFG de filmes ex situ de PAH/PSS com secagem espontânea. Os gráficos são as médias das três medidas da Figura 38. 
Os espectros da Figura 39 são muito parecidos com aqueles da Figura 26, de filmes automontados sobre quartzo a pH 12. Uma diferença notável está no pico do grupo estireno ( $\left.\sim 3060 \mathrm{~cm}^{-1}\right)$, que agora é menos intenso quando comparado com o sinal das cadeias. Isto indica um ordenamento menor dos anéis do PSS da última camada, provavelmente devido a uma menor densidade de carga resultante na interface nesse $\mathrm{pH}$, como pode ser conferido pela Figura 36.

Com base nas medidas apresentadas, é razoável que os filmes a pH 12 sobre o $\mathrm{CaF}_{2}$ e secados por evaporação espontânea tenham uma conformação como sugere a Figura 21, mas com alguns dos grupos $\mathrm{NH}_{3}{ }^{+}$convertidos em $\mathrm{NH}_{2}$. 


\section{O EFEITO DA SECAGEM}

Passemos agora a investigar o efeito da secagem sobre o ordenamento dos filmes automontados. As medidas desta Seção foram feitas a partir de filmes fabricados também na célula de Teflon com substrato de quartzo, realizando-se medidas in situ e secando o filme com jato de nitrogênio após cada passo de lavagem, seguindo-se então as medidas ex situ. Também foram realizadas medidas após 48 horas, em filmes secados com jato de nitrogênio.

Os resultados das medidas em filmes preparados a partir de soluções a pH 4 com uma monocamada de PAH e outro com uma bicamada PAH/PSS secados com $\mathrm{N}_{2}$ estão na Figura 40. Estão apresentados também os espectros SFG do quartzo em contato com água a pH 4 e com soluções de polieletrólitos. As medidas in situ são semelhantes às da Seção 4.2. Os espectros $c$ e $e$ apresentam medidas realizadas em três diferentes pontos do filme. Os sinais presentes na região de $\sim 3200, \sim 3400$ e $\sim 3700 \mathrm{~cm}^{-1}$ nas medidas ex situ indicam que, mesmo tendo sido submetido a um processo de secagem a jato de $\mathrm{N}_{2}$, ainda permanece uma quantidade apreciável de água no filme. Além disso, pode-se notar que, diferentemente das medidas secadas por evaporação espontânea, não ocorre sinal das cadeias dos polieletrólitos. 

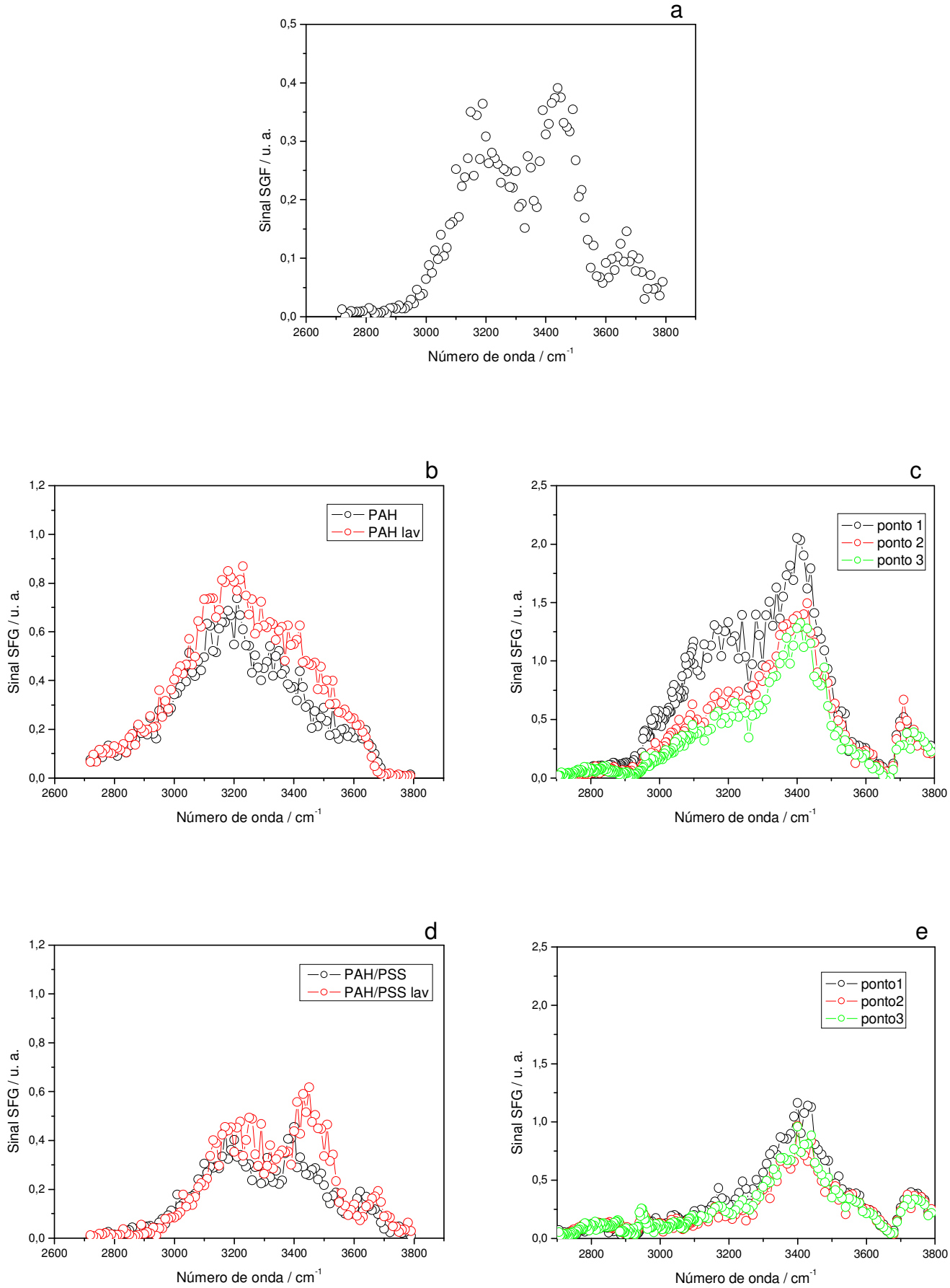

Figura 40: Espectros SFG de filmes PAH/PSS secando com nitrogênio, a pH 4. Os gráficos são: a) espectro da interface quartzo/água; b) medida do filme in situ em contato com solução de PAH e a solução lavagem; c) medida do filme de PAH ex situ após secagem com jato de $\mathrm{N}_{2}$; d) medida do filme in situ em contato com solução de PSS e solução lavagem sobre o filme de PAH; e) medida do filme PAH/PSS ex situ após secagem com jato de $\mathrm{N}_{2}$. 
Porém, para analisar mais sistematicamente o efeito do processo de secagem sobre o ordenamento dos filmes, foram realizadas medidas 48 horas após a fabricação dessas amostras secadas com jato de nitrogênio. O resultado está na Figura 41. Observa-se uma menor quantidade de água presente no filme, e um pequeno sinal das cadeias, que é cerca de dez vezes menor que o das amostras fabricadas por evaporação espontânea da água (Figura 18).
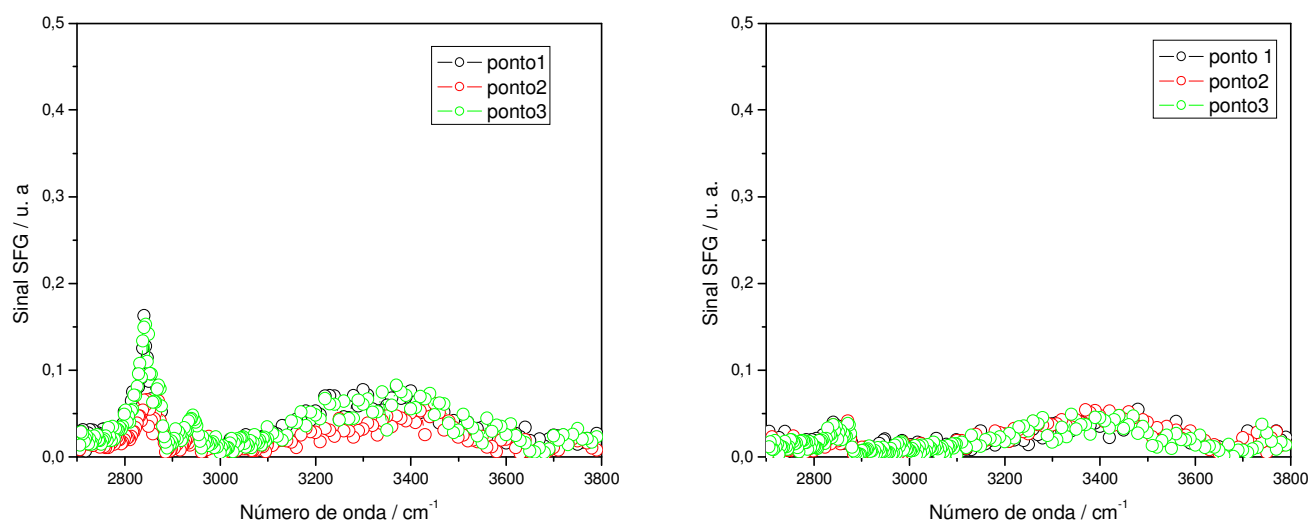

Figura 41: Espectros SFG de filmes PAH/PSS secando com nitrogênio, a pH 4. As medidas foram realizadas após 48 horas de fabricação do filme. À esquerda: monocamada de PAH; à direita: bicamada (PAH/PSS).

O mesmo estudo foi também efetuado para filmes fabricados a $\mathrm{pH} 12 . \mathrm{Na}$ Figura 42, temos o espectro da água a pH 12 e das soluções de polieletrólitos a pH 12 em contato com o quartzo (que são semelhantes às da Seção 4.3.), além das medidas ex situ dos respectivos filmes após secagem com jato de nitrogênio. Nota-se que, em contraste com o caso acima de filmes secados com nitrogênio a pH 4, os filmes retêm menos água e agora apresentam sinal das cadeias, embora irregular, sendo que em alguns pontos dos filmes ele não ocorre, indicando também uma maior inhomogeneidade do filme. 

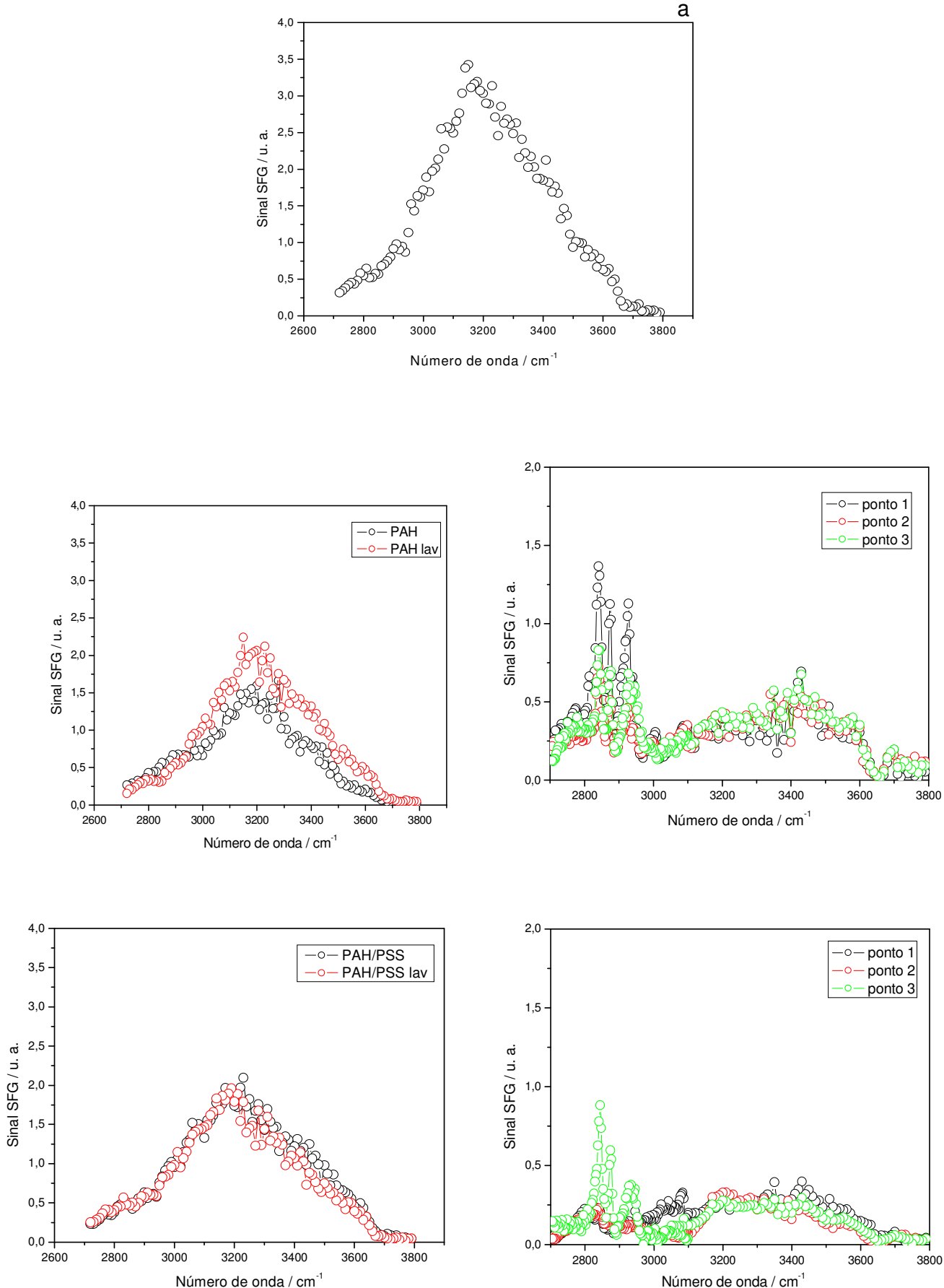

Figura 42: Espectros SFG de filmes PAH/PSS secados com nitrogênio, a pH 12. Os gráficos são: a) interface quartzo/água; b) medida do filme in situ em contato com solução de PAH e a solução lavagem; c) medida do filme de PAH ex situ após secagem com jato de $\mathrm{N}_{2}$; d) medida do filme in situ em contato com solução de PSS e solução lavagem sobre o filme de PAH; e) medida do filme PAH/PSS ex situ após secagem com jato de $\mathrm{N}_{2}$. 
Por fim, as medidas após 48 horas da fabricação dos filmes a pH 12 secados com jato de nitrogênio estão na Figura 43. Pode-se observar que elas ainda retêm água e apresentam sinal das cadeias bastante inhomogêneos. Diferentemente dos filmes a partir de soluções a $\mathrm{pH} 4$, ocorre sinal proveniente das cadeias dos polieletrólitos imediatamente após a secagem com $\mathrm{N}_{2}$, mas não há uma alteração significativa da estrutura do filme após a secagem adicional por 48 horas.
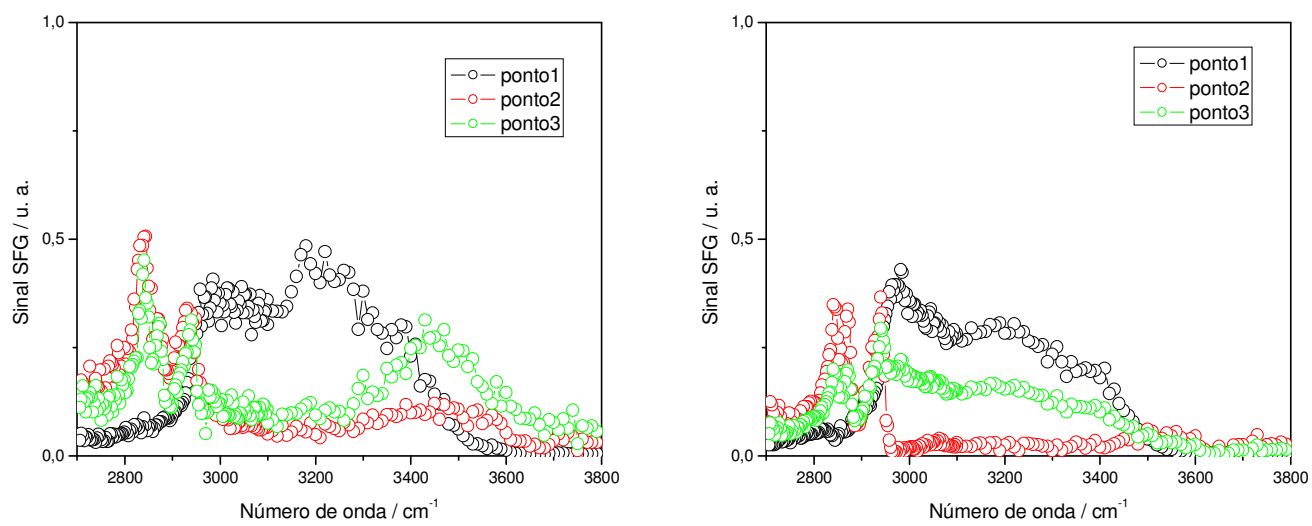

Figura 43: Espectros SFG de filmes PAH/PSS secando com nitrogênio, a pH 12. Como na Figura 41, as medidas foram realizadas após 48 horas de fabricação do filme. À esquerda, espectro do filme com uma monocamada de $\mathrm{PAH}$, e à direita, espectro do filme com uma bicamada (PAH/PSS).

Como dito anteriormente, o PAH tem maior densidade de carga a $\mathrm{pH} 4$ do que a pH 12. Assim, com uma maior densidade de carga do PAH, os filmes retêm mais água inicialmente, mas a configuração das cadeias mais distendidas (abertas) permite maior secagem após 48 horas.

A $\mathrm{pH} 12$, com menor densidade de carga no $\mathrm{PAH}$, o filme retém menos água inicialmente, dando origem a um sinal proveniente das cadeias. Entretanto, as cadeias se tornam mais enoveladas, dificultando a remoção completa da água após o período de 48 horas.

Com relação à influência do passo de secagem na formação do filme, é necessário fazer algumas observações. A ausência de sinal proveniente das cadeias 
pode sugerir que não há moléculas adsorvidas na superfície do quartzo. Entretanto, isso indica na verdade que não há moléculas ordenadas, ou seja, o ordenamento orientacional resultante das cadeias é nulo. A adsorção das moléculas na superfície pode ser comprovada pelas vibrações do campo elétrico na interface quartzo/solução (nas medidas in situ) quando a solução é de PAH, de PSS, ou água sem polieletrólitos, monitorado pelo espectro SFG da água na interface.

Talvez a causa desse desordenamento seja a agitação molecular ou o grau de liberdade que as moléculas experimentam quando em solução ou quando a quantidade de água retida no filme, hidratando as cadeias, for suficientemente alta. $\mathrm{O}$ fato dos filmes secados por jato de nitrogênio se apresentarem mais inhomogêneos pode ser entendido como uma conseqüência do arraste hidrodinâmico da região de contorno do filme de água se movimentando ao longo da superfície durante a secagem. Portanto, esse processo de secagem mais abrupto pode resultar em filmes menos homogêneos e com conformação mais desordenada das cadeias. 


\section{CONCLUSÃO}

Os resultados apresentados de Espectroscopia Vibracional por Geração de Soma de Frequiências de filmes de polieletrólitos possibilitaram o entendimento a nível molecular do fenômeno da adsorção e ordenamento de filmes automontados sobre substratos hidrofílicos de quartzo e de fluoreto de cálcio.

Foi possível concluir, a partir das medidas in situ, que durante o mergulho do substrato na solução de polieletrólito e de lavagem as cadeias adsorvem, mas se encontram em média desordenadas devido à grande agitação molecular na solução. Pôde-se comprovar in situ que a adsorção ocorre, e monitorar a variação do campo elétrico na interface filme/água.

Verificou-se ainda o papel do passo de secagem sobre a fabricação do filme, podendo-se concluir que a secagem com jato de nitrogênio diminui o ordenamento molecular tornando o filme mais inhomogêneo, podendo até mesmo destruir o ordenamento por completo. Filmes secados por evaporação espontânea da água tendem a adquirir maior grau de ordenamento e homogeneidade. Acreditamos que a lenta evaporação da água diminua o efeito de arraste hidrodinâmico que a frente de secagem do filme produz sobre as cadeias adsorvidas. Mesmo assim, notouse que ambos os métodos de secagem ainda deixam uma quantidade apreciável de água incorporada ao filme. 
Entretanto, uma das principais conclusões foi que camadas de polieletrólitos posteriormente adsorvidos influenciam o ordenamento das camadas previamente adsorvidas. Isso é de considerável importância na determinação das propriedades específicas de um filme, quando ele é destinado a uma determinada aplicação, e tal informação seria difícil de ser obtida com outra técnica experimental.

Foi possível verificar ainda a influência do substrato e do $\mathrm{pH}$ das soluções na orientação e ordenamento das monocamadas, pois o $\mathrm{pH}$ pode determinar tanto a densidade de carga do substrato quanto do polieletrólito, afetando sua conformação e interação com o substrato.

Dessa forma, a técnica de Espectroscopia SFG se mostra uma ferramenta poderosa na elucidação dos mecanismos de adsorção de filmes LBL, fornecendo informação a nível molecular sobre a estrutura desses filmes durante cada passo do processo de automontagem. 


\section{REFERÊNCIAS BIBLIOGRÁFICAS}

${ }^{1}$ FERREIRA, M., RUBNER, M. F., Molecular-Level Processing of Conjugated Polymers. 1. Layer-by-Layer Manipulation of Conjugated Polyions, Macromolecules, 28, 7107, (1995).

2 CHEUnG, J. H., STOCKTON, W. B., RUBNER, M. F., Molecular-Level Processing of Conjugated Polymers. 3. Layer-by-Layer Manipulation of Polyaniline via Electrostatic Interactions, Macromolecules, 30, 2712 (1997).

${ }^{3}$ FERREIRA, M., et al., Enzyme-Mediated Amperometric Biosensors Prepared with the Layer-by-Layer (LbL) Adsorption Technique, Biosensors and Bioelectronics, 19, 1611 (2004).

${ }^{4}$ DOYLE, A. W., et al., Protein Deformation of Lipid Hybrid Bilayer Membranes Studied by Sum Frequency Generation Vibrational Spectroscopy, Langmuir, 20, 8961 (2004).

${ }^{5}$ WANG, J., BUCK, S. M., CHEN, Z., Sum Frequency Generation Vibrational Spectroscopy Studies on Protein Adsorption, Journal of Physical Chemistry B, 106, 11666 (2002).

${ }^{6}$ CHENG, Y., WANG, X., CHENG, J., SUN, L., XU, W., ZHAO, B., Structure and Phase Transition in Self-Assembled Films of an Anti-Ferroelectric Liquid Crystal 
Studied by Two-Dimensional Correlation FTIR Spectroscopy, Spectrochimica acta.

Part A: Molecular and Biomolecular Spectroscopy, 62, 905 (2005).

${ }^{7}$ DECHER, G., HONG, J. D., SCHIMTT, J., Buildup of Ultrathin Multilayer Films by a Self-Assembly Process: III. Consecutively Alternating Adsorption of Anionic and Cationic Polyelectrolytes on Charged Surfaces, Thin Solids Films, 210/211, 831 (1992).

${ }^{8}$ LVOV, Y., ARIGA, K., ICHINOSE, I., KUNITAKE, T., Molecular Film Assembly via Layer-by-Layer Adsorption of Oppositely Charged Macromolecules (Linear Polymer, Protein and Clay) and Concanavalin A and Glycogen, Thin Solid Films, 284, 797 (1996).

${ }^{9}$ LVOV, Yuri M., Handbook of Surfaces and Materials, editado por H. S. Nalwa, Volume 3: Nanostructured Materials, Micelles, and Colloids, 2001.

${ }^{10}$ OLIVEIRA JR., RAPOSO, AND DHANABALAN, Handbook of Surfaces and Interfaces of Materials, editado por H. S. Nalwa, Volume 4: LB and Self-assembly Polymeric Films, 2001.

${ }^{11}$ O. N. OLIVEIRA JR., J.-A. HE, V. ZUCOLOTTO, S. BALASUBRAMANIAN, L. Li, H. S. NALWA, J. KUMAR, and S. K. TRIPATHY, Handbook of Polyelectrolytes and Their Applications, editado por S. K. Tripathy, J. Kumar and H. S. Nalwa, Volume 1: Polyelectrolyte-Based Multilayers, Self-Assemblies and Nanoestructures, 2001.

12 ILER, R., Multilayers of Colloidal Particles, Journal of Colloid and Interface Science, 21, 569 (1966).

13 NETZER, L., SAGIV, J., A New Approach to Construction of Artificial Monolayer Assemblies, Journal of American Chemistry Society, 105, 674 (1983). 
${ }^{14}$ NETZER, L., ISCOVICI, R., SAGIV, J., Adsorbed Monolayers Versus LangmuirBlodgett Monolayers-Why And How? I: From Monolayer To Multilayer, By Adsorption, Thin Solid Films, 99, 235 (1983).

15 LVOV, Y., DECHER, G., MÖHWALD, H., Assembly, Structural Characterization, and Thermal Behavior of Layer-by-Layer Deposited Ultrathin Films of Poly(vinyl sulfate) and Poly(allylamine), Langmuir, 9, 481 (1993).

16 ZUCOlOTTO, V.; Compósitos Poliméricos Nanoestruturados de Azocorantes, Ftalocianinas e Polímeros Luminescentes; Tese apresentada à Área de Interunidades em Ciências e Engenharia de Materiais, da Universidade de São Paulo, 2003.

${ }^{17}$ FOISSY, A., et al., Early Steps of the Film Growth Mechanism in Self-Assembled Multilayers of PAH and PSS on Silica: Polymer Uptake, Charge Balance and AFM Analysis, Colloids and Surfaces A, 228, 26-35 (2006).

${ }^{18}$ HOOGEVEen, N. G., COHEN-STUART, M. A., FLEER, G. F., BÖHMER, M. R., Formation and Stability of Multilayers of Polyelectrolytes, Langmuir, 12, 3675 (1996).

19 WANG, J., BUCK, S. M., EVEN, M. A., CHEN, Z., Molecular Response of Proteins at Different Interfacial Environments Detected by Sum Frequency Generation Vibrational Spectroscopy, Journal American of Chemistry Society, 124, $13302(2002)$.

${ }^{20}$ KIM, J., SAMORJAI, G. A., Molecular Packing of Lysozyme, Fibrinogen, and Bovine Serum Albumin on Hydrophilic and Hydrophobic Surfaces Studied by Infrared-Visible Sum Frequency Generation and Fluorescence Microscopy, Journal American of Chemistry Society, 125, 3150 (2003). 
${ }^{21}$ BOYD, R. W.; Nonlinear Optics; Academic Press, New York, 2004.

22 BLOEMBERGEN, N.; Nonlinear Optics; Addison-Wesley, New York, 1992.

${ }^{23}$ SUTHERLAND, R. L., Handbook of Nonlinear Optics, Marcel Dekker, Inc.,New York, 1996.

${ }^{24}$ COLTHUP, N. B., WIBERLEY, S. E., DALY, L. H., Introduction to Infrared and Raman Spectroscopy, Academic Press, San Diego, 1990.

${ }^{25}$ SHEN, Y. R.; Surface Properties Probed by Second-Harmonic and Sum-Frequency Generation, Nature, Vol. 337, pp 519-525, 1989.

26 SHEN, Y. R.; A Few Select Applications of Surface Nonlinear Optical Spectroscopy, Applied Physical Sciences, Vol. 93, pp 12104-12111, 1996.

27 SHEN, Y. R., Nonlinear Spectroscopy for Molecular Structure Determination, editado por FILED, R. W., HIROTA, E., MAIER, J. P., TSUCHIYA, S., Blackwell Science, Oxford (UK), 1998.

${ }^{28}$ FISCHER, P. \& BUCKINGHAM, A. D., Surface Second-Order Nonlinear Optical Activity, Optical Society of America B, 15, 2951 (1998).

${ }^{29}$ BLOEMBERGEN, N. \& PERShAN, P. S., Light Waves at the Boundary of Nonlinear Media; Physical Review, 128, pp 606-622, 1962.

${ }^{30}$ SHEN, Y. R., Surfaces Probed by Nonlinear Optics, Surface Science, 299/300, 551-562 (1994).

${ }^{31}$ CHEN, X., ClARKE, M. L., WANG, J., CHEN, Z., Sum Frequency Generation Vibrational Spectroscopy Studies on Molecular Conformation and Orientation of Biological Molecules at Interfaces, International Journal of Modern Physics B, 19, 691-713 (2005). 
${ }^{32}$ PRASAD, P. N., WILLIAMS, D. J., Introduction to Nonlinear Optical Effects in Molecules and Polymers, John Wiley \& Sons, New York, 1991.

${ }^{33}$ SHEN, Y. R., HUNT, J. H., GUYOT-SIONNEST, P., Observation of C-H Stretch Vibrational of Monolayers of Molecules Optical Sum-Frequency Generation, Chemistry Physics Letter, 133, 189-192.

${ }^{34}$ LAMBERT, A. G., DAVIS, P.B., NEIVANDT, D. J., Implementing the Theory of Sum Frequency Generation Vibrational Spectroscopy: A Tutorial Review, Applied Spectroscopy Reviews, 40, 103-145 (2005).

${ }^{35}$ DU, Q., FREYSZ, E., SHEN, Y. R., Vibrational spectra of water molecules at quartz/water interfaces, Physical Review Letters 1994, 72, 238-241.

${ }^{36}$ SHEN, Y. R., OSTROVERKHOV, V., Sum-Frequency Spectroscopy on Water Interfaces: Polar Orientation of Water Molecular at Interfaces, American Chemical Society 2005.

${ }^{37}$ MIRANDA, P. B., SHEN, Y. R., Liquid Interfaces: A Study by Sum-Frequency Vibrational Spectroscopy, Journal of Physical Chemistry B 1999, 103, 3292-3307.

${ }^{38}$ STRAUSS, H. L., SNYDER, R. G., C-H Stretching Modes and the Structure of $n$ Alkil Chains. 1. Long, Disordered Chains, Journal of Physical Chemistry 1982, 86, $5145-5150$.

${ }^{39}$ STRAUSS, H. L., SNYDER, R. G., MACPHAIL, R. A., C-H Stretching Modes and the Structure of $n$-Alkil Chains. 2. Long, All-Trans Chains, Journal of Physical Chemistry 1984, 88, 334-341.

40 GRUNZE, M., BUCK, M., HIMMELHAUS, Self-Assembly of n-Alkanethiol Monolayers. A Study by IR-Visible Sum Frequency Spectroscopy (SFG), Journal of Physical Chemistry B 2000, 104, 576-584. 
${ }^{41}$ LEBAS, J.-M., G-LAGRANGE, C., JOSIEN, M-L., Étude Comparée des Spectres de Vibration dês Déviés p-Disubstitués du Benzène, Spectrochimica Acta, 1959, 225235.

${ }^{42}$ ZHANG, D., SAMORJAI, G.A., SHEN, Y. R., Environment-Induced Surface Structural Changes of a Polymer: An in Situ IR + Visible Sum-Frequency Spectroscopic Study, Journal of Physical Chemistry B 101, 9060 (1997).

${ }^{43}$ FOX, J. J., MARTIN, A. E., Proceedings of the Royal Society, Series A 167, 257 (1983).

${ }^{44}$ BRISSETTE, C., SANDORFY, C., Canadian Journal of Chemistry 38, 34 (1960).

${ }^{45}$ CHENON, B., SANDORFY, C., Canadian Journal of Chemistry 36, 1181 (1958).

${ }^{46}$ BECRAFT, K. A., RICHMOND, G. L., In Situ Vibrational Spectroscopic Studies of the $\mathrm{CaF}_{2} / \mathrm{H}_{2} \mathrm{O}$ Interface, Langmuir 2001, 17,7721-7724.

${ }^{47}$ WU, L., FORSLING, W., Surface Complexation of Calcium Minerals in Aqueous Solution: III. Ion Exchange and Acid-Base Properties of Hydrous Fluorite Surfaces, Journal of Colloids and Interface Science 1995, 174, 178-184.

48 LAGARDE, P., NERENBRG, M. A. H., FARGE, Y., $\mathrm{Ca}(\mathrm{OH})_{2}$ Infrared Vibrational Spectra around $3600 \mathrm{~cm}^{-1}$ : Experimental and Theoretical Study on Microcrystals and Single Crystals, Physical Review B 1973, 8, 1731-1746. 